\title{
Atenção integral ao portador de Pé Diabético
}

\author{
Jackson Silveira Caiafa', Aldemar Araujo Castro², Cícero Fidelis³, Vanessa Prado Santos ${ }^{4}$, Erasmo Simão da Silva ${ }^{5}$, Cid J. Sitrângulo Jr.
}

\begin{abstract}
Resumo
São apresentadas, nessa separata, as principais orientações sobre a atenção às complicações do pé diabético. A neuropatia, com suas diversas apresentações que acometem os membros inferiores dos diabéticos, as lesões da doença arterial obstrutiva periférica (DAOP), as múltiplas apresentações da infecção do pé diabético, e, principalmente, os cuidados preventivos que possam impedir o estabelecimento ou a evolução dessas complicações são tratados de forma sistemática e simplificada, visando a atenção integral desses doentes. Especial cuidado é dado às orientações diferenciadas para os diversos níveis de atenção nos serviços públicos de saúde, porta de entrada virtual de $80 \%$ dos infelizes portadores dessa complicação. São aqui apresentados modelos de atenção e sugeridos protocolos que podem contribuir para a efetiva redução do número de amputações, internações e óbitos de diabéticos com complicações nos membros inferiores.
\end{abstract}

Palavras-chave: Pé diabético; Neuropatia diabética; Doença vascular periférica; Amputação; Prevenção \& controle

\section{Introdução}

Pé Diabético é o termo empregado para nomear as diversas alterações e complicações ocorridas, isoladamente ou em conjunto, nos pés e nos membros inferiores dos diabéticos. Hoje uma preocupação mundial, o custo humano e financeiro dessa complicação é imenso e dependente, para o seu controle ou prevenção, da conscientização quanto à necessidade de um bom controle da doença e da implantação de medidas relativamente simples de assistência preventiva, de diagnóstico precoce e de tratamento mais resolutivo nos estágios iniciais da doença.

Para tanto, é primordial a disseminação do conceito de que o pé diabético é caracterizado pela presença de pelo menos uma das seguintes alterações: neurológicas, ortopédicas, vasculares e infecciosas, que podem ocorrer no pé do paciente portador de diabetes. Essa visão se contrapõe, de forma decisiva, à visão corrente do membro em estágio terminal, necrosado e infectado, encontrado em todos os serviços de emergência, resultado da prevenção inexistente e de meses ou anos de atendimentos inespecíficos e falta de diagnóstico.

\section{Objetivos}

Essa separata foi elaborada com o intuito de fornecer orientação aos cirurgiões em geral e, em particular, àqueles que integram as equipes de saúde que atendem pacientes diabéticos. A identificação e classificação do paciente de risco, o tratamento precoce, a educação individual, familiar e comunitária constituem as bases sólidas para a prevenção da amputação de membros nesta população ${ }^{1}$, e serão objeto de uma detalhada descrição que deverá ser dominada com a leitura do capítulo. Todo o esforço que envolve a abordagem do paciente diabético indica que um dos maiores e mais graves problemas destes indivíduos é o desenvolvimento de úlceras na extremidade inferior, geralmente precursoras da amputação. Portanto, o objetivo fundamental da atuação relativa ao pé diabético é evitar este desfecho, através do reconhecimento de situações de risco e imediata intervenção nas áreas social, educativa e de assistência médica global e especializada.

A abordagem do membro inferior do paciente diabético não é desvinculada dos cuidados gerais (controle da glicemia, hipertensão, obesidade, dislipidemia, tabagismo, atividade física, alimentação) que são decisivos para melhorar

\footnotetext{
'Especialista em Cirurgia Vascular e Endovascular pela Sociedade Brasileira de Angiologia e Cirurgia Vascular (SBACV), Membro Titular do CBC e da SBACV, Cirurgião vascular do Serviço de Cirurgia Vascular do Hospital Federal dos Servidores do Estado e do Hospital Municipal Miguel Couto, no Rio de Janeiro

${ }_{2}^{2}$ Médico (Cirurgião Vascular), Mestrado em Cirurgia Vascular pela Universidade Federal de São Paulo/Escola Paulista de Medicina, Lattes: Http://Lattes.Cnpq.Br/2259022333178681

${ }^{3}$ Professor Auxiliar da Fac. de Medicina da Univ. Federal da Bahia, Título de Especialista em Angiologia e Cirurgia Vascular pela SBACV, Responsável pelo Ambulatório de Pé Diabético do Centro de Referencia em Diabetes da Sec. de Saúde do Estado da Bahia.

${ }^{4}$ Mestre e Doutora pela Faculdade de Ciências Médicas da Santa Casa de São Paulo; Professora da Faculdade de Medicina da Universidade Federal da Bahia

${ }^{5}$ Livre-Docente da Disciplina de Cirurgia Vascular e Endovascular da Faculdade de Medicina da USP.

${ }^{6}$ Professor Doutor da Disciplina de Cirurgia Vascular e Endovascular da Faculdade de Medicina da Universidade de São Paulo
} 
a qualidade de vida e aumentar a sua sobrevida. Todos esses tópicos e protocolos estão sistematizados ao longo do texto para um melhor entendimento dessa complicação multidisciplinar do Diabetes Melitus.

Quadro 1 - Recomendações iniciais ${ }^{2-7}$

1 - Nos serviços de saúde pública, é primordial o treinamento de equipes interdisciplinares (medico clínico, enfermeira e técnico de enfermagem), na atenção básica, para a classificação do risco e controle das intercorrências clínicas iniciais dos pés dos diabéticos.

2 - Os diversos serviços de atenção à saúde, particularmente os de saúde pública, devem providenciar protocolos e fluxogramas, com níveis secundários e terciários, dispondo de atendimento especializado e imediato (com orientações claras de serviços de referência)

3 - Todos os diabéticos devem ter seus pés examinados em todas as consultas de saúde. O exame sistemático deve obedecer a um protocolo clínico e pode ser usado o decálogo especificado no apêndice 1.

\section{Neuropatia}

A avaliação periódica da sensibilidade plantar ao monofilamento é necessária em todos os diabéticos para estadiamento e classificação do risco.7.8

\section{Aspectos gerais}

Muitos fatores de risco para ulceração/amputação podem ser descobertos com o exame cuidadoso dos pés. $\mathrm{O}$ exame clínico é o método diagnóstico mais efetivo, simples e de baixo custo para diagnóstico da neuropatia. $\mathrm{Na}$ anamnese é importante analisar o grau de aderência do paciente e familiares próximos ao tratamento, bem como o estado nutricional, imunidade e comorbidades. ${ }^{9-11}$

\section{Aspectos específicos}

Duas teorias merecem destaque para explicar o desencadeamento da neuropatia no diabético: a teoria vascular, na qual a microangiopatia da vasa nervorum levaria à isquemia, que causaria a lesão do nervo, e a teoria bioquímica, na qual o aumento de substâncias tóxicas (sorbitol e frutose) e a depleção do mionisitol causariam lesão no nervo (células de Schwann) $)^{12,13}$.

As consequências dessas alterações para os pés do paciente diabético, na prática clínica, se refletem nos tipos de neuropatia descritos a seguir ${ }^{14-17}$ :

\section{Neuropatia Sensitivo-Motora:}

a. Acarreta perda gradual da sensibilidade tátil e dolorosa que torna os pés vulneráveis a traumas, denominada de "perda da sensação protetora” . Exemplo: um indivíduo diabético com perda da sensação protetora poderá não mais sentir o incômodo da pressão repetitiva de um sapato apertado, a dor de um objeto pontiagudo ou cortante no chão ou da ponta da tesoura durante $\mathrm{o}$ ato de cortar unhas; b. Acarreta também a atrofia da musculatura intrínseca do pé, causando desequilíbrio entre músculos flexores e extensores, desencadeando deformidades osteoarticulares (exemplos: dedos "em garra", dedos "em martelo", dedos sobrepostos, proeminências das cabeças dos metatarsos, hálux valgo (joanete)). Tais deformidades alteram os pontos de pressão na região plantar levando à sobrecarga e reação da pele com hiperceratose local (calo), que com a contínua deambulação evolui para ulceração (mal perfurante plantar).

c. A perda da integridade da pele nas situações acima descritas constitui-se em importante porta de entrada para o desenvolvimento de infecções, que podem evoluir para amputação.

\section{Neuropatia Autonômica (Lesão do Sistema Nervoso} Autônomo, em particular dos Nervos Simpáticos) $)^{6,17,18}$ :

a. Acarreta a perda do tônus vascular, levando a vasodilatação com aumento da abertura de comunicações arterio-venosas e, conseqüentemente, passagem direta de fluxo sangüíneo da rede arterial para a venosa, reduzindo a nutrição aos tecidos.

b. Acarreta também a anidrose, que causa o ressecamento da pele, culminando com a formação de fissuras, e alterações no crescimento e na matriz das unhas que, à semelhança das úlceras crônicas, se constituem em importantes portas de entrada para infecções. FIGURAS 1 a 11

Notas:

1. A Neuropatia Autonômica pode ser responsável por outros sinais e sintomas do Sistema Cardiovascular (hipotensão postural, tonteiras, síncopes e morte súbita), no Sistema Gastrointestinal (diarréias de difícil controle, vômitos, constipação, perda do controle esficteriano, plenitude gástrica, etc) e do Sistema Urogenital (impotência sexual, bexiga neurogênica, etc).

2-. A lesão da inervação simpática dos membros inferiores é conhecida como auto-simpatectomia do diabético. Quando presente, é responsável pelas já descritas alterações do tônus vascular fazendo com que a indicação da clássica cirurgia de simpatectomia lombar, para melhorar a circulação da pele e facilitar a cicatrização das lesões cutâneas, seja desnecessária, e mesmo contra-indicada.

\section{História:}

O questionamento ativo na anamnese é fundamental para descobrir eventos em pacientes considerados assintomáticos. ${ }^{10}$ 


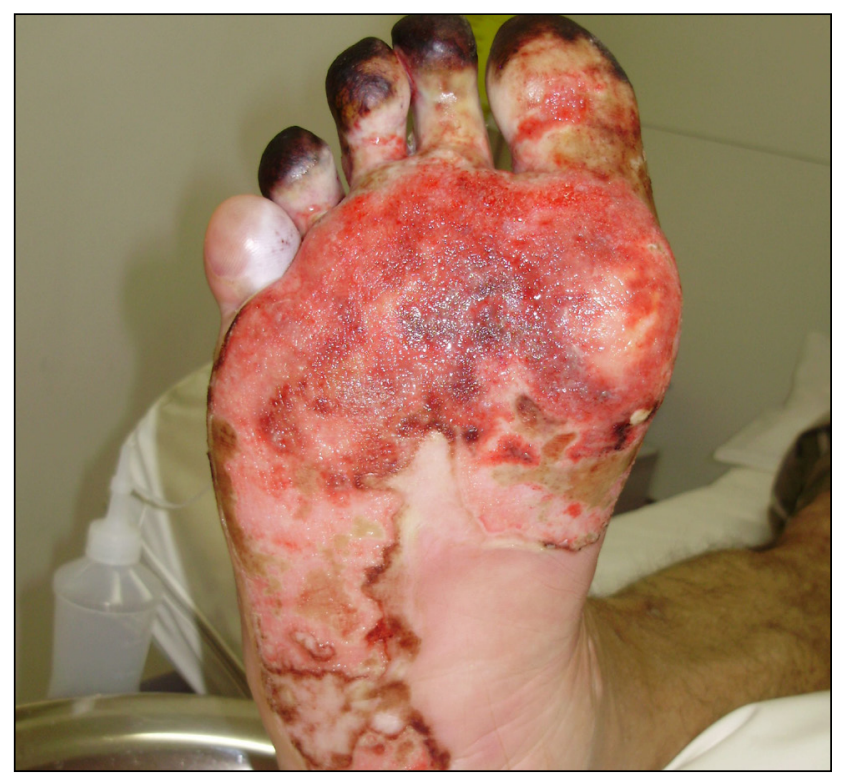

Figura 01 - Neuropatia Sensitiva - Lesão por queimadura na sauna.

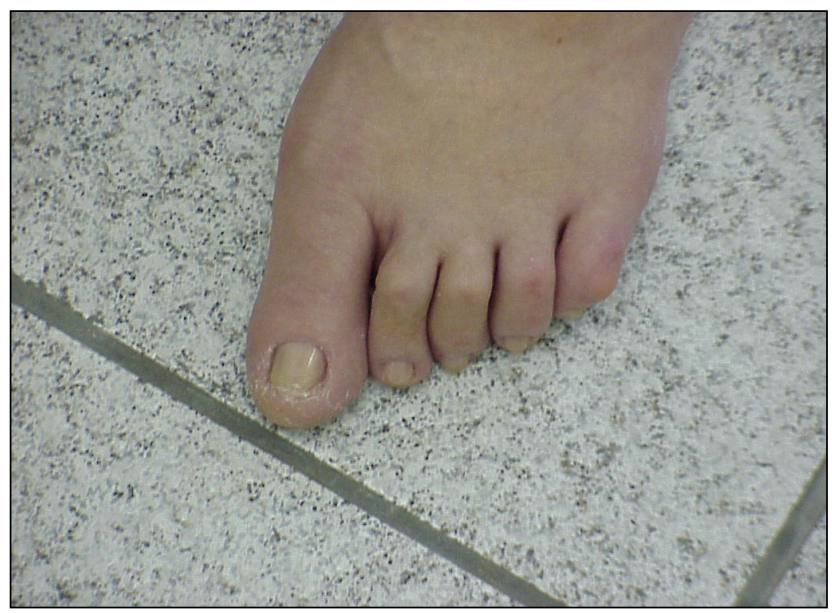

Figura 03 - Deformidade da Neuropatia Motora - Dedos em Garra.

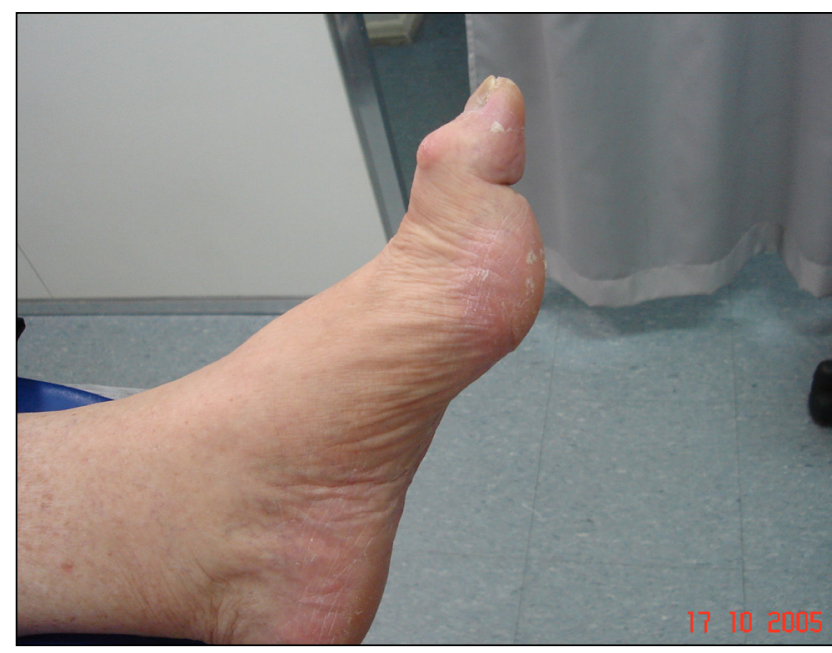

Figura 05 - Deformidades da Neuropatia Motora - Proeminência da cabeça dos metatarsos e dedos em martelo.

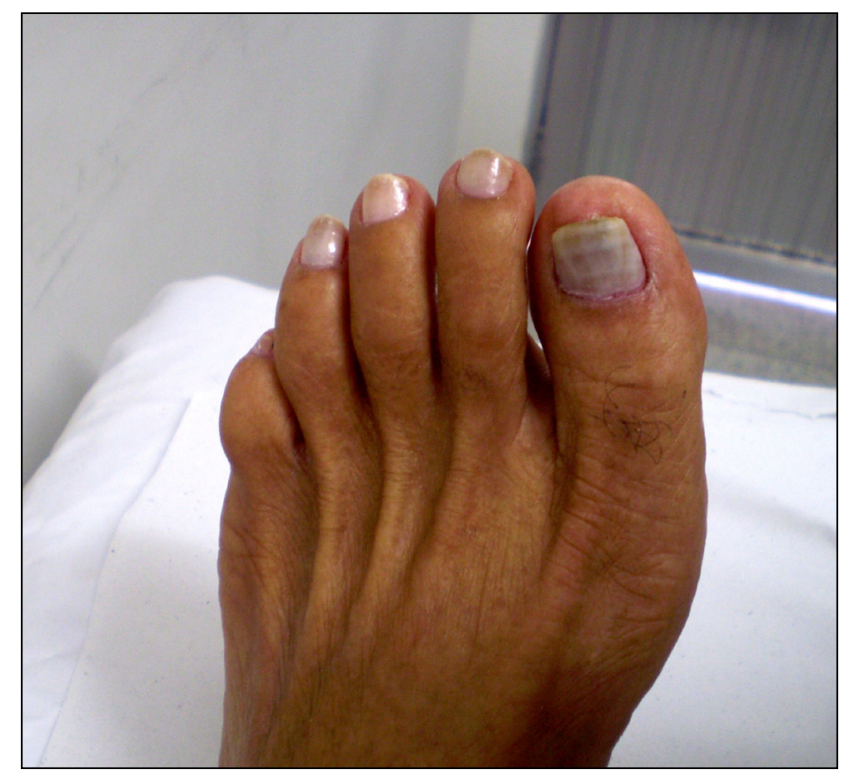

Figura 02 - Deformidade da Neuropatia Motora - Hipotrofia de musculatura intrínseca do pé.

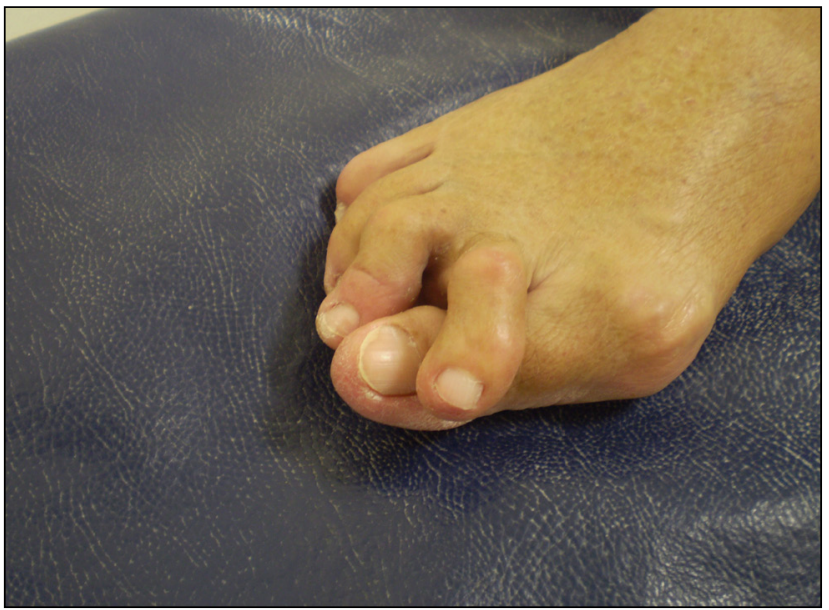

Figura 04 - Deformidade da Neuropatia Motora - Dedos Sobrepostos.

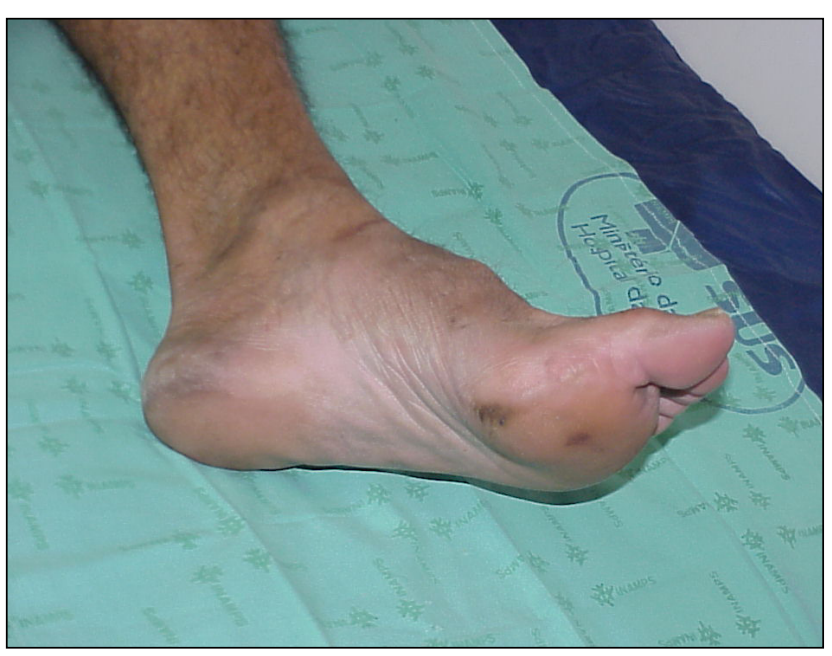

Figura 05.1 - Deformidade da Neuropatia Motora - Proeminência dos metatarsos com hiperceratose (calo) e hematoma sub-dérmico. 


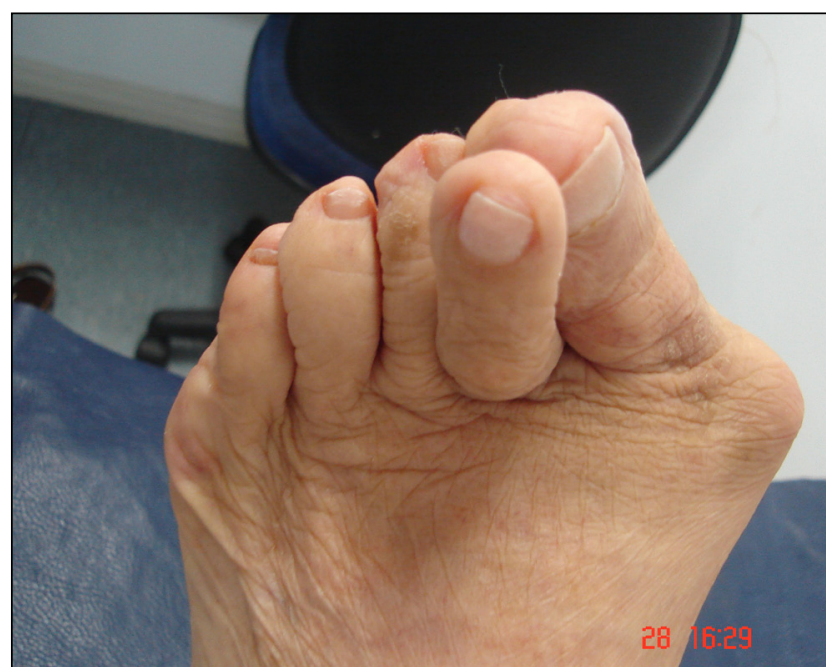

Figura 06 - Deformidade da Neuropatia Motora - Hálux valgo (joanete) + Dedos Sobrepostos.

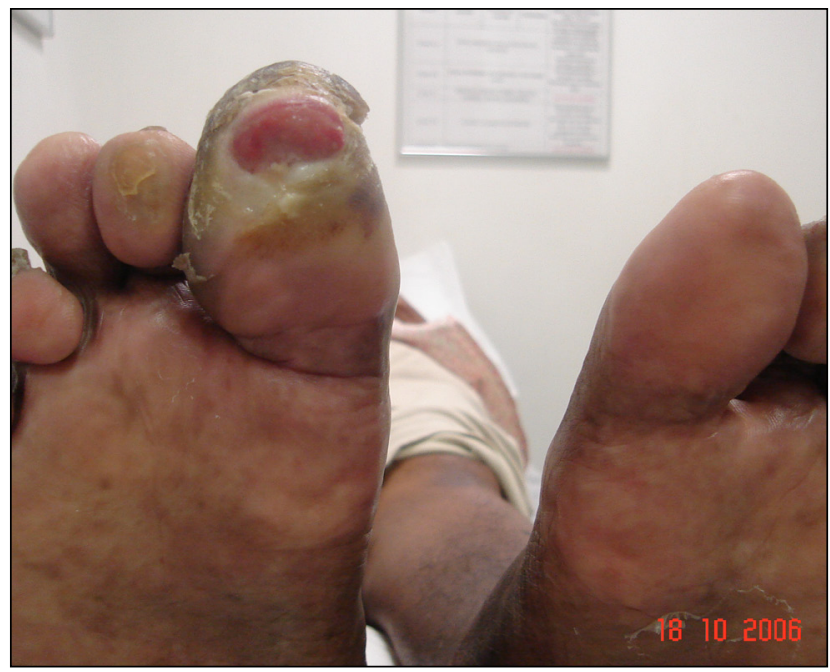

Figura 07 - Deformidades da Neuropatia Motora - Mal perfurante nas falanges distais do $1^{\circ}$ pododáctilo direito e no $2^{\circ}$ pododáctilo esquerdo por dedos em garra.

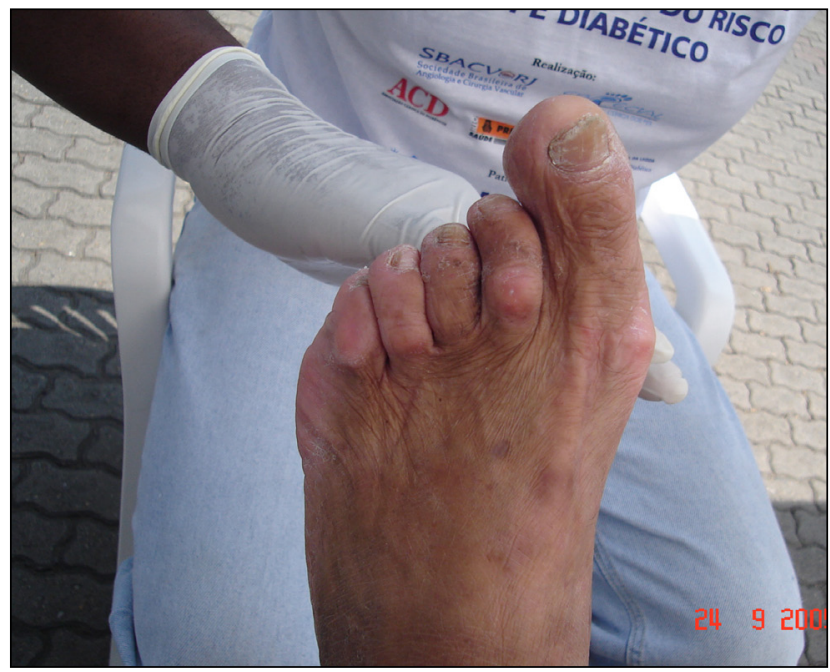

Figura 09 - Deformidades das Neuropatias Motora e Autonômica - Dedos em garra e ressecamento cutâneo.

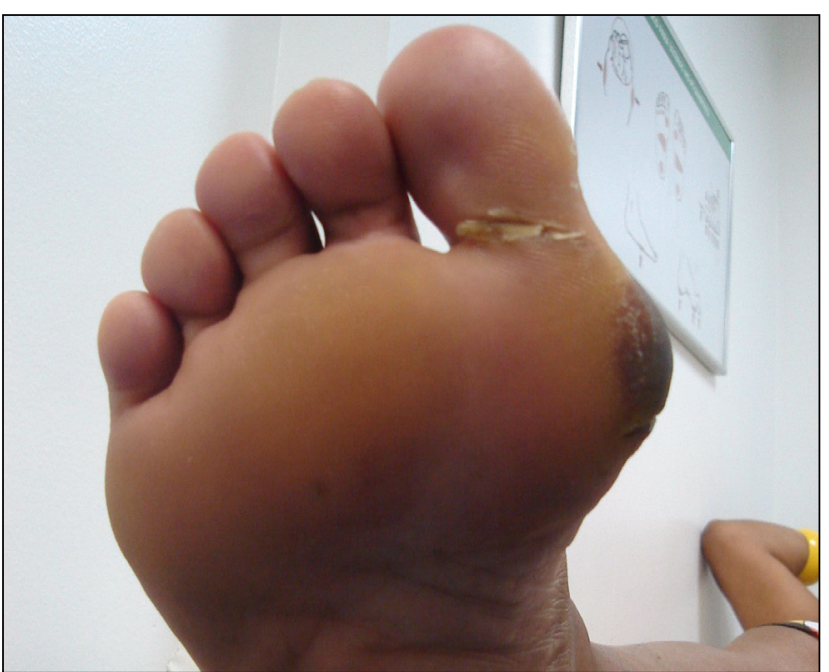

Figura 06.1 - Deformidade da Neuropatia Motora - Hálux valgo (joanete) com hematoma por calçado apertado.

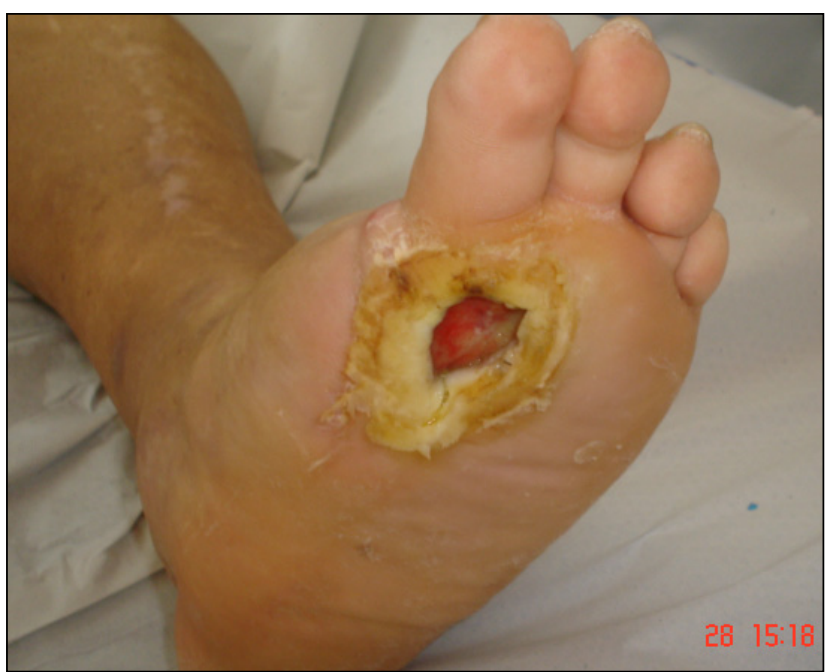

Figura 08 - Deformidade da Neuropatia Motora - Mal perfurante na projeção da cabeça do $1^{\circ}$ metatarso com grande hiperceratose perilesional.

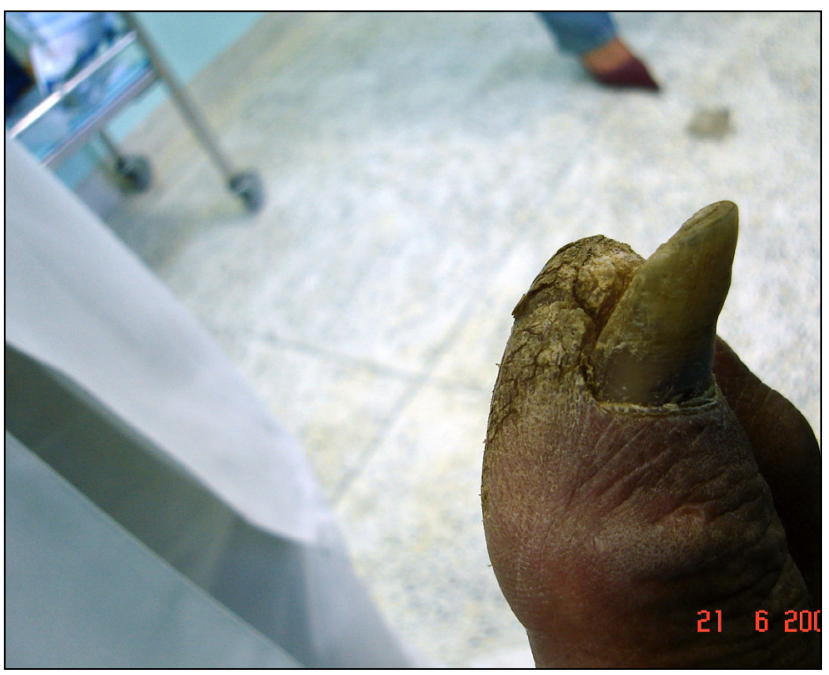

Figura 10 - Deformidades da Neuropatia Autonômica - Rachaduras cutâneas, hiperceratose, onicogrifose (engrossamento) e onicólise (descolamento do leito) na unha do $1^{\circ}$ pododáctilo. 


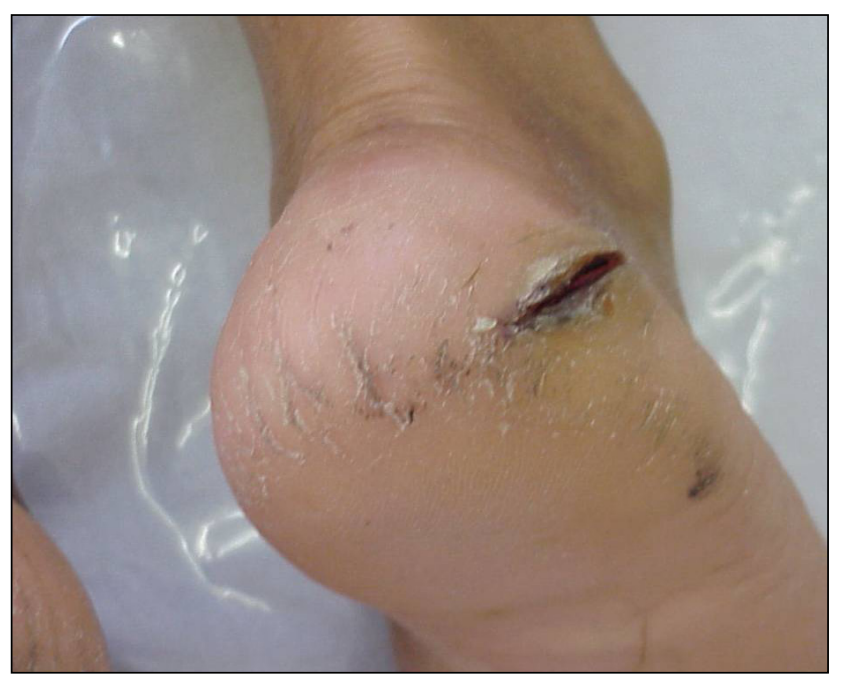

Figura 11 - Neuropatia Autonômica - Rachaduras por ressecamento cutâneo.

Queixas relativas a outros sistemas não afastam a necessidade de avaliação dos membros inferiores, pois geralmente o paciente não valoriza dados importantes: calos, fissuras, micoses, etc. ${ }^{10}$

História familiar, tipo de tratamento e tempo de diagnóstico do diabetes são importantes. ${ }^{19}$

Fazer sempre a pesquisa ativa do mecanismo da lesão: trauma direto, repetitivo, fissura infectada, etc. ${ }^{19}$

História de úlcera e/ou amputação prévia colocam o paciente em grupo de risco elevado para a extremidade afetada e para o membro contralateral. ${ }^{20}$

\section{Sinais e Sintomas}

a) Sensoriais: queimação, pontadas, agulhadas, formigamentos, dormência, dor que varia de leve a forte intensidade (predominantemente noturna), sensação de frio, cãibras. Lembrar que a negação da dor pode traduzir a perda progressiva da sensibilidade dolorosa. ${ }^{20}$

b) Motores: atrofia da musculatura intrínseca do pé e deformidades como: dedos em martelo, dedos em garra, hálux valgo, pé cavo, proeminências ósseas, calosidades (em áreas de pressões anômalas) e úlcera plantar (mal perfurante plantar). É importante a avaliação da limitação da mobilidade articular. ${ }^{20-23}$ FIGURA 12

c) Autonômicos: ressecamento da pele (pé seco) e fissuras, hiperemia, hipertermia, edema (vasodilatação com aumento da abertura de comunicações arteriovenosas) e alterações ungueais. ${ }^{20}$

Notas:

1. A inspeção dos pés deve ser feita independente da queixa. $^{21}$

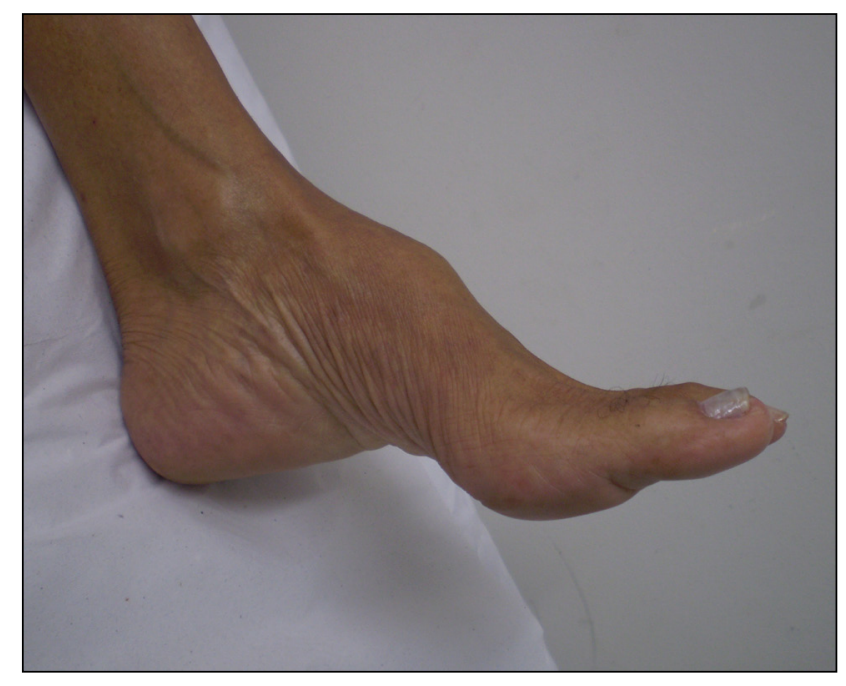

Figura 12 - Deformidade da Neuropatia Motora - Pé Cavo.

2. Inspecionar sempre os calçados. ${ }^{10}$ As alterações nas palmilhas, a presença de secreção, as distorções no corpo do calçado e mesmo o tipo de calçado podem conter informações importantes para o diagnóstico. FIGURAS 13 a 13.2

3. O "Pé de Charcot" (neuro-osteoartropatia) é uma entidade clínica relacionada à polineuropatia periférica do diabético. A neuropatia autonômica provoca a perda da regulação das comunicações arteriovenosas com aumento de fluxo sangüíneo levando à reabsorção óssea, com decorrente osteopenia e fragilidade do tecido ósseo, que associada à perda da sensação dolorosa e ao próprio "trauma" repetitivo da deambulação, pode levar a múltiplas fraturas e deslocamentos (sub-luxações ou luxações).

Ocorrem, então, deformidades importantes (e.g. desabamento do arco plantar) que podem evoluir também para calosidade e ulceração e amputação. $\mathrm{O}$ início deste processo caracteriza a fase aguda e o final a fase crônica, mas, a amputação pode ocorrer em qualquer fase. ${ }^{24-28}$

Pé de Charcot Agudo: Caracterizado pela presença dos sinais da inflamação (edema, hiperemia, hipertermia e dor) sem infecção, sendo muito importante fazer esse diagnóstico diferencial. A dor pode não estar presente se houver concomitantemente a diminuição acentuada da sensibilidade. FIGURAS 14 e 14.1

Pé de Charcot Crônico: Fase avançada da complicação, caracterizada por deformidades osteoarticulares importantes, principalmente do médio-pé, com desenvolvimento de calos e úlceras plantares. ${ }^{18 ; 22 ; 24-29}$ FIGURA 15 


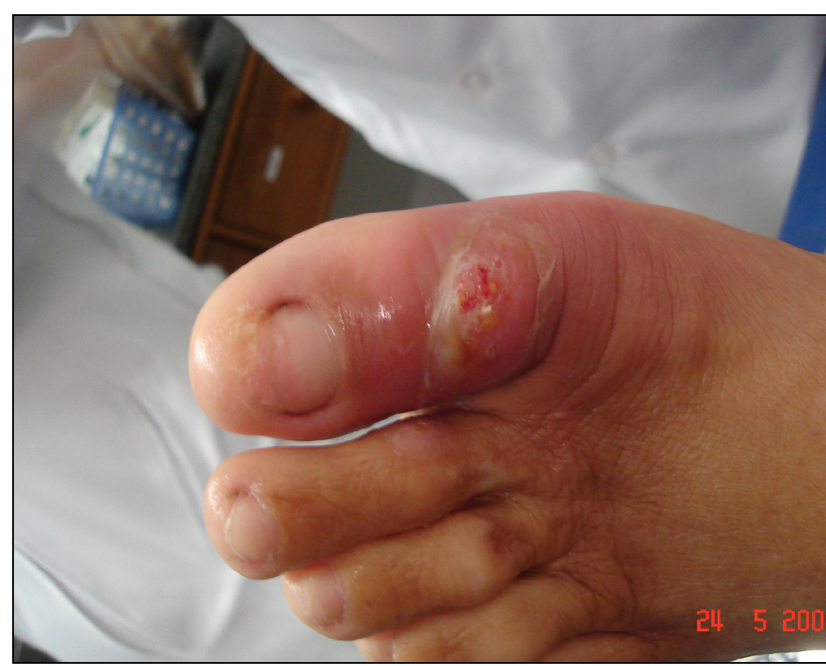

Figura 13 - Abscesso no dorso do hálux e pequena lesão na face medial do segundo pododáctilo, causados por sandália inadequada, com tiras, em paciente com neuropatia sensitiva.

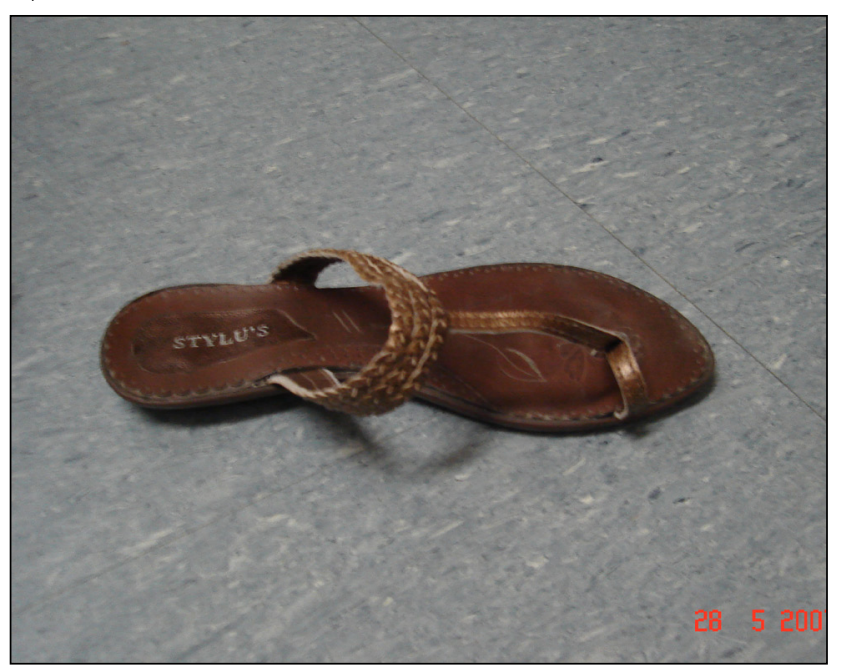

Figura 13.2 - Sandália causadora das lesões observadas nas figuras 13 e 13.1.

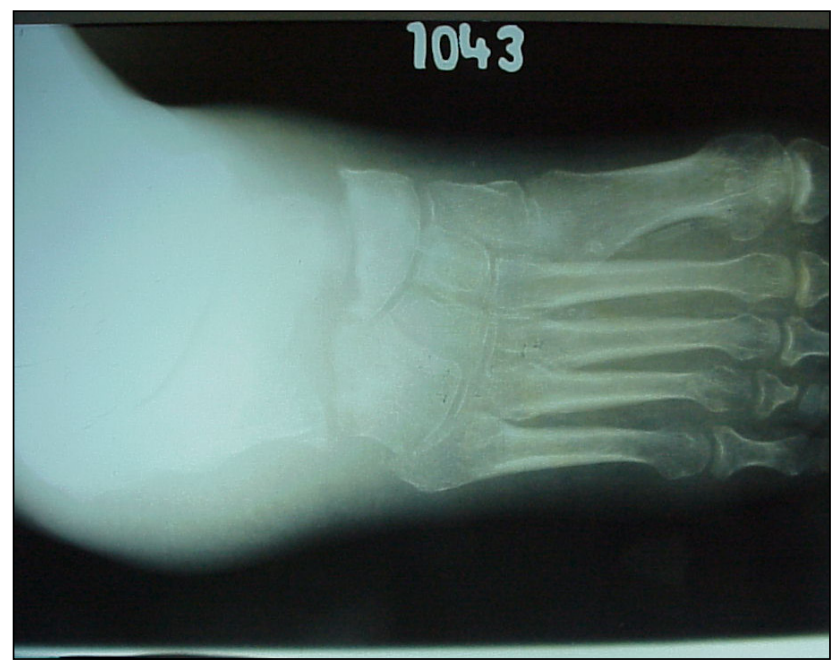

Figura 14.1 - Radiografia do pé da Figura 14 mostrando a erosão, coalescência dos ossos e o desarranjo articular no médio-pé.

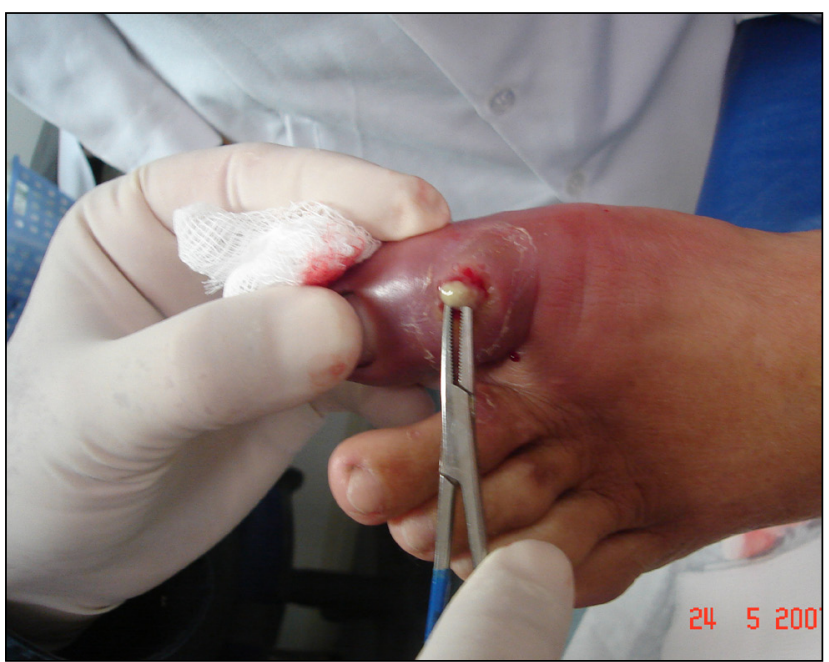

Figura 13.1 - Abscesso no dorso do hálux causado por sandália inadequada, com tiras, em paciente com neuropatia sensitiva.

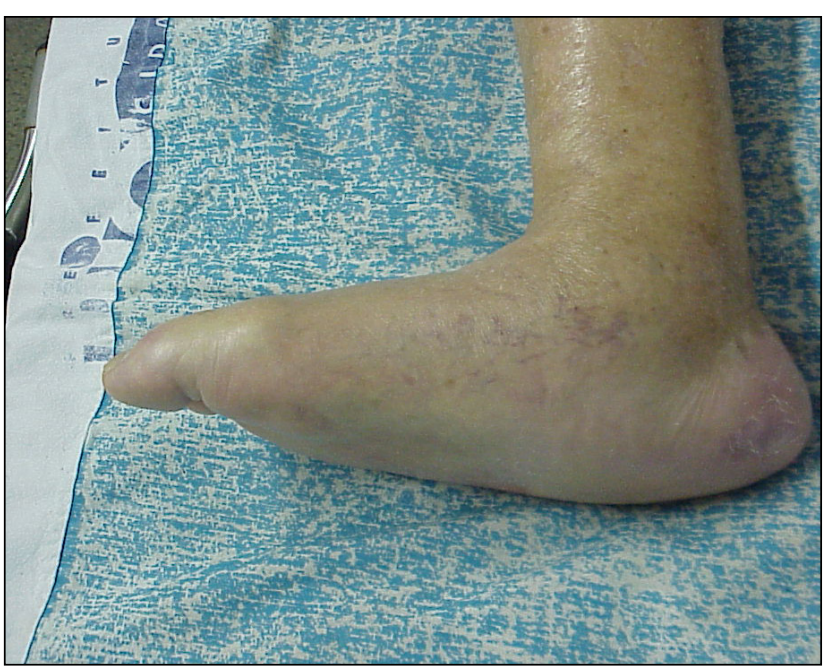

Figura 14 - Pé de Charcot agudo. Observar o desabamento do arco plantar, o edema e a hiperemia.

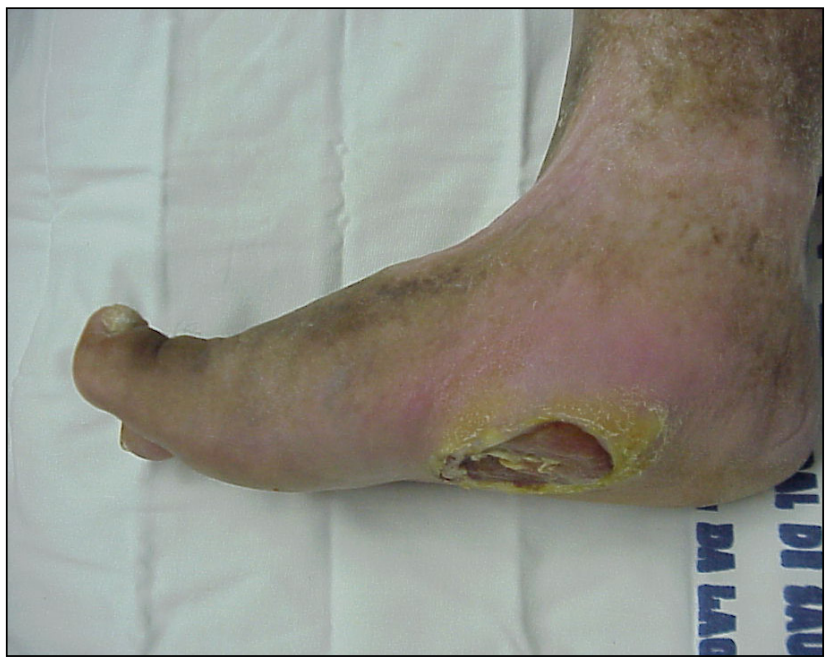

Figura 15 - Pé de Charcot na fase crônica, com mal perfurante extenso e profundo. 
Caso clinico com fotos (FIGURAS 16 a 16.4)

\section{Caso Clínico}

LCS, masculino, 63 anos, diabético há 15 anos, compareceu para avaliação com história de infecção em pé direito, em uso de antibióticos há cerca de 2 meses, sem melhora.

Apresenta deambulação claudicante, em função de desequilíbrio, com pé direito hiperemiado, quente, edemaciado, sem dor ao toque. A mobilização era indolor e revelava amplitude grosseira com crepitação. Pulsos arteriais amplos e sem histórico de hipertermia, com insensibilidade ao exame com monofilamento. Apresentava, ainda, lesão plantar decorrente da deambulação mantida apesar do desabamento grosseiro dos ossos do tarso. Após a avaliação da equipe de multidisciplinar, foi solicitado hemograma completo, VHS e Rx do pé. Orientado repouso e retorno em 48 para a avaliação médica.

Após 48h, retornou para avaliação médica e com os resultados, sendo confirmado o diagnóstico de Charcot Agudo e indicado o tratamento com gesso de contato total por 6 meses.

Resultados dos exames:

- Laboratório VHS maior que 100.

- Leucograma normal

- RX: desabamento dos arcos plantares com deslocamentos, edema, sub-luxações e reação periostal nos ossos do tarso.

O paciente evoluiu com melhora do edema e do aspecto inflamatório, acompanhado de queda do VHS para níveis normais após 6 meses.

Após a retirada do gesso de contato total, apesar das orientações, cometeu exageros na deambulação, sem proteção adequada da órtese e da muleta prescrita, fraturando o tornozelo direito, após torção, em virtude da deficiência proprioceptiva e da osteopenia característica do Charcot, potencializada pela imobilização prolongada. FIGURAS 16 a 16.4 Foi, então, submetido à cirurgia ortopédica com artrodese da articulação do tornozelo.

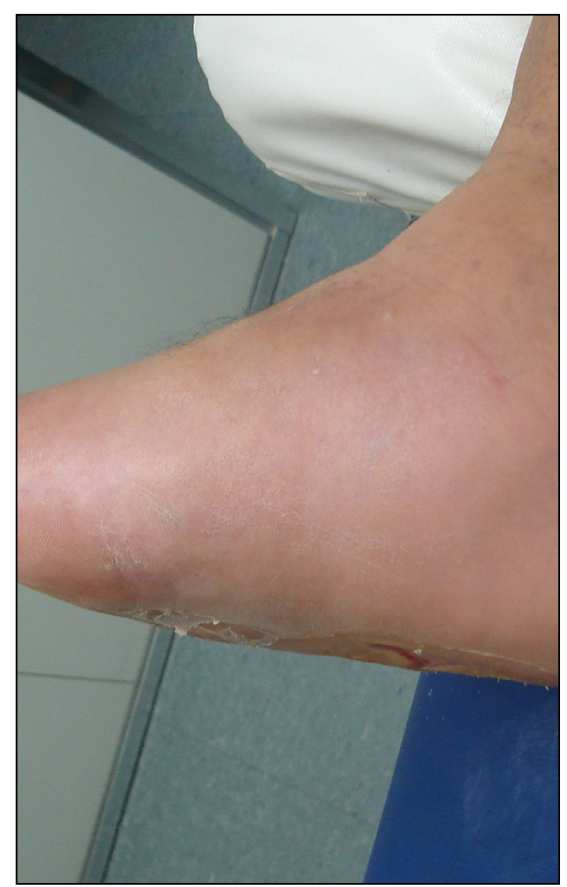

Figura 16 - Pé de Charcot agudo. Observar edema acentuado, hiperemia e desabamento do arco plantar.

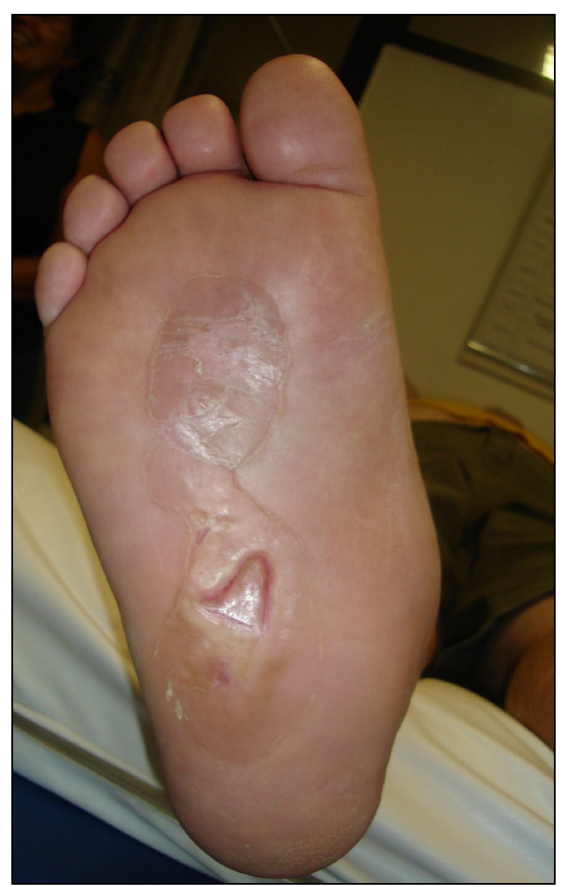

Figura 16.1 - Lesão plantar, com hiperceratose e lesão cutânea, em razão da deambulação mantida em ritmo normal, sobre um pé com desabamento dos ossos do tarso.

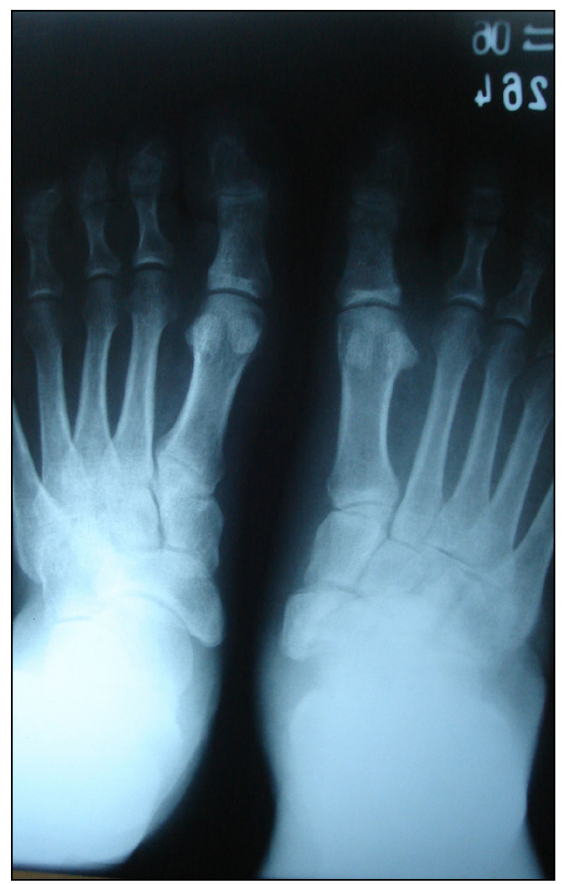

Figura 16.2 - Radiografia inicial do paciente da Figura 16. Observar a coalescência, sub-luxações, edema e reação periostal no pé direito. 


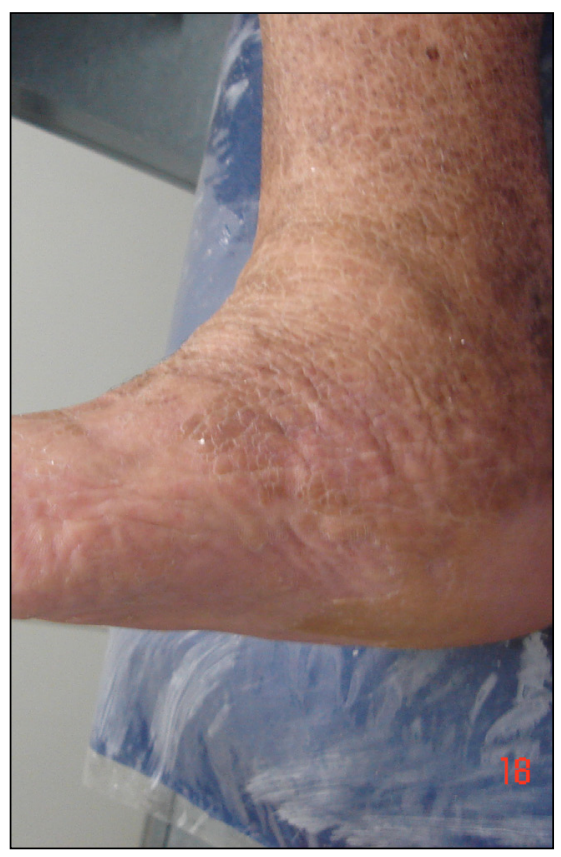

Figura 16.3 - Alta, 9 meses após o $1^{\circ}$ gesso de contato total, para deambulação com uso de muletas e órtese protetora.

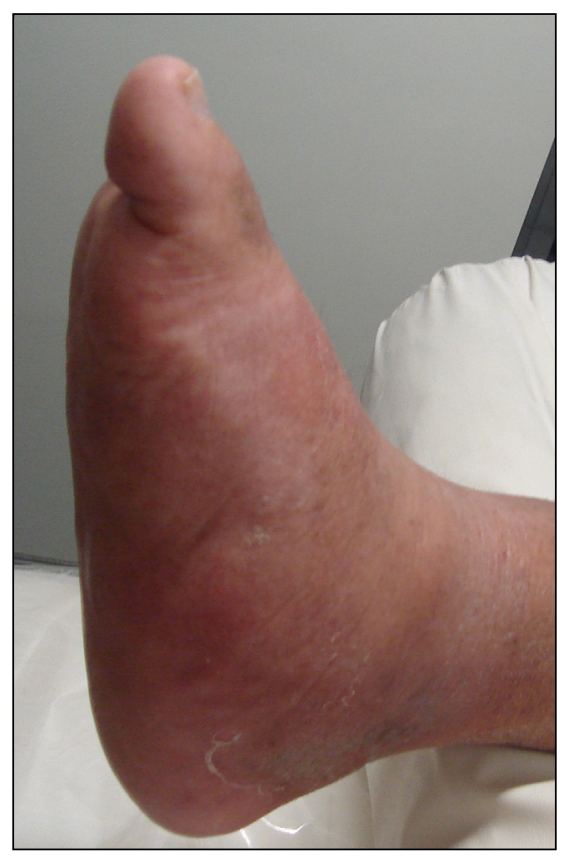

Figura 16.4 - Retorno, 10 dias após a retirada da imobilização prolongada, com história de entorse do tornozelo. Novamente com edema, envolvendo também a articulação do tornozelo.

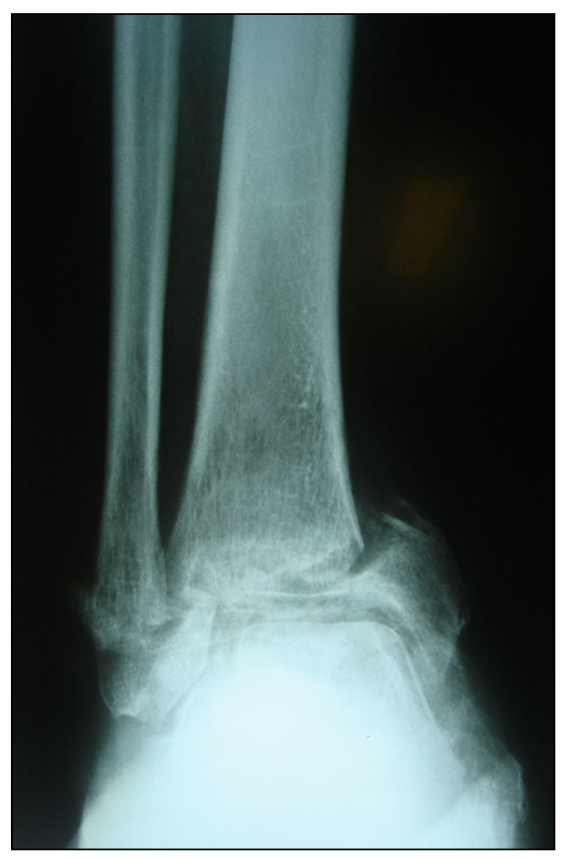

Figura 16.5 - Radiografia após a torção do tornozelo. Observar a fratura dos maléolos com sub-luxação da articulação tibio-társica.

\section{Diagnóstico}

Vários testes são utilizados no diagnóstico da polineuropatia: teste da sensação vibratória com diapasão de 128 $\mathrm{Hz}$, teste da sensação dolorosa com estilete, teste da sensibilidade térmica, teste da sensação profunda com martelo (reflexo do tendão de Aquiles), teste do monofilamento, entre outros.

Entre esses, o Teste do Monofilamento, por detectar as alterações na sensação do tato e da propriocepção, é aconselhado como teste de escolha, nas avaliações por não especialistas, para determinar um risco aumentado de ulceração pelas vantagens da grande sensibilidade, boa especificidade, simplicidade, e do baixo custo. ${ }^{17 ; 29-30}$

Teste do monofilamento (Semmes-Weinstein 10g): Esse teste, mesmo não sendo adequado para o diagnóstico mais precoce da polineuropatia, por não detectar o acometimento das fibras finas responsáveis pela sensibilidade dolorosa superficial e temperatura, certamente avalia a percepção da pressão (tato). Consiste em pressionar (tocar) com a ponta de um fio de nylon especial (monofilamento) em algumas áreas da superfície do pé para testar sua sensibilidade a essa pressão. A incapacidade de sentir a pressão necessária para curvar o monofilamento de $10 \mathrm{~g}$ é compatível com comprometimento da sensibilidade local à pressão ou sensibilidade protetora. ${ }^{7}$ No Quadro 2 está descrita a técnica de aplicação recomendada no Consenso Internacional sobre pé diabético $^{31}$. FIGURA 17

Quadro 2 - Técnica de aplicação do Teste do Monofilamento (Monofilamento de 5,07 de Semmes-Weinstein) (D) ${ }^{31}$

\begin{tabular}{|c|}
\hline $\begin{array}{l}1^{\circ} \text { - Aplicar o Monofilamento perpendicular à superfície da pele sem que o } \\
\text { paciente veja o momento do toque }\end{array}$ \\
\hline $2^{\circ}$ - Pressionar com força suficiente apenas para encurvar o Monofilamento \\
\hline $\begin{array}{l}3^{\circ} \text { - O tempo total entre o toque para encurvar o Monofilamento e sua } \\
\text { remoção não deve exceder dois segundos }\end{array}$ \\
\hline $\begin{array}{l}4^{\circ} \text { - Perguntar se o paciente sentiu ou não a pressão/toque (SIM ou NÃO) e } \\
\text { onde está sendo aplicado (Pé Direito ou Esquerdo) }\end{array}$ \\
\hline $5^{\circ}$ - Serão pesquisados 3 pontos \\
\hline $\begin{array}{l}6^{\circ} \text { - Aplicar duas vezes no mesmo local alternando com pelo menos uma vez } \\
\text { simulada ( sem tocar), portanto, são no mínimo três perguntas por aplicação }\end{array}$ \\
\hline $\begin{array}{l}7^{\circ} \text { - A percepção da pressão (sensação protetora) está presente se duas } \\
\text { respostas forem corretas das três aplicações }\end{array}$ \\
\hline $\begin{array}{l}8^{\circ} \text { - A percepção da pressão (sensação protetora) está ausente se duas } \\
\text { respostas forem incorretas das três aplicações (risco de ulceração) }\end{array}$ \\
\hline
\end{tabular}

Notas:

1. Não há consenso em relação ao número de pontos ou locais onde o monofilamento deve ser aplicado ${ }^{29 ; 31}$, mas a técnica do Quadro 2 tem se mostrado adequada e é utilizada rotineiramente em muitos serviços especializados. 


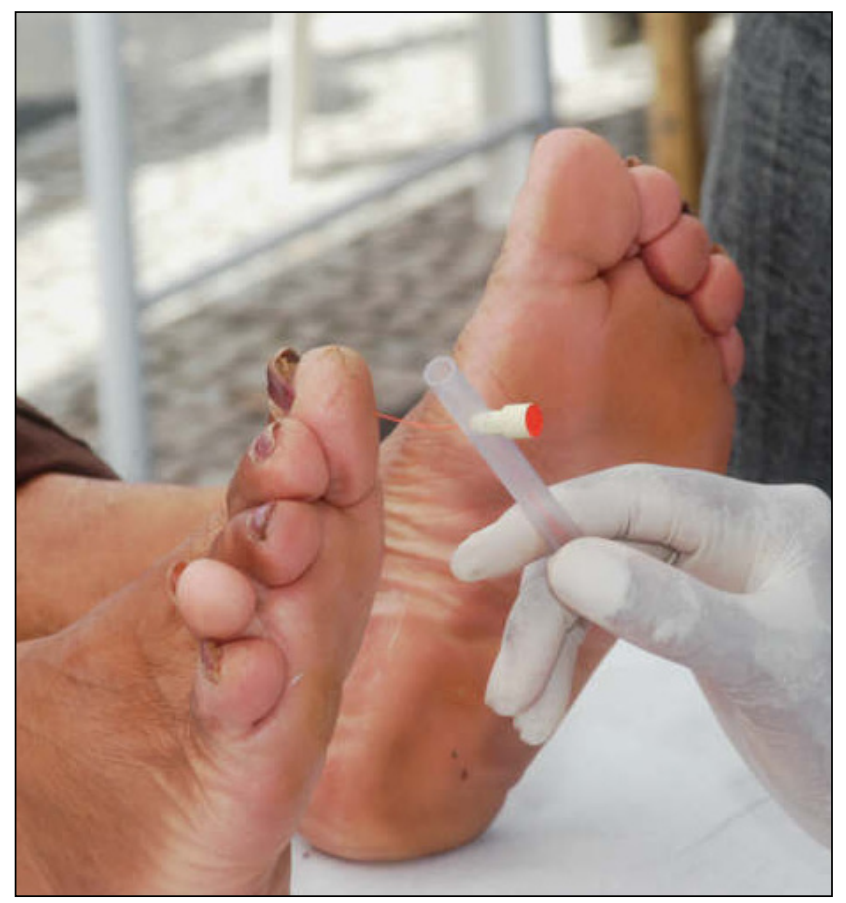

Figura 17 - Teste do monofilamento.

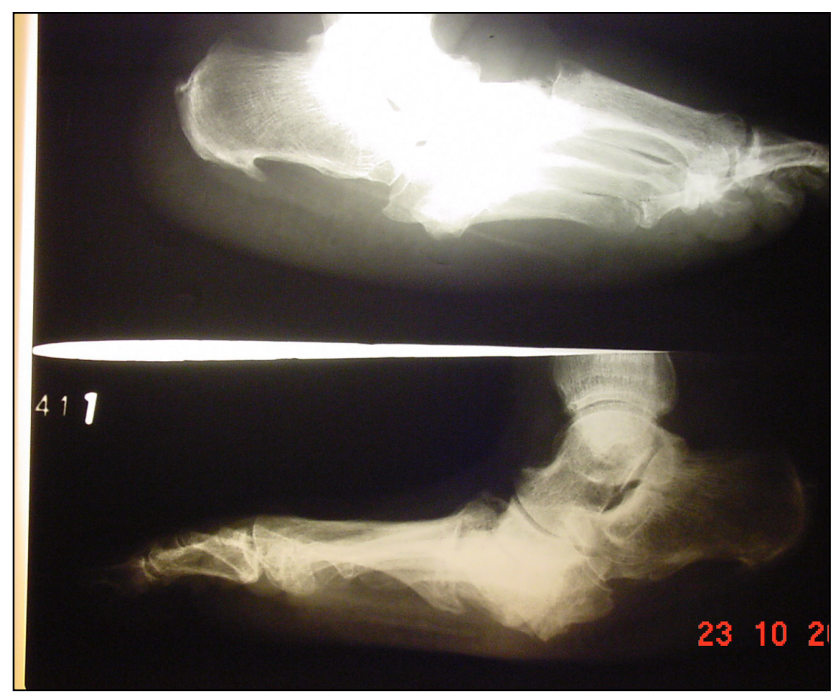

Figura 19 - Radiografia no Charcot crônico. Observar a esclerose, neoformação e a fusão de fragmentos ósseos, com o colapso do médio-pé.

2. A incapacidade de perceber o toque do monofilamento tem sensibilidade elevada para identificar a perda da sensação protetora. ${ }^{32}$

3. Um resultado normal ao teste do monofilamento, apesar de apontar para um menor risco imediato de ulceração nos pés, certamente não exclui a presença de neuropatia e uma anamnese precisa com um exame cuidadoso dos pés devem sempre ser realizados em todos os diabéticos a cada avaliação.
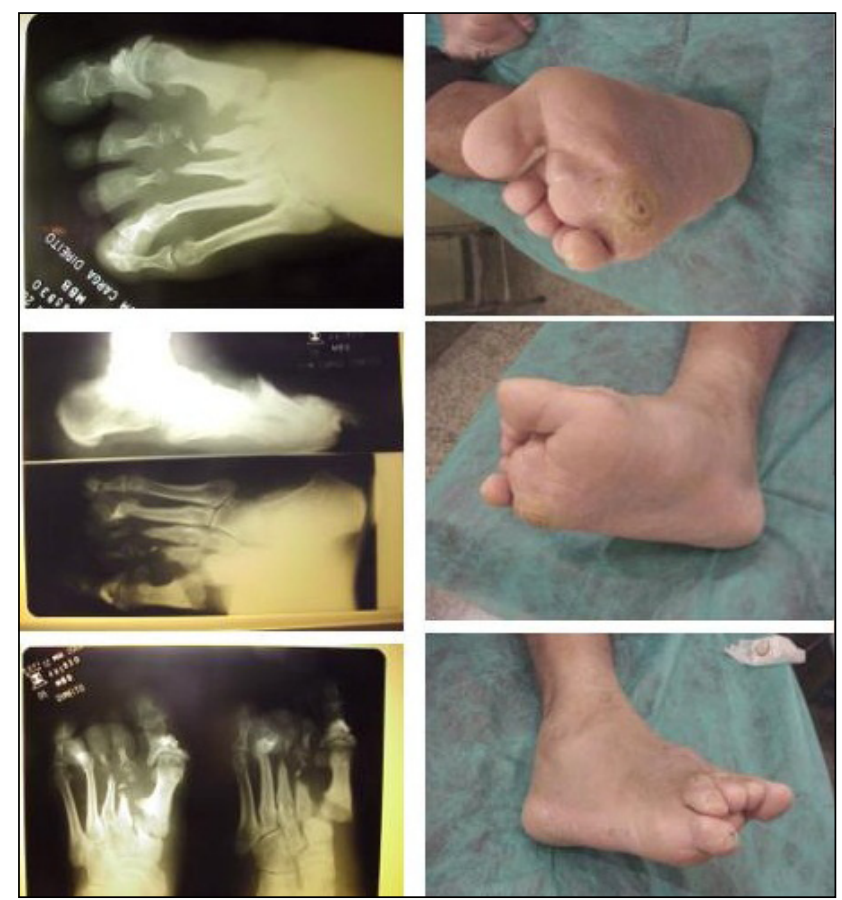

Figura 18 - Charcot crônico. Observar a reabsorção óssea (metatarsos em "lápis"), fratura, deslocamento e a destruição óssea e articular.

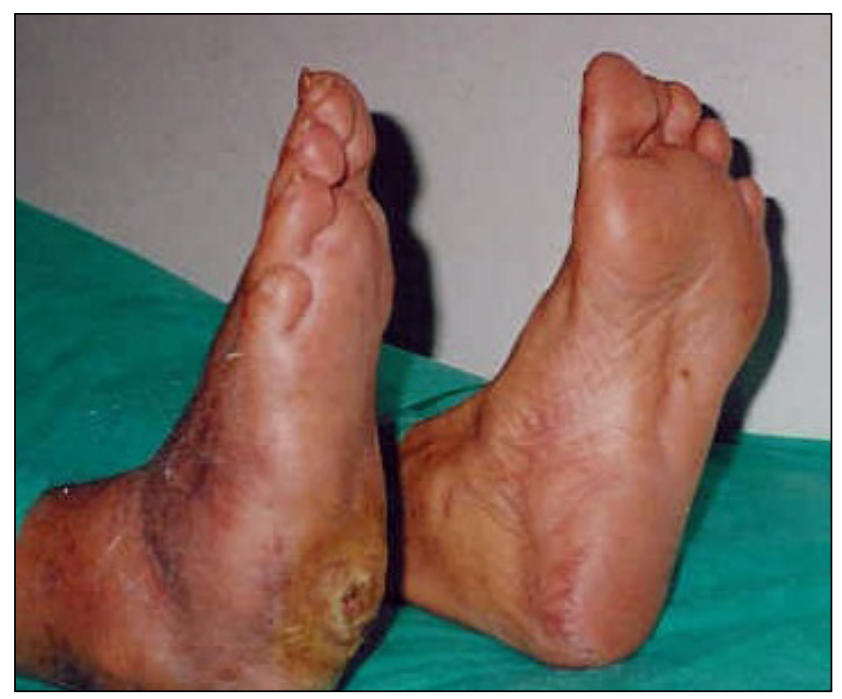

Figura 19.1 - Charcot crônico com desabamento e pé em "mata-borrão" com mal perfurante plantar.

\section{Exame de imagem - Radiografia simples}

Exame de baixo custo com informações anatômicas. Importante no diagnóstico de osteomielite e avaliação do pé de Charcot. Pode revelar alterações osteo-articulares do Pé de Charcot agudo ou crônico tais como: rarefação óssea, reabsorção óssea (falanges em "taça invertida" ou "lápis”), fratura, deslocamento, destruição, sequestros ósseos, destruição articular, reação perióstea, neoformação óssea, esclerose, colapso longitudinal do arco médio, FIGURA 18 
Na fase aguda há predominância de reabsorção óssea, osteólise, fraturas, subluxação (alinhamento anormal das articulações), deslocamentos, erosão da cartilagem e instabilidade. Lembrar que nessa fase o pé apresenta-se com hiperemia, hipertermia e edema. FIGURAS 14 e 14.1

$\mathrm{Na}$ fase crônica há predominância da esclerose, exuberante formação óssea (neoformação), deformação com estabilidade ${ }^{7}$, fusão de fragmentos ósseos, reação periostal e colapso dos ossos do médio pé (pé em "mata borrão"). ${ }^{29 ; 33}$ FIGURA 19 e 19.1

\section{Tratamento}

O controle metabólico rigoroso é consensual como prevenção e tratamento da neuropatia. Entretanto, do ponto de vista prático, a abordagem terapêutica é direcionada basicamente para a melhora dos incômodos sintomas já referidos nesse capítulo e na forma do tratamento conservador ou cirúrgico das seqüelas (deformidades, calos, úlceras e do pé de Charcot).

\section{Dor Neuropática:}

A despeito das controvérsias na abordagem das dores em pontadas ou agulhadas, dormências, cãibras e outros sintomas neurológicos, abordaremos as recomendações mais citadas e práticas.

Inicialmente, é necessário excluir as causas não-diabéticas. Em seguida, controlar rigorosamente a glicemia e considerar o uso de drogas. A maioria das recomendações não inclui analgésicos para controlar a dor neuropática, os mais comuns pela sua ineficácia, e os mais potentes devido ao risco de desenvolver dependência à droga. Os fármacos mais citados (Quadro 3) são: os antidepressivos tricíclicos (imipramine, amitriptilina, clomipramina), os inibidores seletivos da recaptação da serotonina (paroxetina, citalopram), os anticonvulsivantes (carbamazepina, gabapentina, fenitoina, ácido valproico), os antiarrítmicos (mexiletina) e os opióides (tramadol). Essas drogas podem ser usadas, na fase inicial, de forma isolada (monoterapia) e, diante de resultados insatisfatórios, podem ser associadas (terapia combinada). As drogas mais utilizadas como monoterapia são os tricíclicos. Desses, a amitriptilina é a mais usada, com doses iniciais de 10 a $25 \mathrm{mg}$ por dia, sendo 100 mg a dose habitualmente necessária para alívio dos sintomas. Os antidepressivos podem também ser associados, em tomadas noturnas, a um tranqüilizante, à carbamazepina ou mexiletina. O uso dessas drogas deve ser bem avaliado, considerando-se sempre seus efeitos colaterais. Vale acrescentar o uso tópico de capsaicina creme para o desconforto localizado, com aplicação mínima por oito semanas. ${ }^{12 ; 29 ; 34-38}$
Quadro 3 - Tratamento da dor neuropática ${ }^{37,38}$

\begin{tabular}{|lcc|}
\hline Droga: Tópica & Dose diária $(\mathrm{mg})$ & Nome comercial \\
\hline Capsaicina & 0,075 & Capsaína \\
\hline Drogas: Via oral & & \\
\hline Amitriptilina & $25-150$ & Tryptanol/ Amytril \\
Imipramina & $25-150$ & Tofranil/ Imipra \\
Paroxetina & 40 & Pondera/ Cebrilin \\
Citalopram & 40 & Procimax/ Cipramil \\
Gabapentina & $900-1800$ & Neurontin/ Progresse \\
Carbamazepina & $>800$ & Tegretol \\
Mexiletina & $>450$ & Mexitil \\
Tramadol & $50-400$ & Tramal/ Sylador \\
\hline
\end{tabular}

Notas:

1. Os medicamentos de controle da neuropatia podem ter efeitos colaterais importantes para o SNC, fígado, função renal, cardiovascular e globo ocular. ${ }^{39,40}$

2. O ácido alfa-lipóico, ou ácido tióctico, pode ser usado nas fases iniciais da neuropatia, na dose de $600 \mathrm{mg} /$ dia, retardando, impedindo ou mesmo revertendo sua evolução. ${ }^{41-44}$

3. As operações descompressivas dos nervos periféricos ao nível do tornozelo podem impedir a evolução da neuropatia diabética, mas ainda necessitam de pesquisas clínicas controladas que estabeleçam, de forma definitiva, sua segurança e efetividade nessa indicação. ${ }^{45}$

\section{Angiopatia}

\begin{tabular}{l} 
1. A avaliação vascular periférica é necessária em todos os diabéticos para \\
estadiamento e classificação do risco. \\
\hline 2. Na presença de isquemia periférica, a cicatrização das lesões tróficas é \\
difícil ou retardada, possibilitando a presença de material necrótico que \\
potencializa as infecções polimicrobianas severas. \\
\hline $\begin{array}{l}\text { 3. A revascularização da extremidade isquêmica no paciente diabético (por } \\
\text { cirurgia ou angioplastia) deve sempre ser considerada, pois os resultados, de } \\
\text { modo geral, são semelhantes aos dos não diabéticos. }\end{array}$
\end{tabular}

1. A avaliação vascular periférica é necessária em todos os diabéticos para estadiamento e classificação do risco.

2. Na presença de ISQUEMIA PERIFÉRICA, a cicatrização das lesões TRÓFICAS é difícil ou retardada, POSSIBILITANDO A presença de material necrótico que POTENCIALIZA AS infecções polimicrobianas severas.

3. A revascularização da extremidade ISQUÊMICA no paciente diabético (POR cirurgia ou angioplastia) deve sempre ser considerada, pois os resultados, de modo geral, são semelhantes aos DOS não diabéticos. 


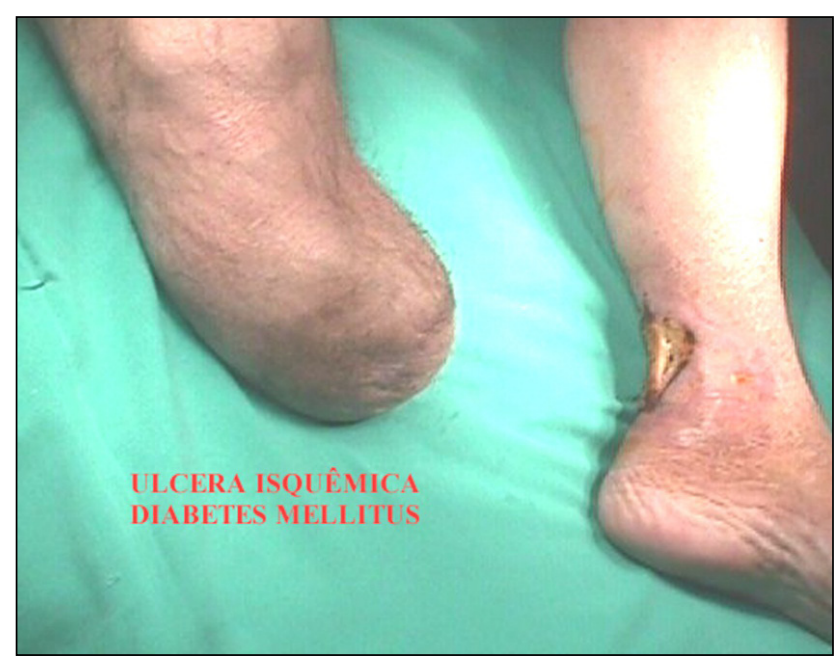

Figura 20 - Ulcera isquêmica no MIE. Observar os bordos marcados, a necrose do fundo da ferida e a amputação prévia do membro contralateral.

História:

Devem sempre ser pesquisados:

- Antecedentes pessoais cardiovasculares importantes: Presença de hipertensão arterial, dislipidemia, insuficiência coronariana, acidente vascular cerebral, nefropatia isquêmica;

- Antecedentes familiares de doença cardiovascular;

- Hábitos: Tabagismo, alcoolismo, dieta inadequada;

\section{Histórico específico e dirigido:}

Claudicação intermitente (dor nos pés, pernas ou em todo o membro, iniciada após o início da deambulação, com piora progressiva até a interrupção da marcha e melhora rápida da dor com essa interrupção);

Pé pendente (dor isquêmica de repouso);

Atrofia dos membros, alterações nos pêlos e unhas;

Úlceras, na maioria das vezes não dolorosas, de difícil cicatrização. ${ }^{19}$

\section{Exame clínico:}

\section{Geral:}

busca ativa de outras manifestações da arterioesclerose:

Sopros e dilatações arteriais (vasos carotídeos, supra-claviculares, aorta abdominal)

\section{Membros inferiores:}

- Aparência e simetria dos membros inferiores;

- Palidez à elevação do membro e hiperemia reativa na posição pendente;

- Ausência dos pulsos e/ou presença de sopros: começando pela análise da aorta abdominal e

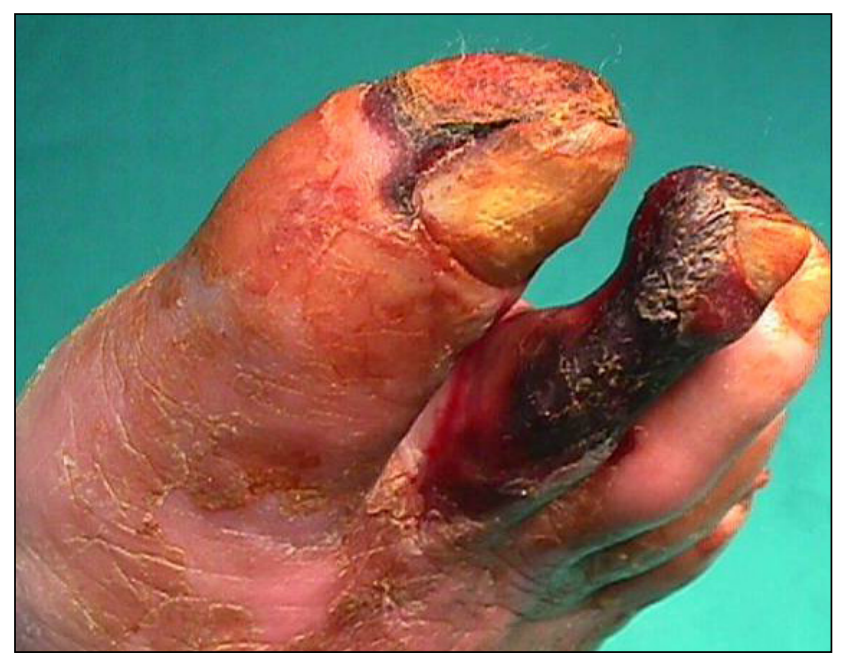

Figura 21 - Necrose do $2^{\circ}$ pododáctilo e da falange distal do hálux.

incluindo todos os pulsos periféricos: femorais, poplíteos, tibiais posteriores e dorsais dos pés;

- Úlceras: com ênfase no aspecto da borda e do fundo da lesão (com necrose, secreção, tecido de granulação avermelhado ou pálido); FIGURA 20

- Necrose de pododáctilos; FIGURA 21

- Cicatrizes cirúrgicas que indiquem revascularizações prévias das extremidades, desbridamentos ou amputações distais anteriores, homo ou contralateral; FIGURA 20

Notas:

1. As úlceras podem ter componente neuropático e infeccioso, associado ao componente vascular. ${ }^{19}$

2. A amputação de um membro não significa o fim de uma afecção severa e o relaxamento do controle, pois cerca de $30 \%$ dos indivíduos poderão, estatísticamente, perder o membro contralateral. ${ }^{47}$

3. A presença de enchimento venoso normal no diabético com polineuropatia não significa, obrigatoriamente, a ausência de estenose ou oclusão arterial no membro, pois a abertura anormal das comunicações artério-venosas, presente na neuropatia autonômica, pode possibilitar esse achado.

\section{Métodos diagnósticos}

\section{Doppler portátil:}

É uma ferramenta útil, de baixo custo, que pode quantificar o grau de isquemia através da medida das pressões absolutas na extremidade inferior e também através da 
medida relativa comparada com o membro superior: índice tornozelo/braço.

Quadro 4 - Critérios para avaliação da cura de lesões dos membros inferiores através das medidas absolutas de pressão arterial nos membros inferiores. ${ }^{48}$

\begin{tabular}{|lcc|}
\hline Cura da lesão & \multicolumn{2}{c|}{ Pressão no tornozelo } \\
\cline { 2 - 3 } & $\begin{array}{c}\text { Não diabéticos } \\
(\mathrm{mmHg})\end{array}$ & $\begin{array}{c}\text { Diabéticos } \\
(\mathrm{mmHg})\end{array}$ \\
\hline Provável & $>65$ & $>90$ \\
Pouco provável & $55 \mathrm{a} 65$ & $80 \mathrm{a} 90$ \\
Improvável & $<55$ & $<80$ \\
\hline
\end{tabular}

Notas:

1. Pressão arterial absoluta no tornozelo menor que a pressão braquial ou relação (índice) entre a pressão tornozelo/ braço menor que 0,9 significam deficiência circulatória arterial. ${ }^{49}$

2. Cerca de $30 \%$ dos diabéticos apresentam os valores das pressões absolutas elevados devido à calcificação da camada média da parede arterial (Arterioesclerose de Monckeberg que leva a artérias de difícil compressão), tornando o exame menos confiável (índice > 1,15). ${ }^{49}$ Uma das formas de contornar este problema é a utilização das medidas da pressão digital, o que, apesar de mais fidedignas, apresentam dificuldades em sua realização rotineira. ${ }^{50}$

\section{Mapeamento duplex (Duplex-scaning):}

A utilização dos recursos do Ultrassom-Doppler permite a análise pré-operatória (tanto das artérias

Quadro 5

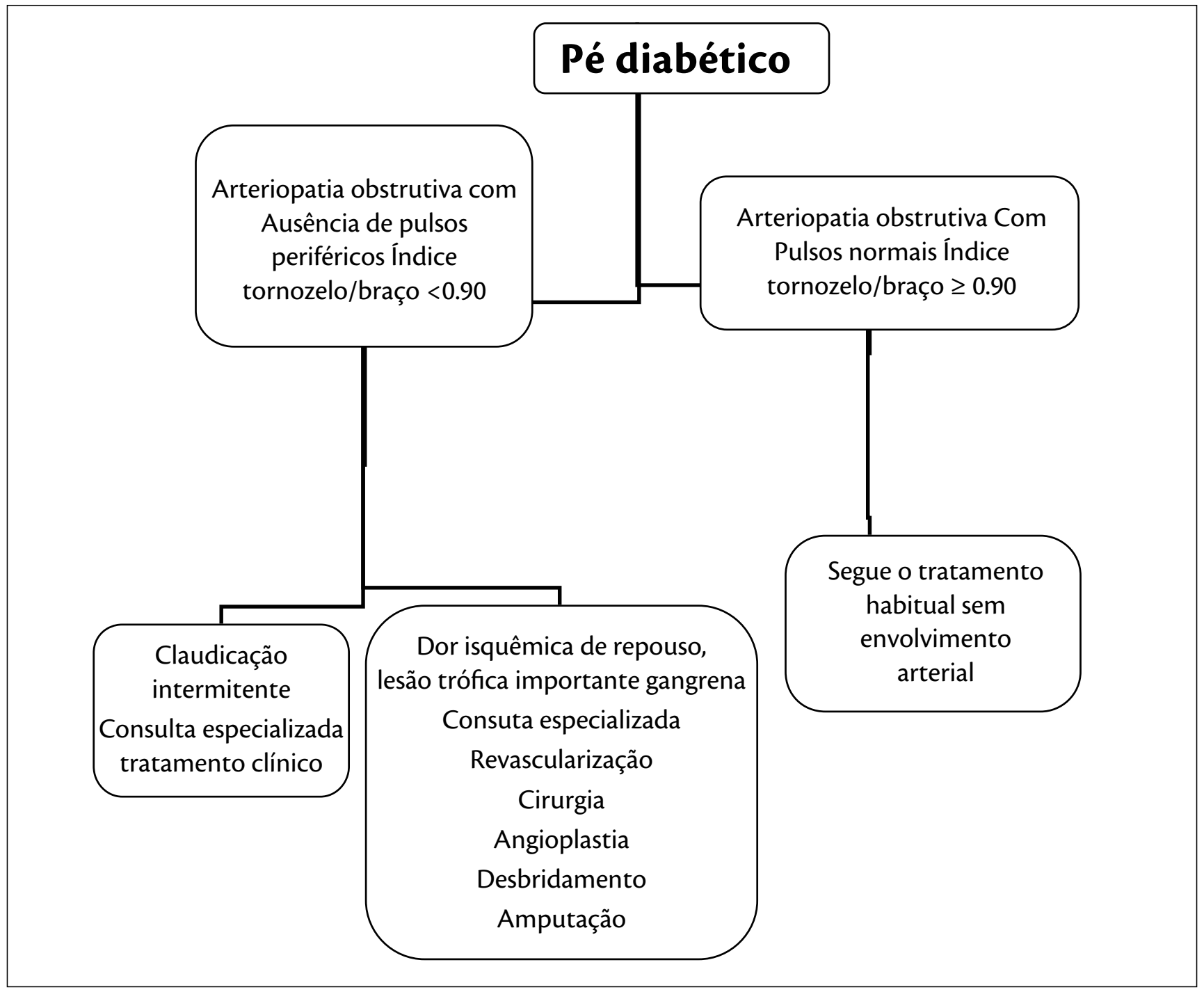


como de seu possível substituto venoso) e o seguimento dos pacientes revascularizados. ${ }^{51}$ Esse exame é dinâmico e sua fidedignidade depende da experiência do examinador, possibilita a realização de exames repetidos e pode, em determinadas situações, orientar o tratamento cirúrgico sem a realização de arteriografia por punção arterial. ${ }^{52}$

\section{Arteriografia por punção direta:}

Estudo invasivo que pode ser utilizado no pré-operatório para planejamento da conduta. Atualmente muito utilizado já como ferramenta diagnóstico-terapêutica ao mesmo tempo. Evidencia território a ser revascularizado, com detalhes de qualidade, da anatomia da doença arterioesclerótica. O exame deve estender-se até a visualização das artérias do pé e seus ramos, pois nos diabéticos é freqüente o padrão de oclusão das artérias da perna, poupando as artérias dos pés. ${ }^{53,54}$

Notas:

1. A nefrotoxicidade dos contrastes iodados é uma grande preocupação nos exames arteriográficos e procedimentos endovasculares em diabéticos em virtude da doença já figurar como um dos mais importantes fatores de risco para Insuficiência Renal Crônica. ${ }^{55,56}$

2. Nos diabéticos em uso de metformina, em função da ocorrência de acidose lática, ${ }^{57}$ a medicação deve ser suspensa no dia do exame e reiniciada apenas 48 horas após o procedimento, se a função renal estiver normal. ${ }^{58,59}$.

\section{Angiotomografia}

Utiliza quantidades grandes de contraste iodado por via endovenosa e radiação. Nas atuais modalidades de tomografia espiral as imagens são adequadas, de boa qualidade, em especial nos territórios aorto-ilíaco e fêmoro-poplíteo, com amplas perspectivas para estudo das artérias da perna. ${ }^{60,61}$

\section{Angioressonância magnética}

Não utiliza contraste iodado, mas o gadolíneo, contraste usado nesse exame, encontra limitações para seu uso em pacientes nefropatas. É exame não invasivo e que, apesar de potencializar as imagens de estenose arterial, fornece imagens de melhor qualidade no território AORTO-ILÍACO. ${ }^{62}$

\section{Tratamento}

As linhas gerais estão apresentadas no QUADRO 5

\section{Tratamento clínico}

Uma vez detectada a doença arterial obstrutiva periférica no paciente, duas preocupações são pertinentes: a primeira é se o paciente tem um quadro estável de claudicação intermitente; aqui, além do reforço educacional quanto à preservação da extremidade, a preocupação com a sobrevida é importante. ${ }^{63}$ Os controles glicêmico, da pressão arterial, nível dos lípides, do peso (alimentação), parada do tabagismo, etilismo e atividade física leve/moderada se impõem. A segunda é a presença de isquemia grave com associação de lesão trófica e infecção. Nessa situação a avaliação vascular especializada é fundamental, com o objetivo de avaliar as possibilidades de revascularização para salvamento do membro, cicatrização de lesão e melhor controle da infecção. ${ }^{11}$

\section{Tratamento medicamentoso da doença arterial} obstrutiva periférica (DAOP) no paciente diabético

Em virtude da sobrevida limitada do paciente diabético com $\mathrm{DAOP}^{63-65}$, uma vez detectada sua presença, a prescrição da melhor terapia médica nestes indivíduos torna-se necessária, caso ainda não esteja instituída. Esta terapia é baseada nos aspectos favoráveis, em pacientes com arterioesclerose difusa, do uso dos antiagregantes plaquetários, estatinas, inibidores da enzima de conversão e beta-bloqueadores (além do controle do peso, do tabagismo, do etilismo e do sedentarismo). ${ }^{66,67}$

Especificamente para o tratamento da claudicação intermitente as drogas hemorreológicas tem sido utilizadas amplamente. Entre elas destacam-se a pentoxilfilina e o cilostazol. No passado o agente mais utilizado foi a pentoxifilina, porém, atualmente, existem evidências da superioridade do cilostazol. ${ }^{68}$

\section{Tratamento intervencionista (operação convencional ou angioplastia com ou sem stent)}

Existe ampla discussão na literatura e entre especialistas a respeito do papel da intervenção invasiva para tratamento de pacientes com DAOP e diabetes. A indicação mais tradicional e estabelecida inclui pacientes com isquemia crítica do membro inferior (lesão trófica importante e /ou dor isquêmica de repouso), isto é, aqueles com risco de perda da extremidade. Essa abordagem mostra resultados cirúrgicos (pontes com veia autóloga, pontes com prótese e endarterectomia) semelhantes aos dos pacientes não diabéticos, em termos de resultados de funcionamento dos enxertos e salvamento da extremidade, a curto e longo prazo. ${ }^{53,64,69-71}$ FIGURA 22 


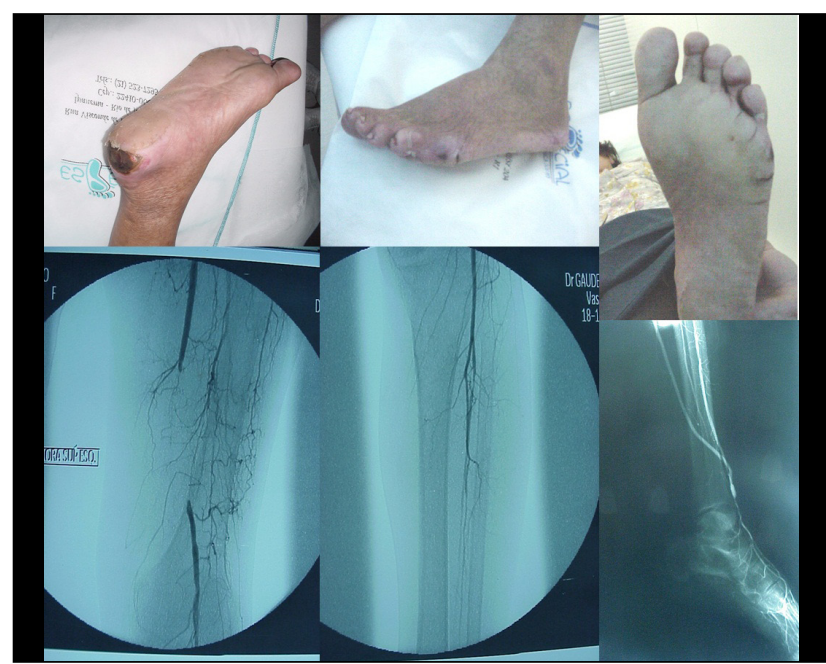

Figura 22 - Pé diabético com lesões isquêmicas. Observar a oclusão da artéria femoral superficial e das artérias infra-patelares. A porção distal da ponte fêmoro-tibial anterior aparece no canto inferior da figura.

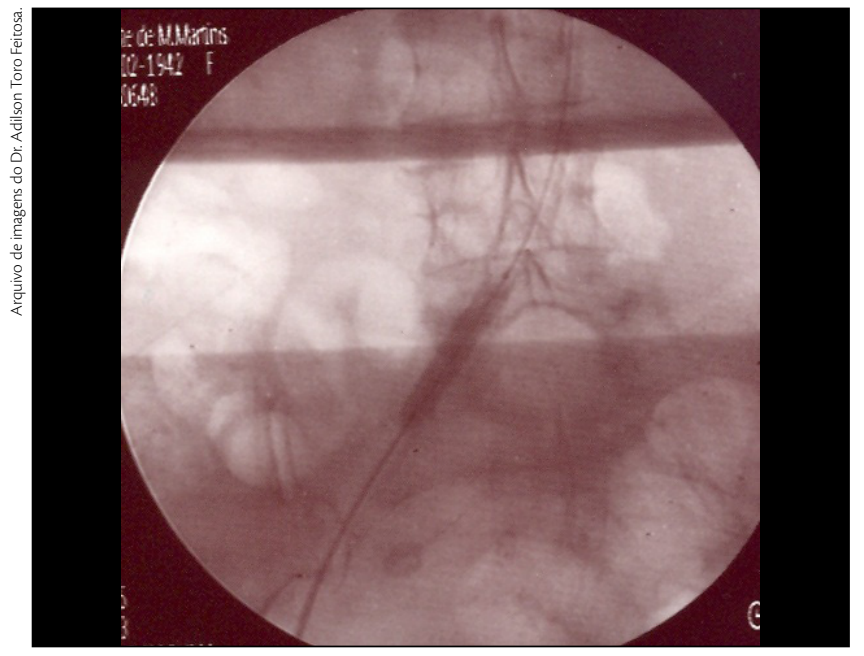

Figura 23.1 - Angioplastia de artéria ilíaca comum direita durante o procedimento. Observar o balão de dilatação inflado no interior da artéria.

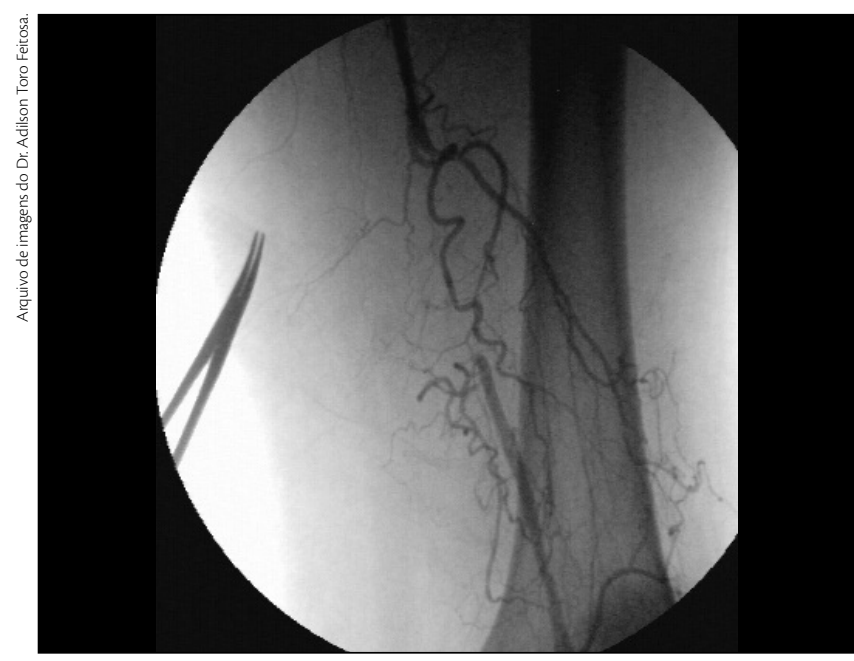

Figura 24 - Angioplastia de artéria femoral superficial antes do procedimento. Observar a oclusão da artéria e a circulação colateral, com reabitação da artéria poplítea proximal.

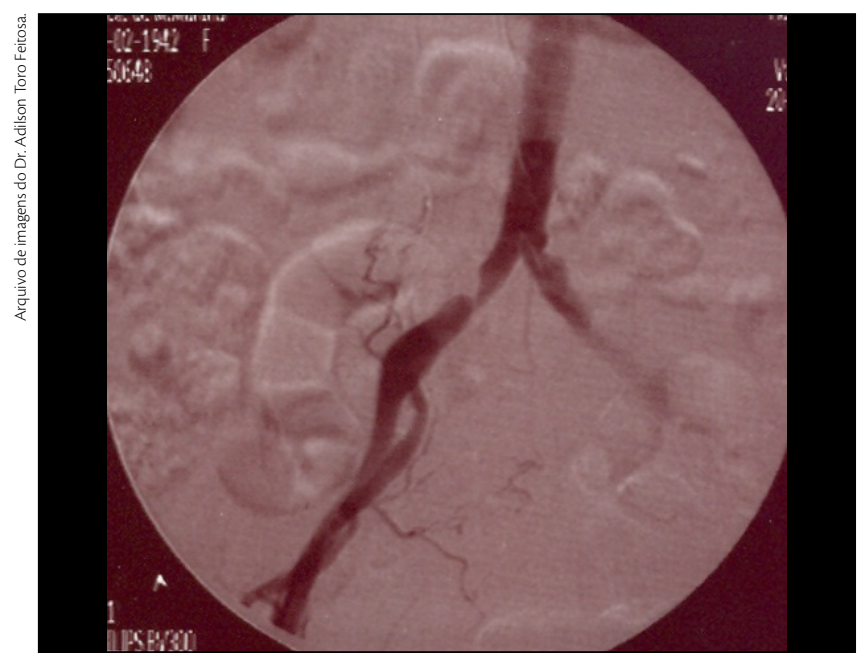

Figura 23 - Angioplastia de artéria ilíaca comum direita antes do procedimento. Observar a estenose interessando acima de $70 \%$ da luz arterial.

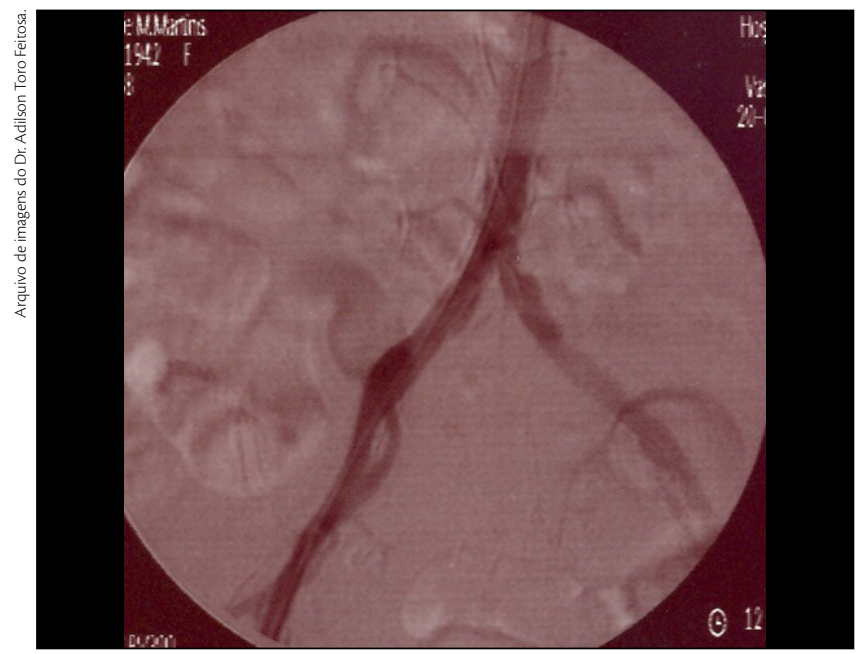

Figura 23.2 - Angioplastia com stent da artéria ilíaca comum direita após o procedimento.

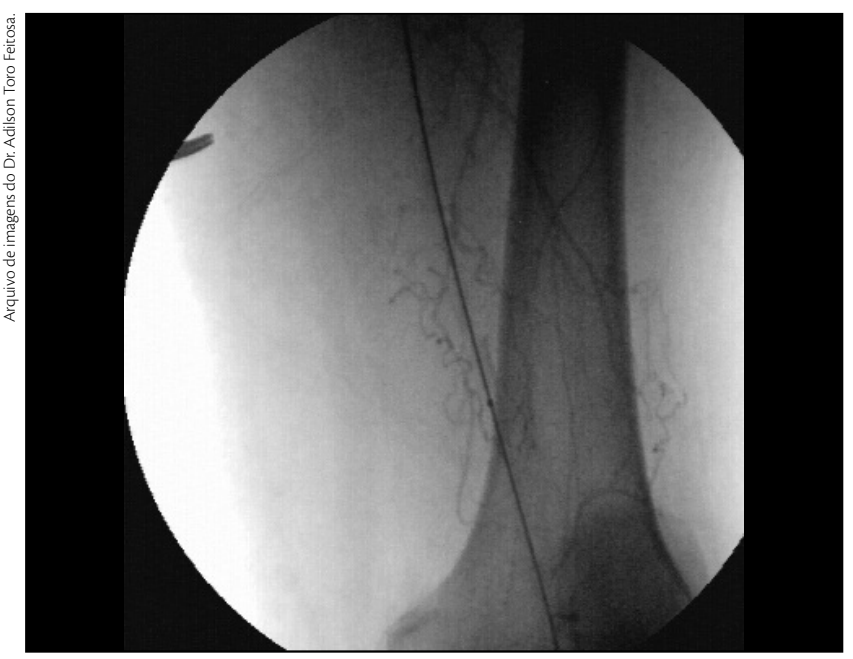

Figura 24.1 - Angioplastia de artéria femoral superficial durante o procedimento. Observar o balão de dilatação, ainda não insuflado, no interior da artéria. 


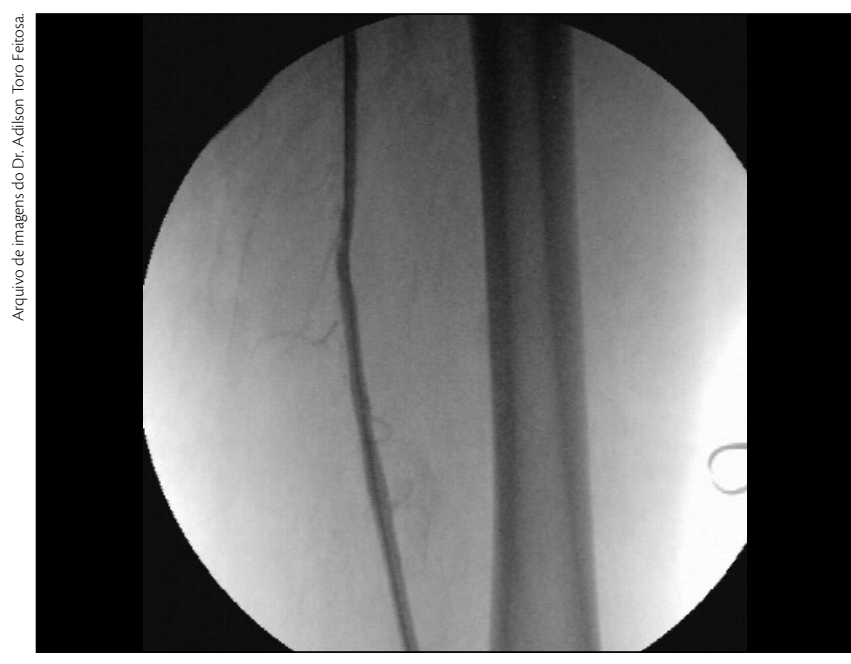

Figura 24.2 - Angioplastia de artéria femoral superficial após o procedimento.

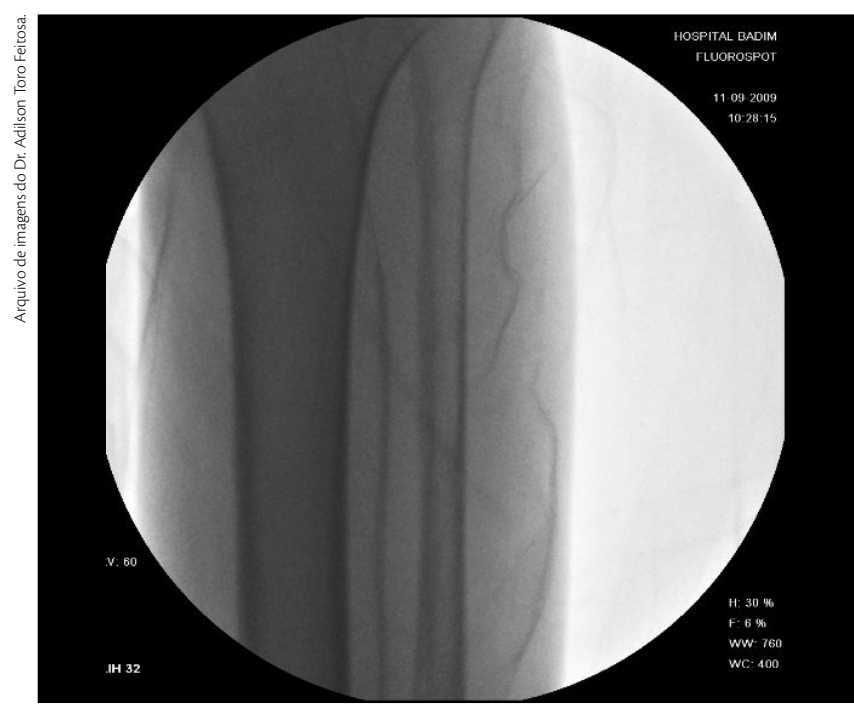

Figura 25.1 - Angioplastia de artérias fibular e tibial anterior durante o procedimento. Observar o balão de dilatação no interior da artéria fibular.

A incorporação da angioplastia, associada ou não ao uso de stent, constitui-se atualmente em mais uma valiosa ferramenta para o tratamento dos pacientes diabéticos com DAOP. Os primeiros resultados do procedimento tiveram sua eficácia contestada, ${ }^{72,73}$ porém com o desenvolvimento de materiais específicos para abordagem não apenas do território aorto-ilíaco, mas infra-iguinal e, especialmente, infra-patelar, as condições técnicas melhoraram e, apesar de ainda haver controvérsias, os resultados em pacientes diabéticos mostraram-se também adequados. ${ }^{66,71,74-77}$ FIGURAS 23, 24 e 25

Notas:

1. O conceito de microangiopatia que afeta os vasos da extremidade inferior refere-se ao espessamento da membrana basal do capilar e a falta de controle sobre

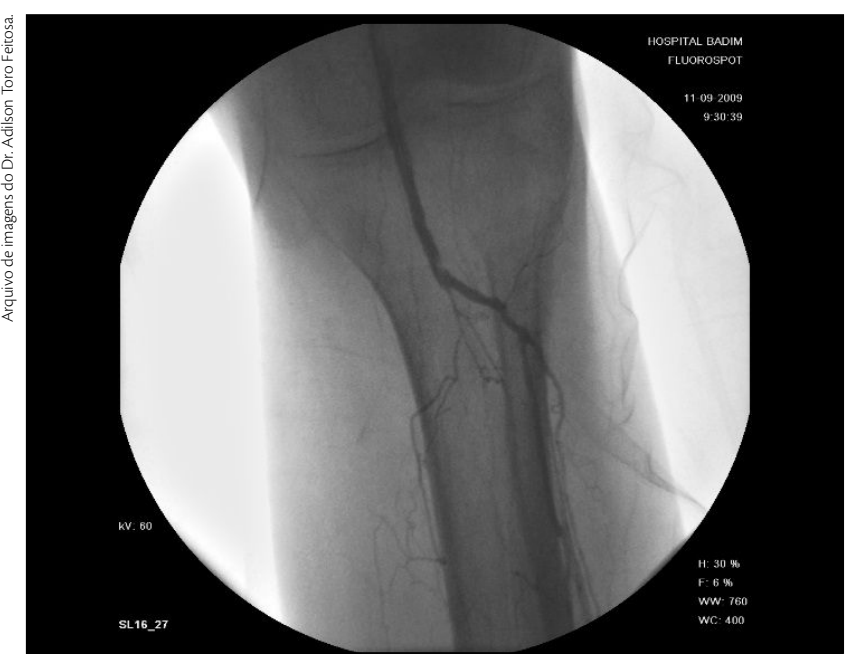

Figura 25 - Angioplastia de artérias fibular e tibial anterior antes do procedimento.

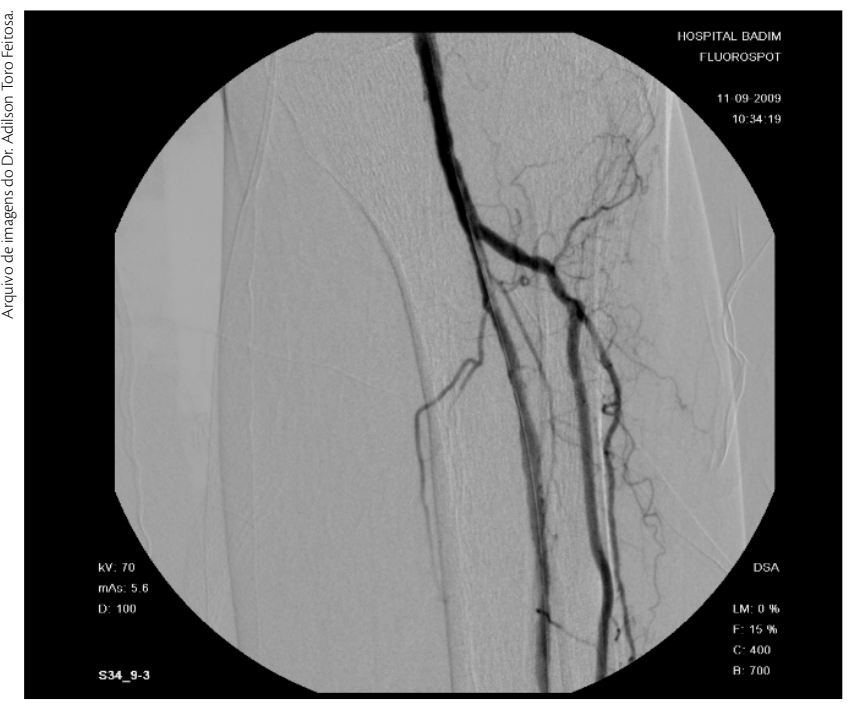

Figura 25.2 - Angioplastia de artérias fibular e tibial anterior após o procedimento.

o fechamento/ abertura de shunts artério-venosos periféricos. Estes fatores não contra-indicam a revascularização da extremidade afetada e não tornam piores os resultados dessas revascularizações em diabéticos. ${ }^{78}$

2. A macroangiopatia é precoce, agressiva, sistêmica e acelerada no diabético. Cerca de $15 \%$ a $25 \%$ dos diabéticos tem macroangiopatia clinicamente significativa nos membros inferiores. ${ }^{79}$

3. Ao contrário dos não diabéticos, é comum o achado de pacientes diabéticos com isquemia, pulso poplíteo normal, oclusão de artérias da perna, e artérias do pé poupadas do processo oclusivo. ${ }^{54}$

4. Revascularizações poplíteo-distais, com uso de pontes venosas, mostraram bons resultados na literatura com uma média $88,5 \%$ de preservação do membro, no seguimento de um ano. ${ }^{80}$ 
5. Na revascularização da extremidade, por qualquer método, a vigilância quanto ao seu funcionamento e quanto aos outros aspectos do pé diabético, é fator determinante da qualidade de vida do paciente. ${ }^{64,81}$

6. Alguns artigos e meta-análises, incluindo pacientes diabéticos, têm sido publicados confirmando o bom resultado das prostaglandinas, em particular da prostaglandina E1 (PGE1), no tratamento das isquemias periféricas estágio III/IV, com melhora ou cicatrização das lesões em pacientes que tenham um membro viável, no qual a revascularização seja impossível, tenha pouca chance de sucesso ou já tenha sido tentada sem sucesso. TASC II ${ }^{66}$

\section{Infecção}

1. A infecção nos pés é, isoladamente, a principal causa de internação de pacientes diabéticos, contituindo um sério fator causal de amputação e ameaça à vida destes pacientes.

2. Para seu controle adequado é necessária a avaliação do paciente (estado geral), da lesão (características) e da infecção (microbiologia).

\section{Anamnese}

\section{Sintomas:}

A história com questionamentos dirigidos é oportuna, pois o paciente diabético pode não valorizar aspectos importantes como dor, rubor, tumor plantar ou dorsal e febre, devido à intensidade diminuída destes sintomas em função da neuropatia periférica. Sede, aumento da ingestão de líquidos e aumento da necessidade de medicamentos hipoglicemiantes podem sugerir infecção presente, em desenvolvimento, ou potencialmente severa.

O tempo de aparecimento e mecanismo causal da lesão são aspectos importantes, pois as lesões agudas tendem a ser superficiais, com flora patogênica sensível aos antibióticos de uso oral, e de caráter benigno. ${ }^{82,83}$

Ferimento agudo puntiforme profundo na planta do pé pode causar infecção devastadora, pois esta pode se estabelecer e se desenvolver em compartimentos profundos do pé.

Quando a infecção tem caráter crônico (osteomielite, úlcera crônica infectada) a história deve ser minuciosa, pois devido ao prolongado convívio do paciente com o quadro, mudanças podem não ser relatadas. Histórico de mudança no aspecto da lesão, do pé ou do membro são importantes para detecção de infecção em evolução. ${ }^{84}$

\section{Enfatizando aspectos relevantes da história:}

- Diabetes descontrolado sem causa aparente;

- $\quad$ Alteração no aspecto do pé (inchaço, vermelhidão, rubor);
- Mudança no aspecto de lesão prévia (aumento, secreção e odor fétido);

- História prévia de desbridamento, osteomielite, múltiplas visitas ao serviço médico, antibioticoterapia prolongada e tempo de duração da lesão sugerem comprometimento infeccioso crônico.

Sinais:

- Gerais: taquicardia, febre, desidratação e prostração são sinais associados à infecção sistêmica grave e podem estar ausentes em até $50 \%$ dos pacientes sob sério risco. ${ }^{84}$

- Locais: rubor, calor e abaulamento. Infecções superficiais (erisipelas e celulites) precisam ser analisadas quanto à extensão do processo inflamatório secundário, pois assumem maior gravidade e caráter sistêmico quando muito extensas.

As lesões devem ser classificadas e diferenciadas no exame clínico. Lesões com tecido de granulação de bom aspecto (vermelho), sem odor e sem secreção necessariamente devem ser analisadas de forma diferente das lesões com material necrótico, odor fétido, saída de secreção purulenta, associadas ou não à deficiência dos pulsos periféricos. FIGURAS 26 e 27 Deformações na morfologia do pé, o aumento de partes moles e a instrumentação da lesão são aspectos clínicos que precisam ser registrados. ${ }^{84}$

Notas:

1. Em decorrência das características anatômicas dos compartimentos do pé e da perna, além das características clínicas dos diabéticos (neuropatia e deficiência imunológica), infecções profundas e graves, a partir de lesões superficiais, podem se manifestar com apresentação tardia dos sinais clássicos. ${ }^{19,85,86}$ FIGURA 27

2. Úlceras profundas e maiores de $2,0 \mathrm{~cm}$ têm maior chance de provocar osteomielite. ${ }^{87}$

3. A inspeção da úlcera com haste metálica romba estéril ("probing") é extremamente útil, de fácil execução e com alta sensibilidade para o difícil diagnóstico de osteomielite. ${ }^{88} \mathrm{~A}$ exposição de segmento ósseo ou a eliminação de fragmentos ósseos pela ferida infectada são diagnósticos de osteomielite. FIGURA 28

4. O diagnóstico precoce e o tratamento rápido e agressivo evitam perda do membro e reduzem tempo e custo da internação. ${ }^{89}$

5. As principais portas de entrada das infecções agudas são através de micoses interdigitais, pequenas lesões por sapatos inadequados, traumas banais e úlceras crônicas. Os traumas por sapatos apertados podem 


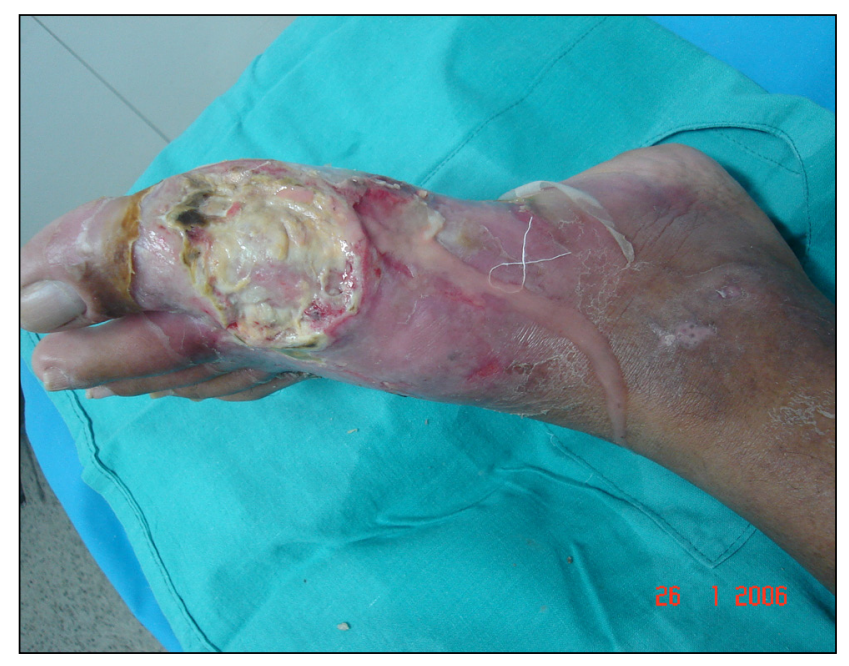

Figura 26 - Infecção grave em pé diabético, sem isquemia troncular.

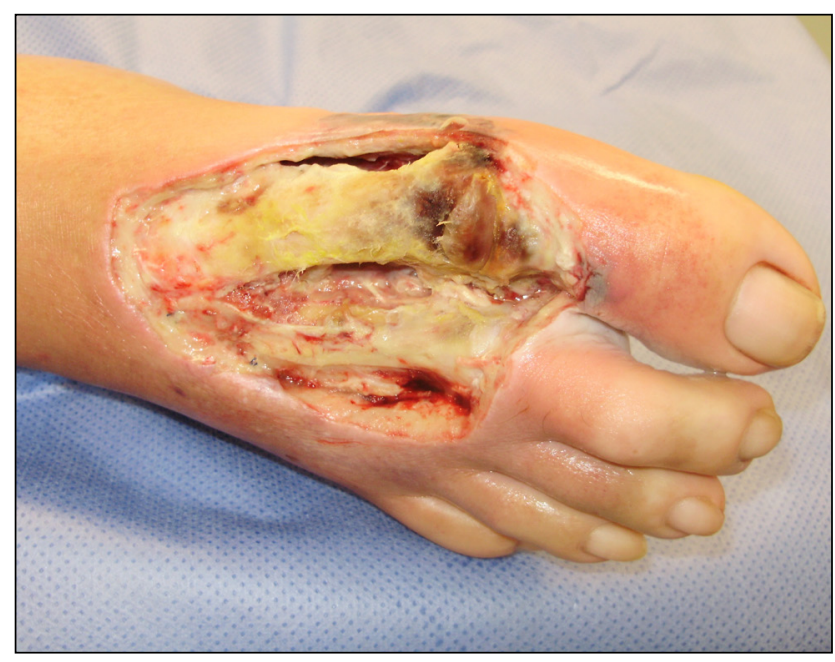

Figura 27.1 - Infecção grave do paciente da Figura 27. Observar, após o debridamento inicial, a palidez da musculatura e a necrose de tecidos profundos.

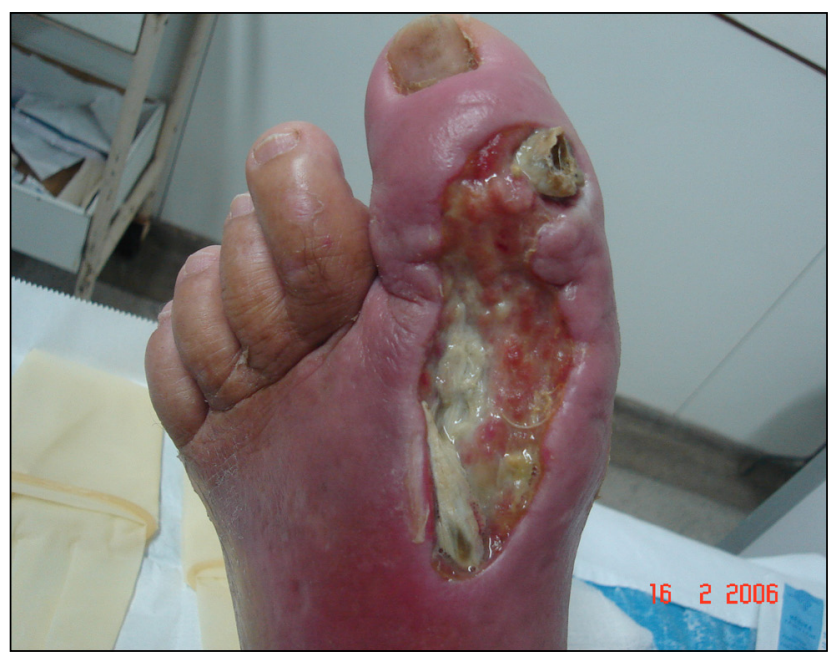

Figura 28 - Lesão com osteomielite de longa duração. Observar a eliminação de framentos ósseos pela lesão.

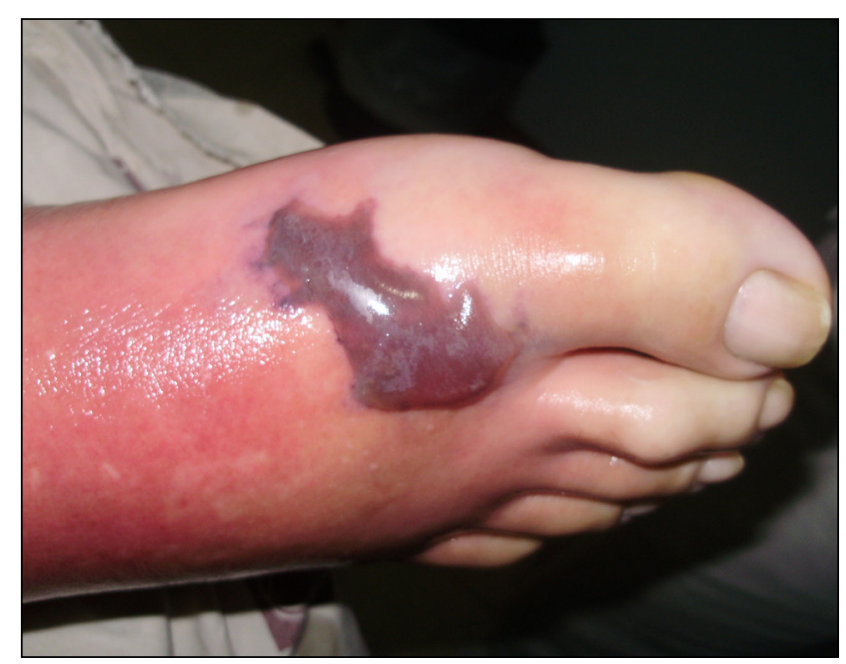

Figura 27 - Infecção grave em paciente com oclusão arterial troncular proximal. A infecção se iniciou após picada de inseto e evoluiu de forma oligosintomática por 2 semanas até o diagnóstico.

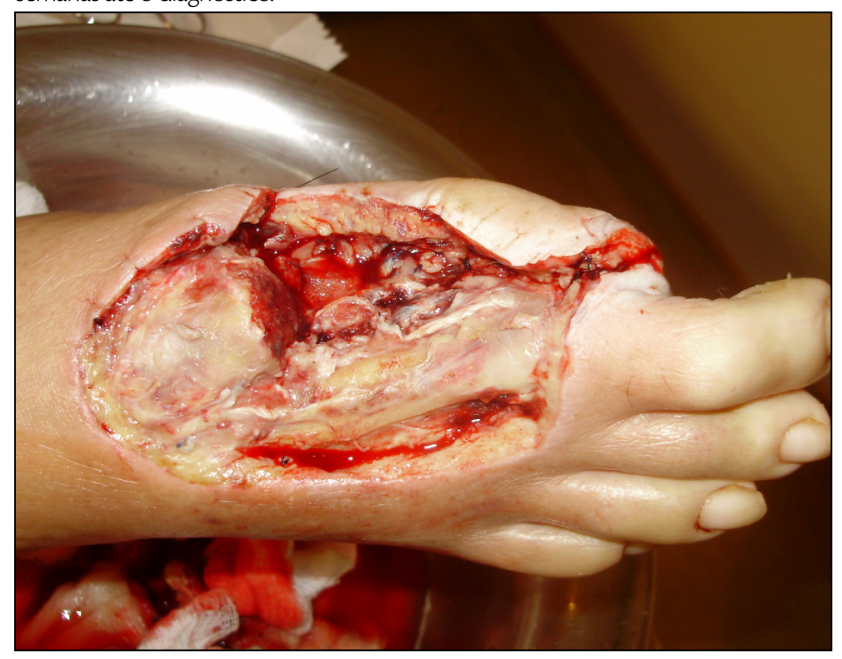

Figura 27.2 - Infecção grave do paciente da Figura 27. Situação após o debridamento mais agressivo com ressecção parcial do $1^{\circ}$ metatarso.

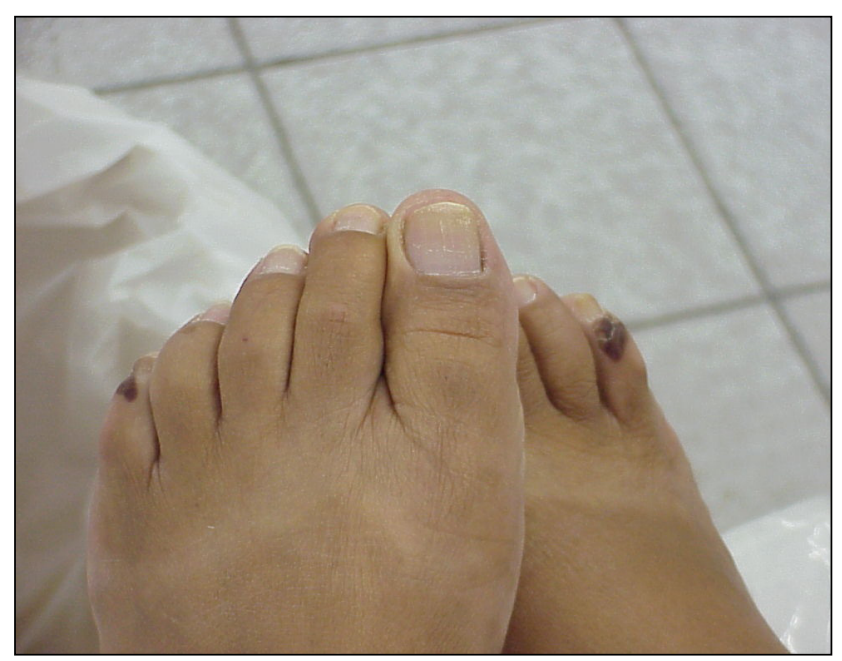

Figura 29 - Lesões com hematomas e necroses superficiais por uso prolongado de sapatos apertados. 


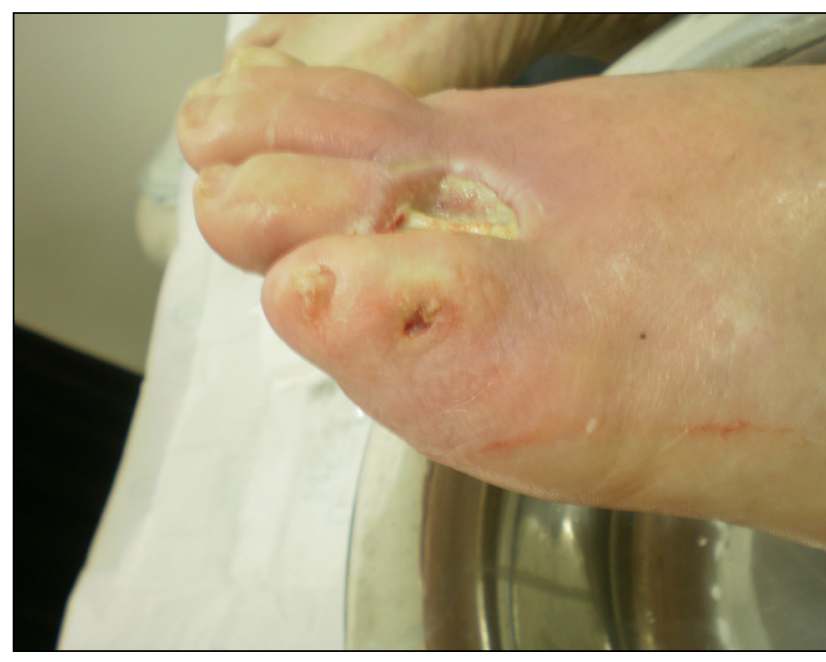

Figura 30 - Infecção grave no $5^{\circ}$ pododáctilo a partir de hiperceratose causada por calçado apertado.

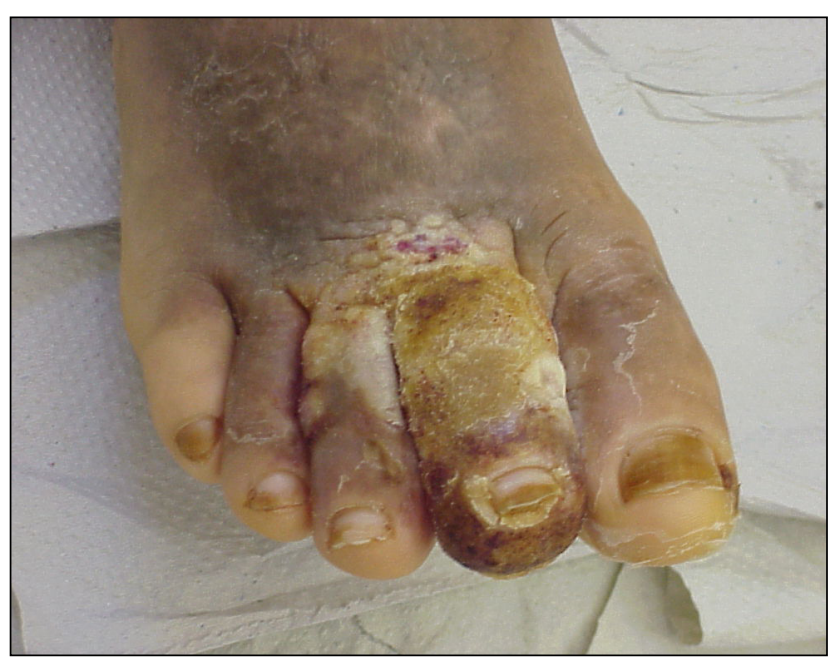

Figura 31 - Infecção crônica no $2^{\circ}$ pododáctilo. Observar as alterações cutâneas e o aumento característico de volume do dedo.

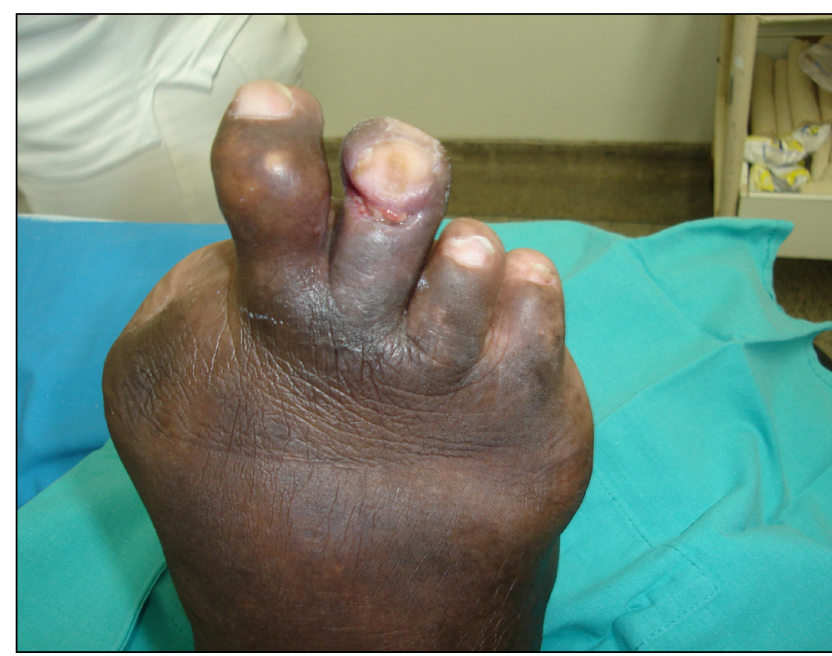

Figura 32 - Infeccão crônica ao nivel do ante-pé com desarticulação prévia do hálux abscesso dorsal e aumento do volume do $2^{\circ}$ pododáctilo.

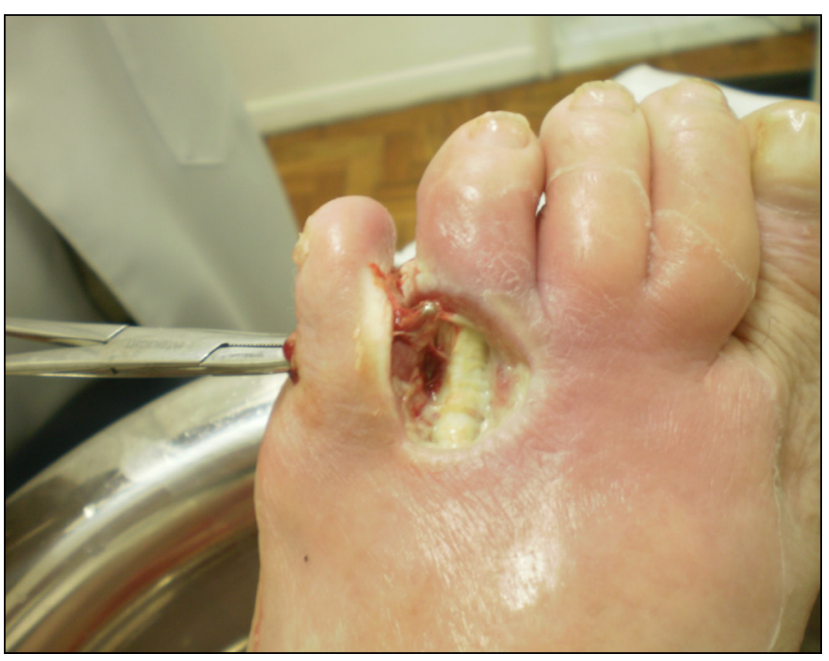

Figura 30.1 - Infecção grave da Figura 29. Observar a pinça passando pela articulação interfalangeana com osteomielite e os abscessos nas regiões interdigital e dorsal.

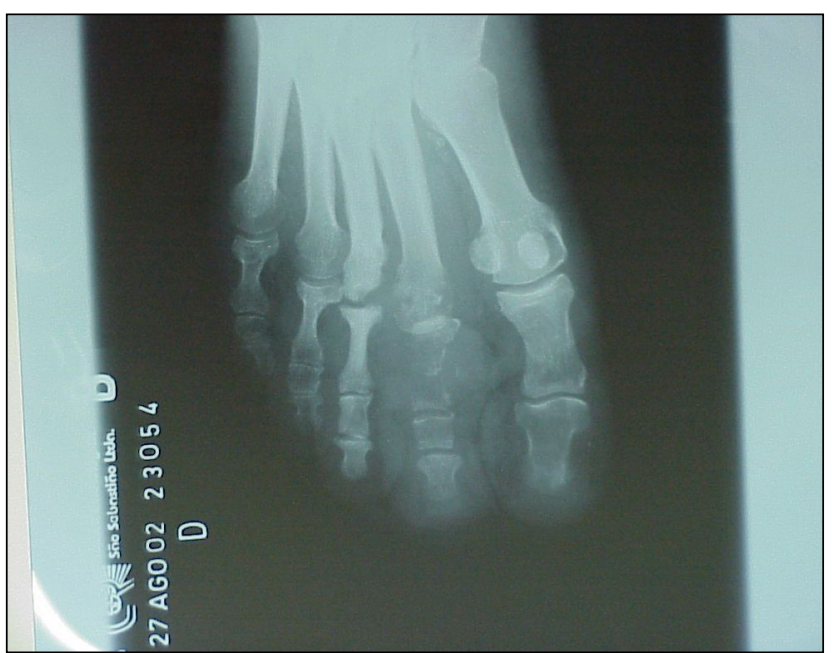

Figura 31.1 - Radiografia do paciente da Figura 31. Osteomielite da cabeça do $2^{\circ}$ metatarso da falange proximal do $2^{\circ}$ pododáctilo com sequestro ósseo, lesões osteolíticas e destruição da cortical.

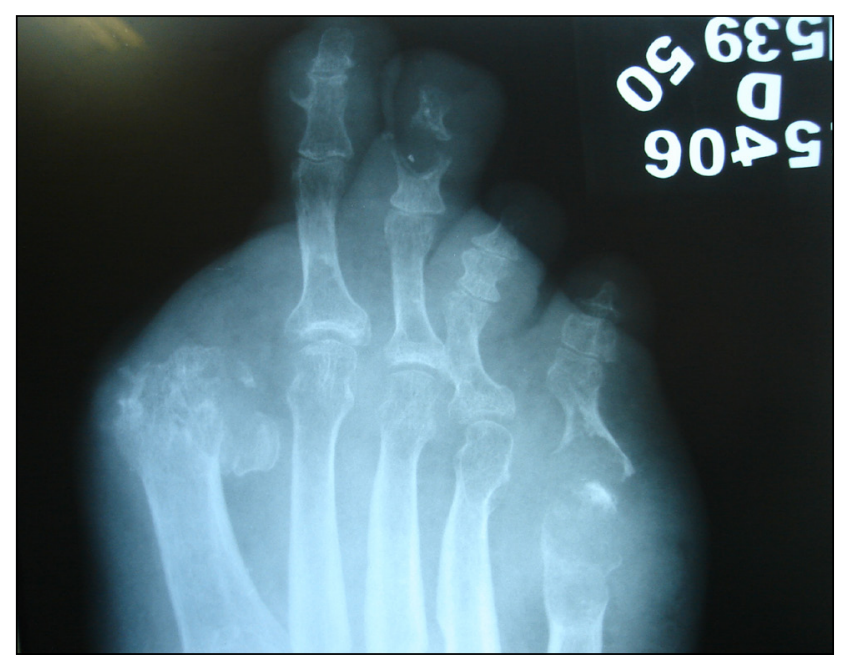

Figura 32.1 - Radiografia simples do pé da figura 32 mostrando osteomielite com destruição cortical e fragmentação da cabeça do $1^{\circ}$ e do $5^{\circ}$ metatarsos e lesões osteolíticas no $3^{\circ}$ e $5^{\circ}$ pododáctilos. 
gerar dede simples hematomas e necroses superficiais FIGURA 29 até abscessos e lesões infecciosas osteo-articulares graves. FIGURA 30

6. Devido à freqüente associação com neuropatia e infecção, as queixas e os achados físicos podem não ser típicos, portanto a variabilidade na forma de apresentação clínica deve ser destacada. ${ }^{19,46}$

Quadro 6 - aspectos importantes da história e exame clinico

1- Valorização das queixas relativas ao pé;

2- Questionamento ativo de problemas na extremidade;

3- Valorização da referência a mudanças no aspecto do pé ou de lesões antigas;

4- Exame sistêmico e local independente da queixa;

5- Palpação de pulsos;

6- Inspeção de lesão plantar crônica com instrumento estéril para detecção

de exposição óssea e diagnóstico de osteomielite.

\section{Diagnóstico}

\section{Exames hematológicos}

A leucocitose e os níveis de glicemia elevados em paciente previamente bem controlado sugerem infecção. Exames gerais voltados ao estado nutricional-imunológico e função renal são importantes para orientar a antibioticoterapia. ${ }^{87}$

\section{Radiografia simples do pé}

A radiografia simples detecta infecção de partes moles, quando existe produção de gás, e osteomielite, ressaltando que na infecção aguda pode não existir imagem sugestiva de osteomielite. Tem papel importante na diferenciação de osteomielite (lesão osteolítica, seqüestros ósseos, reação periosteal ou destruição da cortical e aumento de partes moles) e osteoartropatia (diminuição dos espaços articulares, irregularidade nas articulações, desalinhamento ósseo, esclerose e cistos subcondrais). ${ }^{90}$ Quando estes aspectos ósseos estão associados à lesão trófica e ao contato do osso através da instrumentação ("probing"), a possibilidade de osteomielite aumenta muito. ${ }^{9,87}$ Figuras 31 e 32 Deve ser o primeiro exame a ser solicitado quando as características clínicas levarem à suspeita de osteomielite.

\section{Ressonância magnética}

A ressonância magnética é hoje um importante instrumento para detecção de imagem de infecção profunda na fase inicial (pequenas coleções sem alteração do sinal ósseo) e para o diagnóstico de osteomielite (medula óssea com hipossinal em T1, hiper-sinal em T2, realce com contraste: áreas hipodensas de permeio na medula correspondem a pequenas coleções). Na ressonância as alterações secundárias à artropatia estão presentes nas regiões periarticulares e em geral poupam a medula ao longo do osso. ${ }^{88,90,91}$

\section{Cintilografia óssea}

As modalidades de cintilografia óssea (com gálio, tecnesium) tem baixa especificidade devido à captação prejudicada quando existe artropatia. Cintilografia com leucócitos marcados com índio-111 pode diferenciar osteomielite de artropatia. Estes exames são trabalhosos, caros e demorados, razão de sua utilização limitada. ${ }^{88,92}$ Seu papel secundário e limitado é devido ao custo do exame e disponibilidade restrita. São utililizados nos casos de dúvida quanto à presença de osteomielite.

Nota:

Testes de diagnóstico para detecção de osteomielite são dispendiosos e não demonstraram vantagem na evolução dos pacientes quando comparados àqueles tratados empiricamente. Portanto, na dúvida, o paciente deve ser tratado. ${ }^{88}$

\section{Culturas}

Tem valor quando o tecido profundo, ou de curetagem da base da lesão, é encaminhado para exame sem a contaminação superficial por bactérias que não são, obrigatoriamente, as mesmas causadoras da infecção profunda. ${ }^{21}$ Os exames de cultura de tecido e osso removido devem ser estimulados sob dois aspectos: primeiro para a adequação da antibioticoterapia (substituição do uso empírico pelo antibiótico específico), poupando recursos, e para evitar a seleção de germes e resistência bacteriana. Segundo, pela possibilidade de se estabelecer um perfil de germes mais frequentes naquela comunidade, orientando a antibioticoterapia empírica quando necessária. ${ }^{19}$

O método diagnóstico definitivo de osteomielite é feito através da cultura de exame histológico do osso. As evidências sugerem que na maioria das infecções ósseas o germe infectante das partes moles também é responsável pela infecção do osso, desde que a cultura seja feita de material profundo infectado e não contaminado por tecido superficial. ${ }^{88,93-95}$

Forma da Coleta: A coleta do material para cultura deve ser de tecido profundo. Como alternativa a coleta do material após limpeza da úlcera com soro fisiológico e curetagem da borda profunda é melhor que a coleta superficial. ${ }^{83}$ Em especial no isolamento de bactérias anaeróbias a positividade depende da forma de coleta, transporte e sofisticação laboratorial. Trabalhando com os melhores recursos e com a coleta de material profundo e transporte ágil e adequado isolam-se anaeróbios em até 75\% a 90\% dos pacientes. $^{96}$ 


\section{Tratamento}

Evitar o uso de antibióticos nos casos de lesões não infectadas. Manter a higiene local com curativos e remover a carga, ou seja, evitar o atrito constante sobre a lesão. Antibiótico tópico não tem lugar no tratamento do pé diabético.

Tratamento empírico: as infecções no pé do paciente diabético podem ser classificadas segundo a gravidade, profundidade e tempo de evolução. Além disso, a presença de material necrótico e a forma de coleta de material para cultura podem influenciar a terapia. A maioria das informações necessárias são obtidas clinicamente e ajudam a orientar a terapêutica empírica. ${ }^{83}$

\section{Severidade da Infecção ${ }^{83}$ :}

- infecções leves têm o predomínio dos cocos Gram-positivos, como, Staphylococcus aureus, Streptococcus $\beta$ - hemolítico do grupo B, A, C, G de Lancefield;

- infecções de moderada gravidade (ameaçam a extremidade) tendem apresentar mais de um germe infectante, como cocos Gram-positivos e bacilos Gram-negativos (Proteus mirabilis, Eschirichia coli, Klebsiella pneumoniae, Pseudomonas aeruginosa,...);

- infecções severas (ameaçam a vida) são polimicrobianas (cocos Gram-negativos e positivos, anaeróbios e aeróbios) ou apresentam germes resistentes a diversos antibióticos (Staphilococcus meticilina-resistente, Pseudomonas, Enterococcus).

2. Profundidade e Extensão da Lesão: úlceras superficiais com celulite localizada são comumente causadas por $S$. aureus e $S$. pyogenes. Caracteristicamente são monomicrobianas. Úlceras com comprometimento de tecido profundo, incluindo músculo e osso, tendem a apresentar flora mista, com participação de aeróbios e possivelmente anaeróbios, além de uma grande colonização superficial por outras bactérias.

A maioria das infecções, em pacientes ambulatoriais, são leves e/ou superficiais e os germes mais prevalentes são os cocos gram positivos aeróbicos.

3. Tempo de Evolução: lesões agudas, não manipuladas e sem utilização prévia de antibióticos tendem a ser monomicrobianas, com o $S$. aureus sendo o agente mais comum. Lesões crônicas em pacientes que freqüentam ambulatórios e/ou já internados recentemente e/ ou que já foram submetidos ou estão na vigência do uso de antibióticos, tendem a apresentar infecção polimicrobiana, frequentemente por germes incomuns (Serratia, Morganella, Proteus vulgaris, Haemophilus, Acinetobacter, Enterococcus).

4. Presença de Tecido Necrótico: (gangrena) aumenta a possibilidade da presença de bactérias anaeróbicas tais como: Peptostreptococcus, Bacteróides, Clostridium. ${ }^{93}$ Este aspecto aumenta a importância da palpação dos pulsos, pois, muitas vezes, é quando a arteriopatia se associa com a infecção. ${ }^{46}$

\section{Antibioticoterapia Empírica}

Alguns esquemas empíricos sugeridos para infecção nos pés de diabéticos estão listados abaixo e dependem da severidade da infecção. ${ }^{82,83,97}$

1. infecção leve/moderada (geralmente uso VO)

\begin{tabular}{|ll|}
\hline antibioticoterapia sugerida & antibioticoterapia alternativa \\
\hline cefalosporina de $1^{\text {a }}$ geração & fluorquininolona \\
amoxaciclina/acido clavulônico & sulfametoxazol/ trimetropim \\
clindamicina & linezolida \\
doxiciclina & \\
\hline
\end{tabular}

2. infecção moderada/severa (risco de perda da extremidade- geralmente de uso parenteral)

\begin{tabular}{|ll|}
\hline antibioticoterapia sugerida & antibioticoterapia alternativa \\
\hline ciprofoxacino + clindamicina & ceftazidima + clindamicina \\
ampicilina/sulbactan & linezolid \\
ticarcilina/clavulonato & imipenem/cilastatina \\
pipraciclina/tazobactam & \\
ertapenem & \\
\hline
\end{tabular}

3. infecção severa (risco de óbito - uso intravenoso)

\begin{tabular}{|ll|}
\hline antibioticoterapia sugerida & antibioticoterapia alternativa \\
\hline ampicilina/sulbactan + aztreonam & \\
piperaciclina/tazobactam & fluorquinolona + vancomicina + \\
+ vancomicina & metronidazol \\
imipenen/cilastatina & vancomicina + aztreonam + \\
& metronidazol \\
clindamicina + tobramicina + & \\
ampicilina & \\
ertapenem & \\
\hline
\end{tabular}

Nota:

A necessidade de hospitalização dos pacientes, quando não há isquemia do membro, pode ser diminuída com o uso de antibioticoterapia, oral ou parenteral (aplicada em ambulatórios secundários especializados no atendimento ao pé diabético), em regime ambulatorial. A cirurgia ambulatorial nesses pacientes é muito facilitada pela presença da neuropatia sensitiva que diminui muito, ou mesmo abole, a necessidade de anestesia local, ou loco-regional. Figura 33

Nos atendimentos realizados pelo sistema único de saúde é necessário, visando o tratamento correto e completo, que os antibióticos previstos pelos protocolos locais, tanto em nível primário como secundário, sejam dispensados pelas unidades de saúde em virtude dos seus custos inalcançáveis por pacientes de baixa renda. 


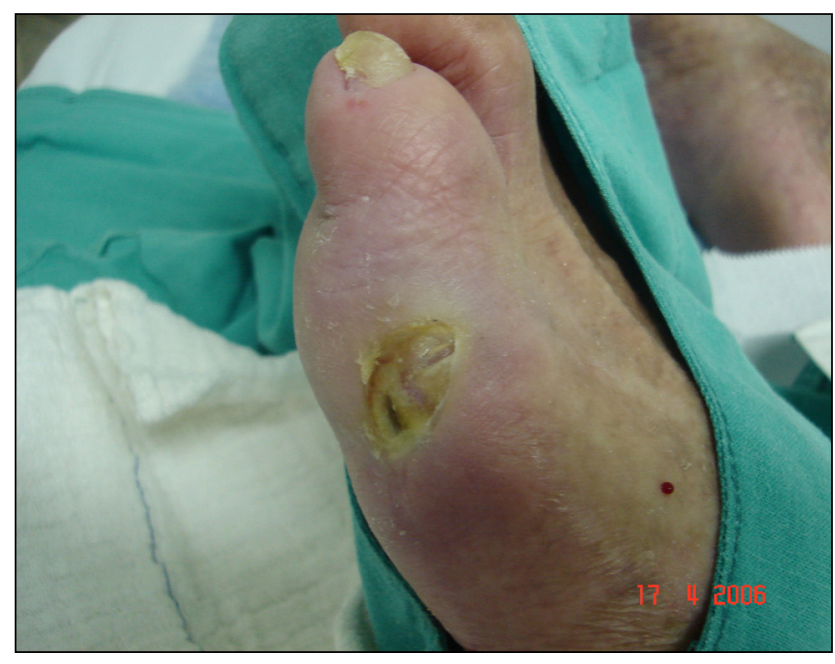

Figura 33 - Lesão crônica infectada a partir de trauma por calçado inadequado.

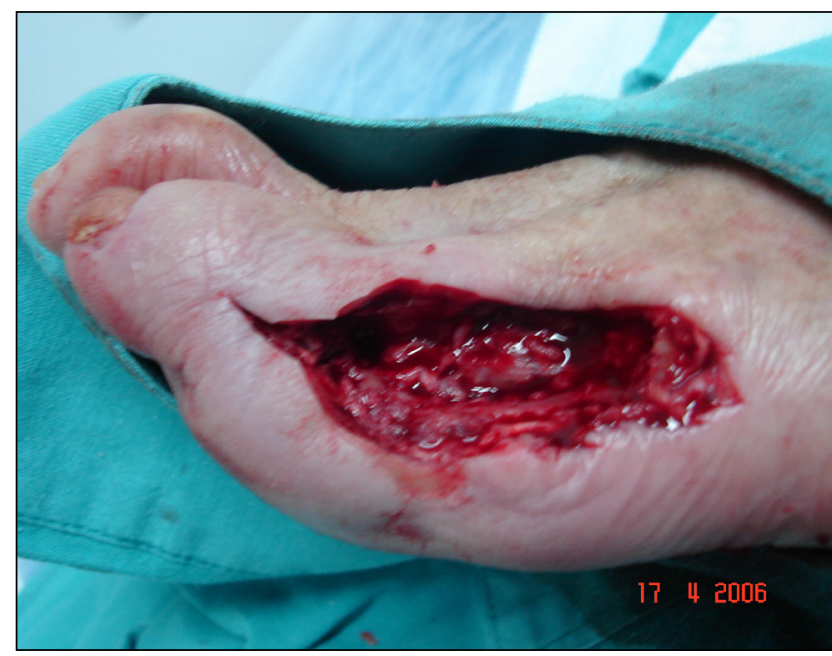

Figura 33.2 - Lesão crônica infectada da figura 33. Cirurgia com ressecção parcial dos ossos infectados. Em regime ambulatorial e sem necessidade do uso de anestesia.

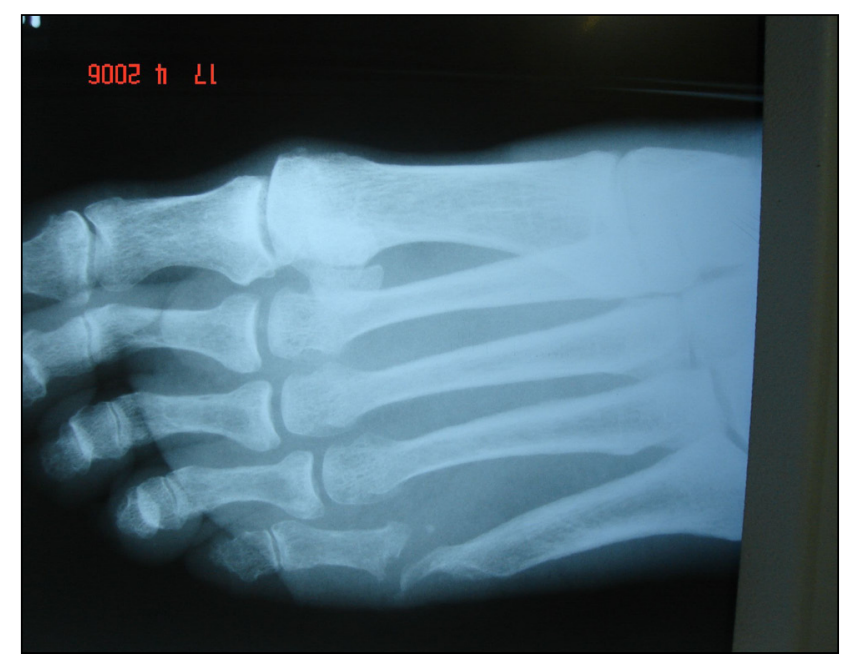

Figura 33.1 - Radiografia simples do paciente da Figura 33. Osteomielite da cabeça do $5^{\circ}$ metatarso e da falange proximal do $5^{\circ}$ pododáctilo.

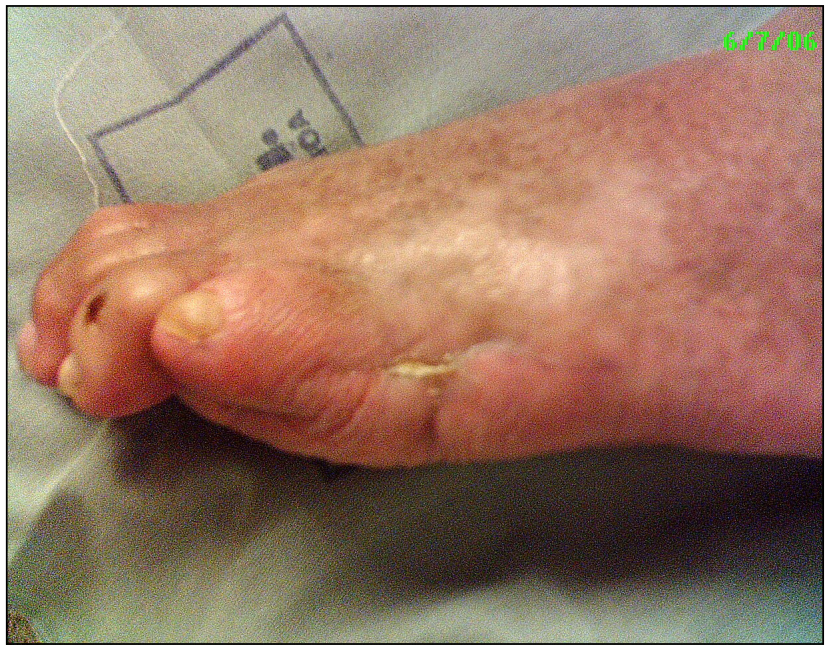

Figura 33.3 - Lesão crônica infectada da figura 33. Após 79 dias da cirurgia.

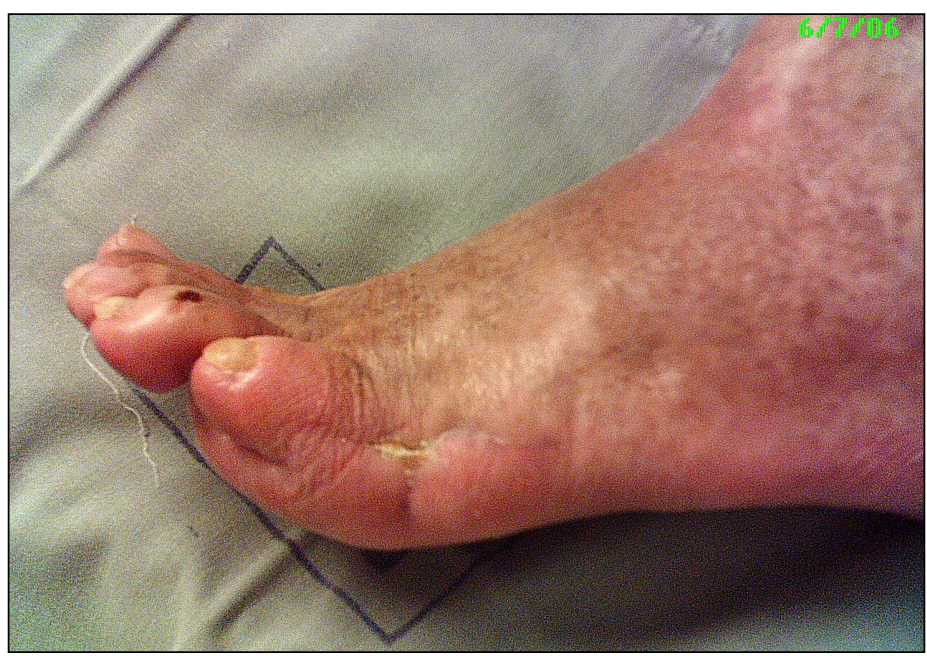

Figura 33.4 - 79 dias após a cirurgia. Observar a mobilidade do $5^{\circ}$ pododáctilo. 


\section{Osteomielite:}

Nos pacientes com suspeita ou na confirmação de osteomielite, a duração do tratamento depende, fundamentalmente, da possibilidade do osso doente ser completamente removido ou não. Nos casos em que isso é possível o tratamento pode ser curto (duas semanas) se a lesão associada está evoluindo bem. $\mathrm{Na}$ impossibilidade da remoção de todo o osso infectado, ou quando esta remoção causa danos graves à biomecânica do pé, o tratamento deve durar pelo menos seis semanas. Existem relatos de tratamento de infecção, não associada à necrose, apenas com a terapia clínica (sem procedimento cirúrgico). Nestes pacientes o tempo mínimo de tratamento é de três meses, com cura da infecção em até $60 \%$ dos indivíduos, em casos selecionados. ${ }^{83}$ O Staphylococcus aureus é o agente patogênico mais frequente e a não concordância importante entre os germes encontrados na lesão e a infecção óssea é devida à contaminação. ${ }^{88,93,98}$

Notas:

1. É fundamental o conhecimento de diversos esquemas de tratamento com antibióticos devido à natureza variável do agente etiológico e da condição clínica do paciente. (Ex. infecção por pseudomonas resistente em paciente com insuficiência renal).

2. Após o conhecimento do resultado da cultura, o esquema antimicrobiano deve ser adequado, baseando-se na resposta clínica, eficiência microbiológica e custo-efetividade. ${ }^{21}$

3. Iniciar empiricamente a antibioticoterapia até identificação do(s) germe(s) de acordo com a frequência bacteriana conhecida no serviço ambulatorial ou no hospital. ${ }^{21}$

4. $\mathrm{Na}$ maioria das publicações encontram-se, pareceres favoráveis à utilização de Oxigenioterapia Hiperbárica em pacientes selecionados, sem retardo da cirurgia de revascularização e com a remoção de todo tecido inviável já realizada. É uma medida coadjuvante para alguns pacientes, desde que precedida de análise criteriosa para seu uso. ${ }^{99}$

5. A utilização de dispositivo a vácuo para controle de infecção e melhora da cicatrização tem se mostrado uma boa alternativa para alguns pacientes (geralmente internados, com longo curso de antibióticos e lesão extensa de difícil cicatrização) nos quais a terapia convencional instituída não mostrou evolução adequada. ${ }^{100}$

Prevenção primária e secundária e tratamento da ulceração como formas de prevenção da amputação (recomendações finais).

\section{Profilaxia da neuropatia e da angiopatia $a^{9,101,102}$}

- Controle rigoroso da glicemia;

- Proibição do tabagismo e etilismo;

- Controle da hipertensão arterial, dislipidemia e vasculopatia.

\section{Profilaxia das complicações da neuropatia nas extremidades inferiores}

É primordial a identificação do paciente de risco para ulceração (perda da sensibilidade, deformidade e história de úlcera prévia) e de risco para amputação (pé de Charcot, infecção e insuficiência vascular) além da estratificação do paciente nas categorias de risco e elaboração de estratégias para atendimento racional. ${ }^{7}$ A metodologia adotada pelo Projeto de Atenção Integral ao Paciente com Pé Diabético ${ }^{5}$, pode ser utilizada para facilitar essa classificação e o acompanhamento, principalmente no Sistema Público de Saúde (Apêndice 2).

\section{Abordagem multidisciplinar}

- A educação do paciente, família e agentes de saúde é fundamental. ${ }^{7}$ Cuidados gerais com os pés, corte adequado e cuidados com as unhas, cuidados para evitar micoses, uso de calçados adequados, higiene diária com o cuidado especial ao secar a umidade entre os dedos, inspeção diária dos pés e dos sapatos, proibição do uso de calicidas e raspadores ou lâminas nos calos pelos pacientes são medidas igualmente importantes. ${ }^{1} \mathrm{O}$ emprego de Equipes Multidisciplinares é essencial para o cuidado integral a esses pacientes e familiares. ${ }^{7,8}$ Devem ser usados cartazes educativos e folhetos para orientação dos pacientes e familiares (modelo no Apêndice 3).

- Todos os diabéticos devem ter seus pés examinados em todas as consultas de saúde. O exame sistemático deve obedecer a um protocolo clínico ${ }^{7,8}$, e pode ser usado o decálogo utilizado pelo Projeto de Atenção Integral ao Paciente com Pé Diabético (Apêndice 1).

- Paciente que não adere ao tratamento tem probabilidade 50 vezes maior de ulcerar o pé e 20 vezes maior de ser amputado do que aqueles que seguem corretamente as orientações. ${ }^{7}$

\section{Tratamento das conseqüências da neuropatia para os pés - prevenção e tratamento da ulceração $e$ prevenção da amputação}

- Déficit de sensibilidade: educação, cuidados com os pés e sapatos comuns com bico largo e caixa alta (caixa de dedos). ${ }^{20}$ 


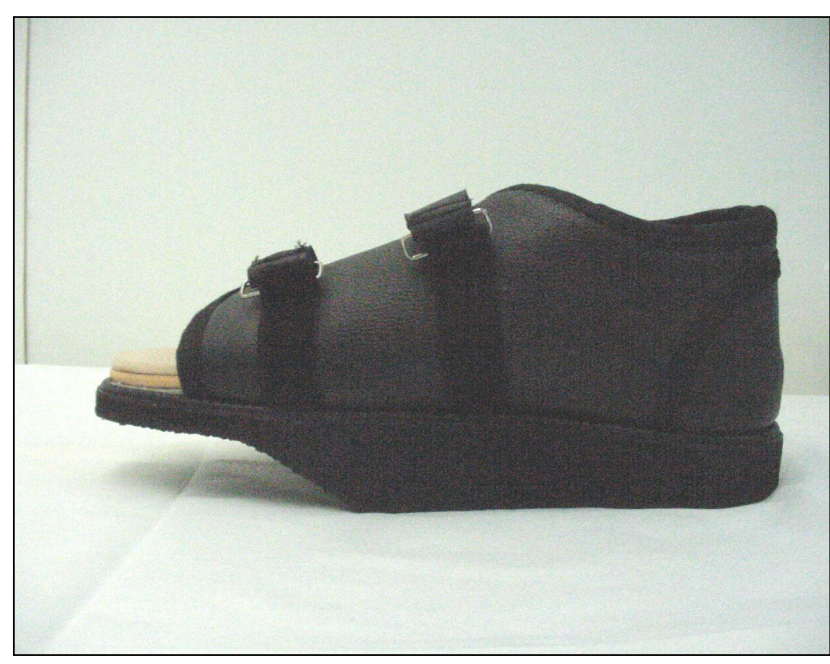

Figura 34 - Sandália de curativo com alívio da pressão no ante-pé.

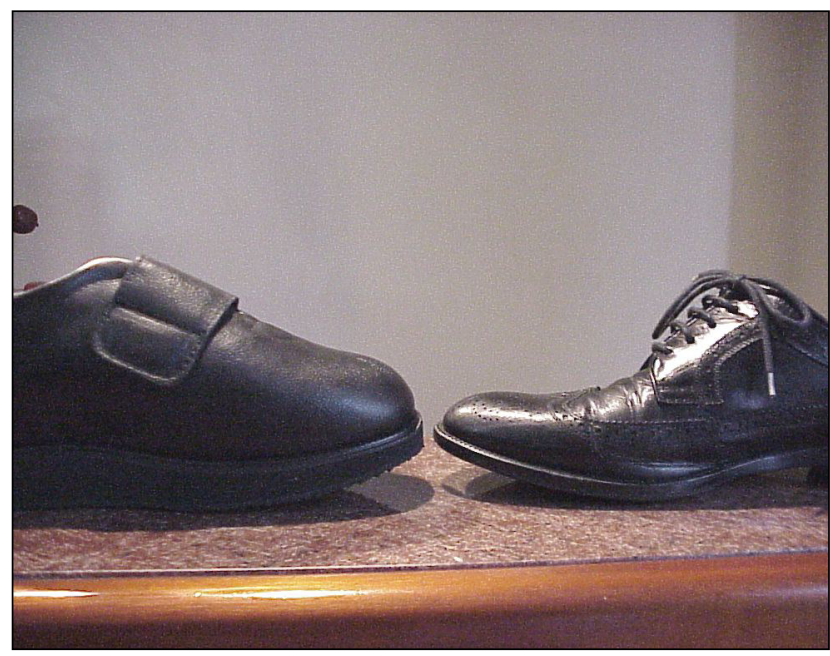

Figura 36 - Órtese para pé diabético à esquerda. Observar a diferença da altura na "caixa de dedos" do sapato normal.

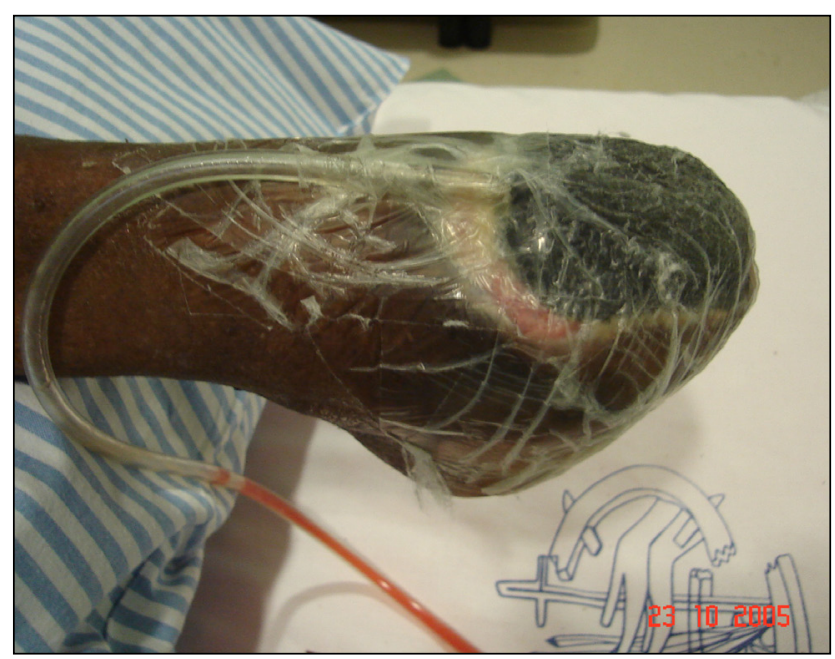

Figura 38 - Curativo a vácuo em pé diabético.

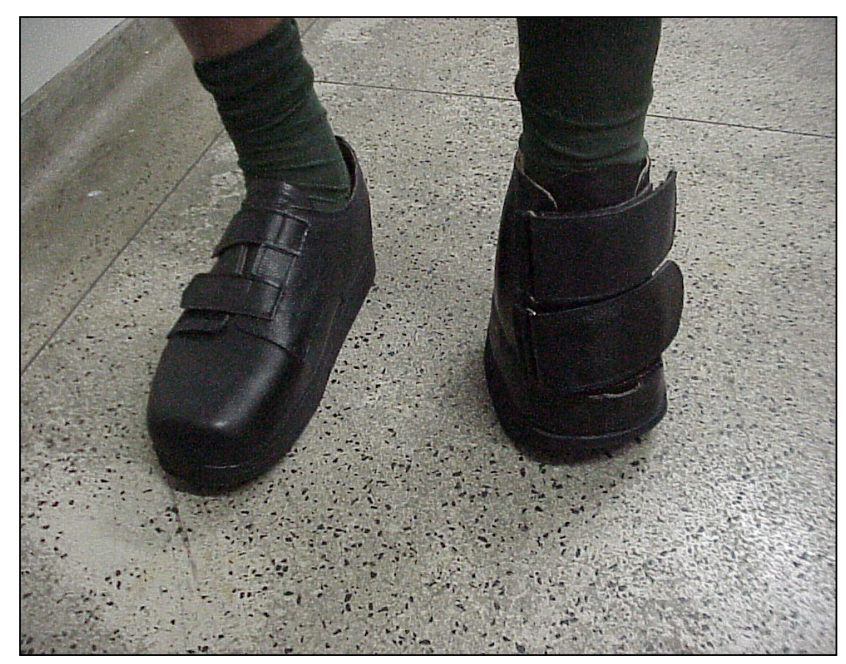

Figura 35 - Órteses confeccionadas sob medida.

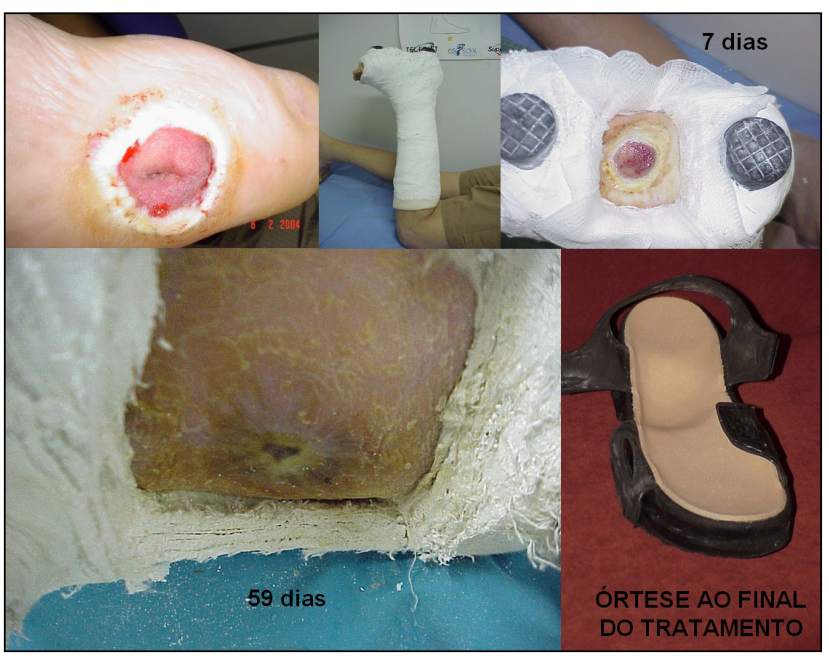

Figura 37 - Uso do gesso de contato total em mal perfurante plantar com 7 anos de evolução. Observar a rapidez da cicatrização após a retirada da pressão sobre a ferida.

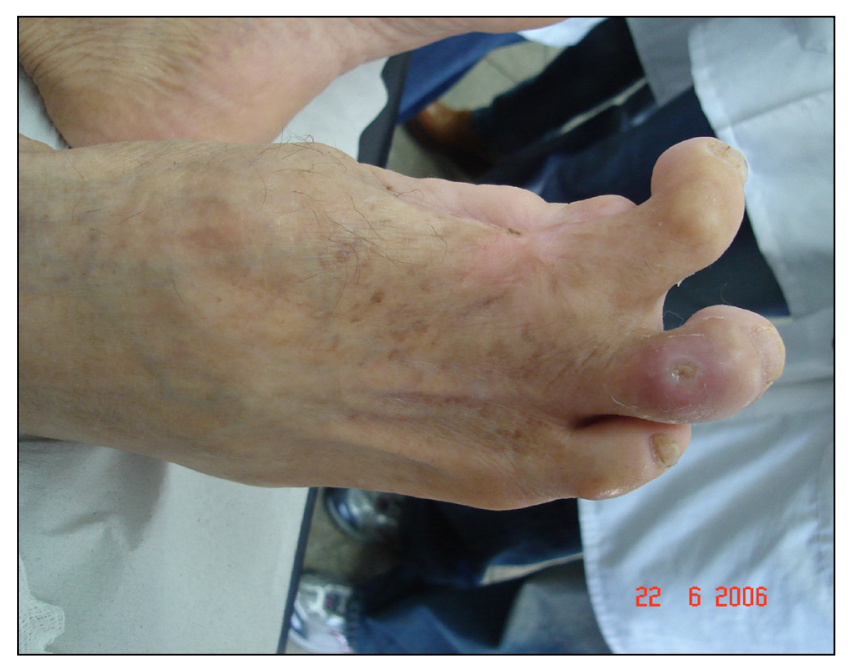

Figura 39 - Deformidades pós cirúrgica gerando novos pontos de pressão - observe a lesão no dorso do $4^{\circ}$ pododáctilo. 
- Pé ressecado: uso de cremes hidratantes diariamente (evitar o uso entre os dedos). ${ }^{20}$

- Calosidades iniciais e pequenas deformidades: uso de sapatos comerciais comuns com bico largo, de caixa alta (caixa de dedos), palmilhas e remoção gradativa das calosidades com lixas. ${ }^{20}$

- Calosidades maiores, dolorosas ou não, e com ou sem hematomas: remoção cirúrgica (para diminuir a pressão sob a calosidade) e prescrição de palmilhas e órteses adequadas. ${ }^{20,103-109}$

- Grandes deformidades causadas pela neuropatia motora, por úlceras cicatrizadas ou após amputações parciais: uso de órteses confeccionadas sob medida com alívio da pressão. ${ }^{17}$

- As cirurgias ortopédicas reconstrutivas e corretivas das alterações biomecânicas devem ser consideradas em casos selecionados e em pacientes não isquêmicos. Os procedimentos cirúrgicos mais comuns envolvem alongamento do Tendão de Aquiles, exostectomia, osteotomia, artrodese e/ou artroplastia interfalangiana $\mathrm{e}$ metatarsofalangiana. ${ }^{?}$

- Úlceras:

- Controle metabólico e nutricional adequado. ${ }^{17}$

- Curativos diários, a não ser quando em uso de coberturas específicas. ${ }^{17}$

- O uso de coberturas especiais apropriadas para as diversas fases de evolução da ferida pode acelerar sua cicatrização. ${ }^{17}$

- Repouso

- Técnicas de alívio da Pressão. ${ }^{103-115}$

- Sandálias de alívio Figura 34

- Órteses sob medida e palmilhas adequadas Figuras 35 e 36

- Gesso de contato total - tratamento padrão ouro Figura 37

- Cirurgias ortopédicas de alívio da pressão.

- Material necrótico e/ou osteomielite associados: debridamento cirúrgico. ${ }^{116}$

- Curativos com pressão negativa, a vácuo, podem oferecer benefício no tratamento das lesões em diabéticos. ${ }^{117}$ Figura 38

- Neuroartropatia de Charcot:

- Charcot agudo: repouso absoluto e imobilização da extremidade no mínimo até a normalização da temperatura cutânea, do VHS e PCR. ${ }^{39}$

- Charcot crônico e outras alterações morfológicas mais graves ou recidivantes: órteses sob medida, próteses e cirurgias ortopédicas corretivas/ reconstrutivas. ${ }^{39,116,118}$
Notas:

1. As úlceras representam um marco na evolução dos pacientes diabéticos. A probabilidade de amputação na presença da úlcera se multiplica. O tempo médio necessário para o fechamento de $30 \%$ das úlceras chega a 20 semanas, com tratamento bem feito e estrita cooperação do paciente e familiares. ${ }^{1}$

2. Curativos tradicionais com uso apenas de soro fisiológico, desbridantes e gaze estéril, precedidos da degermação peri-úlcera são efetivos no tratamento da úlcera diabética, desde que acompanhados do necessário alívio da pressão. Coberturas especiais devem ser avaliadas em situações especificas e sempre com a análise do custo/beneficio.

3. Re-ulceração após tratamento cirúrgico pode ocorrer em até $30 \%$ dos operados. ${ }^{16,119}$ Figura 39

4. A possibilidade de infecção aguda grave e osteomielite a partir da úlcera é sempre presente, de forma que a sua profilaxia deve ser o principal pontos de atuação dos agentes de saúde. ${ }^{120}$

5. Caso a amputação da extremidade ocorra, é importante providenciar a precoce e adequada protetização do membro, além de multiplicar os esforços preventivos para evitar as ulcerações e amputação contra-lateral. ${ }^{1}$

6. A prevenção dos eventos cardiovasculares, renais e retinianos deve fazer parte da abordagem destes pacientes. ${ }^{1}$

O cuidado com os pés de diabéticos, particularmente daqueles com alterações vasculares e/ou neuropáticas, efetuados por profissionais não habilitados ou não treinados, não pertencentes à área da saúde e sem supervisão adequada por uma equipe de saúde, é totalmente desaconselhável e constitui exercício ilegal da medicina, expondo os diabéticos a grave risco de infecção e/ou amputação.

\section{Conclusão}

O pé diabético é uma entidade com fisiopatologia complexa e de prevalência elevada, dependendo para sua prevenção e controle de ações de saúde paradoxalmente simples e que dependem, fundamentalmente, de educação e interações multidisciplinares. $\mathrm{O}$ estabelecimento de programas e projetos que enfrentem a dificuldade de acesso em todos os níveis de atenção, que privilegiem a educação dos profissionais de saúde e dos pacientes e seus familiares, e que organizem um fluxo diferenciado na hierarquia dos sistemas de saúde poderá trazer, finalmente, uma redução das internações e amputações de diabéticos com complicações nos membros inferiores.

\section{Referências Bibliográficas}

1. Faber DC, Faber JS. Office-based screening, prevention, and management of diabetic foot disorders. Prim Care 2007 Dec;34(4):873-85. 
2. Sociedade Brasileira de Diabetes. Diagnóstico precoce do Pé Diabético. SBD; 2007 - pg 116-119.

3. Ragnarson T, Apelqvist J, - Health-economic consequences of diabetic foot lesions. Clin Infect Dis 2004;39 Suppl 2: S132-S9.

4. Campbell LV, Graham AR, Kidd RM, Molloy HF, O'Rourke SR, Colagiuri S. The lower limb in people with diabetes: Position statement of the Australian Diabetes Society. EMJA 2000; 173: 369-72.

5. Caiafa JS, Canongia PM. Atenção integral ao paciente com pé diabético: um modelo descentralizado de atuação no Rio de Janeiro. J Vasc Br 2003; 2(1):75-8.

6. Vinik Al, Maser RE, Mitchell BD, Freeman R. Diabetic autonomic neuropathy. Diabetes Care 2003 May;26(5):1553-79.

7. Armstrong DG, Harkless LB. Outcomes of preventive care in a diabetic foot specialty clinic. J Foot Ankle Surg 1998; 37:460-6.

8. Van Gils CC, Wheeler LA, Melltrom M, Brinton EA, Mason S and Wheeler CG. Amputation prevention by vascular surgery and podiatry collaboration in high-risk diabetic and nondiabetic patients. The Operation Desert Foot experience. Diabetes Care 1999;22(5):678-83.

9. Sociedade Brasileira de Diabetes. Consenso Sobre DiabetesDiagnóstico e Classificação dos Diabetes Mellitus Tipo II-2001.

10. de Heus-van Putten MA, Schaper NC, Bakker K. The clinical examination of the diabetic foot in daily practise. Diabetic Med 1996;13:S55-7.

11. Scottish Intercollegiate Guidelines Network. Implementation of the St Vincent Declaration-The Care of Diabetic Patients in Scotland. Management of Diabetic Foot Disease-1997.

12. Kozak GP, Giurini JM. Diabetic Neurophaties: Lower Extremities. In: Kozak GP, Campbell DR, Frykberg RG, Habershaw GM (ed.), Management of diabetic foot problems. 2a edition, W.B. Saunders Company: Philadelphia, p. 43-52, 1995.

13. Thomaz JB, Herdy CDC, Bracaglio SB, Abílio FM, Oliveira JCP, Thomaz YCM, Lima MV. Pé Diabético. Ars Curandi, 1996, p.61-103

14. Campell DR, Freeman DV, Kozak GP. Guidelines in the Examination of the Diabetic Leg and Foot. In: Kozak GP, Campbell DR, Frykberg RG, Habershaw GM (ed.), Management of diabetic foot problems. 2a edition, W.B. Saunders: Philadelphia, 1995. p. 10-5.

15. Obrosova IG. Increased sorbitol pathway activity generates oxidative stress in tissue sites for diabetic complications. Antioxid Redox Signal 2005 Nov-Dec;7(11-12):1543-52.

16. Pedrosa HC, Nery ES, Sena FV, Novaes C, Feldkircher TC, Dias MSO, Leme LAP, Miziara M, Assis MA, Kaluma C. O Desafio do Projeto Salvando o Pé Diabético. Terapêutica em Diabetes - Boletim Médico do Centro B-D de Educação em Diabetes, 19, 10p 1998.

17. Steed DL, Attinger C, Colaizzi T et al. Guidelines for the treatment of diabetic ulcers. Wound Rep Reg 2006;14:680-92.

18. Liatis S, Marinou K, Tentolouris N, Pagoni S, Katsilambros N. Usefulness of a new indicator test for the diagnosis of peripheral and autonomic neuropathy in patients with diabetes mellitus. Diabet Med 2007 Dec;24(12):1375-80.

19. Lavery LA, Armstrong DG, Harkless LB. Classification of diabetic foot wounds. J Foot Ankle Surg 1996;35:528-31.

20. Boulton AJ. The pathogenesis of diabetic foot problems: an overview. Diabet Med 1996; 13:S12-6.
21. Edelson GW, Armstrong DG, Lavery LA, Caicco G. The acutely infected diabetic foot is not adequately evaluated in a inpatient setting. Arch Intern Med 1996;156:2373-5.

22. Campbell RR, Hawkins SJ, Maddison PJ, Reckless JP. Limited joint mobility in diabetes mellitus. Ann Rheum Dis 1985;44:93-7.

23. Fernando DJ, Masson EA, Veves A, Boulton AJ. Relationship of limited joint motility to abnormal foot pressures and diabetic foot ulceration. Diabetes Care 1991;14:8-11.

24. Sanders LJ, Frykberg LJ. Charcot Foot. In: Levin ME, O'Neal LW, Boker JH (editors.), The Diabetic Foot. 5a edition, Mosby Year Book: St. Louis, 1993 p. 149-180.

25. Frykberg RG, Kozak GP. The Diabetic Charcot Foot. In: Kozak GP, Campbell DR, Frykberg RG, Habershaw GM (ed.), Management of diabetic foot problems. 2a edition, W.B. Saunders: Philadelphia, p. 10-5, 1995.

26. Armstrong DG, Lavery LA, Harkless LB. Treatment based classification system for assessment and care of diabetic feet. Journal of the American Podiatric Medical Association 1996b;86:311-6.

27. Levin ME. Diabetic Foot Wounds: Pathogenesis and Management. Advances in Wound Care 1977;10:24-30.

28. Lavery LA, Armstrong DG, Vela SA, Quebedeaux TL, Fleischli JG. Practical Criteria for Screening Patients at High Risk for Diabetic Foot Ulceration. Archives International Medicine 1998;158:157-62.

29. International Working Group on the Diabetic Foot (IWGDF). International Consensus on the Diabetic Foot, Amsterdam, 96p., 1999a.

30. Guy RJ, Clark CA, Malcolm PN, Watkins PJ. Evaluation of thermal and vibration sensation in diabetic neuropathy. Diabetologia 1985; 28:131-7.

31. International Working Group on the Diabetic Foot (IWGDF). Practical Guidelines on the Management and the prevention of the Diabetic Foot Based upon the International Consensus on the Diabetic Foot, Amsterdam, 16p., 1999 b.

32. Armstrong DG, Lavery AL, Wunderlich RP. Risk Factors for Diabetic Foot Ulceration: A Logical Approach to Treatment. Journal Wound Ostomy Continence Nurse 1998;25:123-8.

33. Rajbhandari SM, Jenkins RC, Davies C, S. Tesfaye S. Charcot neuroarthropathy in diabetes mellitus. Diabetologia 2002;45:1085-96.

34. Cole BE. Diabetic peripheral neuropathic pain: recognition and management. Pain Med 2007 Sep;85 Suppl 2:S27-32.

35. Boulton AJM, Malik RA. Diabetic Neuropathy. Med Clin North Am 1998;82: 909- 29.

36. Illa I. Diagnosis and Management of Diabetic Peripheral Neuropathy. European Neurology 1999;41: suppl 1;3-7.

37. Boulton AJM, Malik RA, Arezzo JC, Sosenko JM. Diabetic Somatic Neuropathies. Diabetes Care. 2004;27(6):1458-86.

38. Tandan R, Lewis GA, Krusinski PB, Badger GB, Fries TJ. Topical capsaicin in painful diabetic neuropathy. Controlled study with long-term follow-up. Diabetes Care 1992;15:8-14.

39. Ziegler D. Diagnosis and management of diabetic peripheral neuropathy. Diabetic Med 1996;13:S348.

40. Nicolucci A, Carinci F, Graepel JG, Hohman TC, Ferris F, Lachin $J M$. The efficacy of tolrestat in the treatment of diabetic peripheral neuropathy. A meta-analysis of individual patient data. DiabetesCare 1996;19:1091-6. 
41. Ametov AS, Barinov A, Dyck PJ, Hermann R, Kozlova N, Litchy W], Low PA, Nehrdich D, Novosadova M, O'Brien PC, Reljanovic M Samigullin R, Schuette K, Strokov I, Tritschler HJ, Wessel K, Yakhno $\mathrm{N}$, Ziegler D: The sensory symptoms of diabetic polyneuropathy are improved with alpha-lipoic acid: the SYDNEY trial. Diabetes Care 2003;26:770-6.

42. Ziegler D, Nowak H, Kempler P, Vargha P, Low PA: Treatment of symptomatic diabetic polyneuropathy with the antioxidant alphalipoic acid: a meta-analysis. Diabet Med 2004;21:114-21.

43. Ziegler D, Ametov A, Barinov A, Dyck PJ, Gurieva I, Low PA, Munzel U, Yakhno N, Raz I, Novosadova M, Maus J, Samigullin R: Oral treatment with alpha-lipoic acid improves symptomatic diabetic polyneuropathy: the SYDNEY 2 trial. Diabetes Care 2006;29:2365-70.

44. Ziegler D, Low PA, Boulton AJ, Vinik Al, Freeman R, Samigullin R, Tritschler H, Munzel U, Maus J, Schuette K, Dyck P): Effect of 4-Year Antioxidant Treatment with alpha-Lipoic Acid in Diabetic Polyneuropathy: The NATHAN 1 Trial. (Abstract). Diabetes 2007;56:A2

45. Cornblath DR, Vinik A, Feldman E, Freeman R, Boulton AJ: Surgical descompression for diabetic sensorimotor polyneuropathy. Diabetes Care 2007;30:421-2

46. Santos VP, Silveira DR, Caffaro RA. Risk factors for primary major amputation in diabetic patients. São Paulo Med J 2006;124:66070.

47. Malone JM, Snyder M, Anderson G, Bernhard VM, Holloway GA Bunt T). Prevention of amputation by diabetic education. Am Surg 1989; 158:520-4.

48. Raines JK, Darling C, Buth Jacob, Brewster DC, Austen WG. Vascular laboratory criteria for the management of peripheral vascular disease of the lower extremities. Surgery 1976;79:21-8.

49. Takolander R, Rauwerda JA. The use of non-invasive vascular assessment in diabetic patients with foot lesions. Diabetic Med 1996; 13:suppl 1;S39-S42.

50. Yao ST, Hobbs JT, Irvine WT. Ankle systolic pressure measurements in arterial disease affecting the lower extremities. Brit J Surg 1969;56:676-9.

51. Dormandy JA, Rutherford RB. Management of peripheral arterial disease (PAD). TASC Working Group. TransAtlantic Inter-Society Consensus (TASC). J Vasc Surg 2000; 31:S1-S296.

52. Engelhorn CA, Engelhorn AL, Lourenço MA, Pullig R, Ribas E, Miranda Jr. F, Burrihan E. Acurácia da imagem ultra-sonográfica expandida no diagnóstico das obstruções arteriais do segmento infra-inguinal. J Vasc Br 2002;1:55-64.

53. LoGerfo FW, Coffman JD. Current concepts. Vascular and microvascular- disease of foot in diabetes. N Eng I Med 1984; 311(25):1615-9.

54. Pomposelli FB Jr, Jepsen SJ, Gibbons GW, Campbell DR, Freeman DV, Gaughan BM, et al. A flexible approach to infrapopliteal vein grafts in patients with diabetes mellitus. Arch Surg 1991;126:724-9.

55. Levey A S, Coresh J, Balk E, et all. National Kidney Foundation Practice Guidelines for Chronic Kidney Disease: Evaluation, Classification, and Stratification. Ann Intern Med 2003;139( 2):137-49.

56. Meguid El Nahas A, Bello AK. Chronic Kidney Disease: The Global Challenge. Lancet 2005; 365(9456):331-40.
57. Salpeter S, Greyber E, Pasternak G, Salpeter E. Risk of fatal and nonfatal lactic acidosis with metformin use in type 2 diabetes mellitus: systematic review and meta-analysis. Arch Intern Med 2003;163(21): 2594-602

58. Silva R C, Pardini DP, Kater CE . Síndrome dos ovários policísticos, síndrome metabólica, risco cardiovascular e o papel dos agentes sensibilizadores da insulina. Arq Bras Endocrinol Metab 2006;50(2):281-90.

59. Thomsen HS, Morcos SK. Contrast media and the kidney: European Society of Urogenital Radiology (ESUR) guidelines. $\mathrm{Br}$ J Radiol 2003;76(908):513-8.

60. Heijenbrok MH, Kock MCJM, Hunik MGM. Lower extremity arterial disease: multidetector CT angiography - meta-analysis. Radiology 2007;245:433-9.

61. Catalano C, Fraioli F, Laghi A, Napoli A, Bezzi M, Pediconi F, Danti $M$, Nofroni I, Passarello R. Infrarenal aortic and lower-extremity arterial disease: diagnostic performance of multi-detector row CT angiography. Radiology 2004; 231:555-63.

62. Huber TS, Back MR, Ballinger RJ, Culp WC, Flynn TC, Kubilis PS, Seeger JM. Utility of magnetic resonance arteriography for distal lower extremity revascularization. J Vasc Surg 1997 Sep; 26(3):415-24.

63. Jude EB, Oyibo SO, Chalmers N, Boulton A. Peripheral arterial disease in diabetic and nondiabetic patients: a comparison of severity and outcome. Diabetes Care 2001;24(8):1433-7.

64. Dick F, Diehm N, Galimanis A, Husmann M, SchmidliJ, Baumgartner. Surgical or endovascular revascularization in patients with critical limb ischemia: influence of diabetes mellitus on clinical outcome. J Vasc Surg 2007;45(4):751-61.

65. Wölfle KD, Bruijnen $H$, Loeprecht $H$, Rümenapf $G$, Schweiger $H$, Grabitz K, Sandmann W, Lauterjung L, Largiader JA, Erasmi H, Kasprzak PM, Raithel D, Allenberg JR, Lauber A, Berakovich GM, Kretschmer G, Hepp W, Becker HM, Schutz. Graft patency and clinical outcome of femorodistal arterial reconstruction in diabetic and no-diabetic patients: results of a multicentre comparative analysis. Eur J Vasc Endovasc Surg 2003(3);25:229-34.

66. Norgren L, Hiatt WR, Dormandy JA, Nehler MR, Harris KA, Fowkes FGR, on behalf of the TASC II Working Group. Inter-Society Consensus for the Management of Peripheral Disease. J Vasc Surg 2007;45:S5-S67.

67. Mukherjee D, Lingan PBS, Stanley C, Grossman PM, Moscucci M, Luciano AE, Eagle Kim. Missed opportunities to treat atherosclerosis in patients undergoing peripheral vascular interventions: insights from the University of Michigan peripheral vascular disease quality improvement initiative. Circulation 2002;106(15):1909-12.

68. Dawson DL, Cutler BS, Hiatt WR, HobsonIl RW, Martin JD, Bortey $E B$, Forbes WP, Strandness DE. A comparison of cilostazol and pentoxifylline for treating intermittent claudication. Am I Med 2000;109:523-30

69. Pomposelli FB Jr, Marcaccio EJ, Gibbons GW, Campbell DR, Freeman DV, Burgess AM, et al. Dorsalis pedis arterial bypass: durable limb salvage for foot isquemia in patients with diabetes mellitus. I Vasc Surg 1995;21(3):375-84.

70. LoGerfo FW, Gibbons GW. Vascular disease of the lower extremities in diabetes mellitus. Endocrinol Metab Clin North Am 1996;25(12):439-45.

71. Awad S, Karkos CD, Serrachino-Inglott F, Cooper NJ, Butterfield JS, Ashleigh R, Nasim A. The impact of diabetes on current 
revascularization practice and clinical outcome in patients with critical lower limb ischaemia. Eur J Vasc Endovasc Surg 2006;32(1):51-9.

72. Golledge J, Ferguson K, Sabharwal T, Davles AH, Greenhalgh RM, Powell JT. Outcome of femoropopliteal angioplasty. Ann Surg 1999;229:146-53.

73. Adam DJ, Beard JD, Cleveland T, Bell J, Bradbury AW, Forbes JF, et al. BASIL trial participants. Bypass vs angioplasty in severe ischaemia of the leg (BASIL) (multicenter, randomized controlled trial). Lancet. 2005;366(9501):1925-34.

74. Schillinger M, Sabeti S, Loewe C, Dick P, Amighi J, Mlekusch W, Schager O, Cejna M, Lammer J, Minar E. Balloon angioplasty versus implantation of nitinol stents in the superficial femoral artery. $\mathrm{N}$ Engl J Med 2006;354(18):1879-88.

75. Daielsson G, Albrechtsson U, Norgren L, Daneisson P, Ribbe E, Thorne J, Zdanowski Z. Percutaneous transluminal angioplasty of crural arteries: Diabetes and other factors influencing outcome. Eur J Vasc Endovasc Surg 2001;21(5):432-6.

76. Söder HK, Mannien HI, Jaakkola P, Matsi PJ, Rasanen UT, Kaukanen E, Loponen P, Soimakallio S. Prospective trial of infrapopliteal artery balloon angioplasty for critical limb ischemia: angiographic and clinical results. J Vasc Interv Radiol 2000;11(8):1021-31.

77. van der Zaag ES, Legemate DA, Prins MH, Prins MH, Reekers JA, Jacobs MJ. Angioplasty or bypass for superficial femoral artery disease? A randomized controlled trial. Eur J Vasc Endovasc Surg 2004;28(2):132-7.

78. Bühler-Singer S, Hiller D, Albrecht HP, Seidel C, Hornstein OP. Disturbances of cutaneous microcirculation in patients with diabetic legs: additional parameters for a new therapeutic concept? Acta Derm Venereol 1994;74(4):250-6.

79. Schaper NC. Early atherogenesis in diabetes mellitus. Diabetic Med 1996; 13(suppl 11):S23-5.

80. Albers M, Romiti M, Brochado-Neto, De Luccia N, Pereira CA. Meta-analysis of popliteal-to-distal vein bypass grafts for critical ischemia. J Vasc Surg 2006;43(3):498-503

81. Gibbons GW, Burgess AM, Guadagnoli E, Pomposelli FB Jr, Freeman DV, Campbell DR, et al. Return to well-being and function after infrainguinal revascularization. J Vasc Surg 1995; 21(suppl 1):35-45.

82. Frykberg RG, Zgonis T, Amstrong DG, Driver VR, Giurini JM, Kravitz SR, Landsman AS, Lavery LA, Moore JC, Schberth JM, Wukich DK, Andersen C, Vanore JV. Diabetic foot disorders: a clinical practice guideline (2006 revision). J Foot Ankle Surg 2006;45(suppl 5):S1-S66.

83. Lipsky BA, Berendt AR, Deery HG, Embil JM, JosephII WS, Krchmer AW, LeFrock JL, Lew DP, Mader JT, Norden C, Tan JS. Diagnosis and treatment of diabetic foot infections. Plast Reconstr Surg 2006 Jun;117(suppl):212S-238S.

84. Caballero E, Frykberg RG. Diabetic foot infections. J Foot Ankle Surg 1998;37(3):248-55.

85. Loeffler RD, Ballard A. Plantar fascial spaces of the foot and a proposed surgical approach. Foot Ankle 1980;1(1):11-4.

86. da Silva ES, Tozzi FL. Afecções vasculares: aneurisma, pé diabético, trombose venosa. In Manual de Cirurgia do Hospital Universitário. Tolosa EMC, Tozzi FL, Reina Neto JH, Otoch JP, Pereira PRB. $1^{\text {a }}$ ed. Editora Ateneu, São Paulo, 2002.

87. Lipsky BA. Osteomyelitis of the Foot in Diabetic Patients. Clin Infect Dis 1997;25(6):1318-26.
88. Grayson ML, Gibbons GW, Balogh K, Levin E, Karchmer AW. Probing to bone in infected pedal ulcers: a clinical sign of underlying osteomyelitis in diabetic patients. JAMA 1995; 273(9):721-3.

89. Tan JS, Friedman NM, Hazelton-Miller C, Flanagan JP, File TM Jr. Can aggressive treatment of diabetic foot infections reduce the need for above-ankle amputation? Clin Infect Dis 1996;23(2):286-91.

90. Fernandes ARC, Aihara AY, Peçanha PC, Natour J. Avaliação por meio de exame radiológico convencional e ressonância magnética do pé diabético. Rev Bras Reumatol 2003;43:316-23.

91. Guimarães Maria Carolina, Yamaguchi Claudia Kazue, Aihara André Yui, Hartmann Luiz Guilherme, Pröglhöf Jorge, Fernandes Artur da Rocha Corrêa. Metatarsalgias: differential diagnosis with magnetic resonance imaging. Radiol Bras. [serial in the Internet]. 2006 Aug [cited 2006 Oct 08]; 39(4): 297-304. Available from: http://www.scielo.br/scielo.php?script=sci_arttext\&pid=S010039 $842006000400013 \&$ Ing $=e n \& n r m=i s o$.

92. Shults DW, Hunter GC, McIntyre KE, Parent FN, Piotrowski J), Bernhard VM. Value of radiographs and bone scans in determining the need for therapy in diabetic patients with foot ulcers. Am J Surg 1989;158(6):525-30.

93. Lavery L.A, Sariaya M. Microbiology of Osteomyelitis in Diabetic Foot Infections. J Foot Ankle Surg. 1995 Jan-Feb;34(1):61-4.

94. Zuluaga AF, Galvis W, Saldarriaga JG, Agudelo M, Salazar BE, Vesga O. Etiologic diagnosis of chronic osteomyelitis: a prospective study. Arch Int Med 2006;166(1):95-100.

95. Seneville E, Lombart A, Beltrand E, Valette M, Legout L, Cazaubiel $M$, Yazdanpanah $Y$, Fontaine P. Outcome of diabetic foot osteomyelitis treated nonsurgically. A retrospective cohort study. Diabetes Care 2008;31(4):637-42.

96. Gerding D. Foot infections in diabetic patients: the role of anaerobes. Clin Infect Dis 1995; 20(Suppl2):S283-8.

97. Guia de utilização de anti-infecciosos e recomendações para a prevenção de infecções hospitalares. Hospital das Clínicas da Faculdade de Medicina da USP, 2005-2006.

98. Grayson ML, Gibbons GW, Habershaw mGM, Freeman DV, Pomposelli FB, et al. Use of ampicillin/sulbctam versus imipenem/ cilastatin in the treatment of limb-threatening foot infection in diabetic patients. Clin Infect Dis 1994;18(5):683-93.

99. Abidia A, Laden G, Kuhan G, Wilkinson AR, Renwick PM, Masson EA, McCollun PT. The role of hyperbaric oxygen therapy in ischaemic diabetic lower extremity ulcers: a double-blind Randomisedcontrolled trial. Eur J Vasc Endovasc Surg 2003;25(6):513-8.

100. Vucrstack JDD, Vainas T, Wuite J, Nelemans P, Neumann MHA, Veraat JCJM. State-of-the-art treatment of chronic leg ulcers: a randomized controlled trial comparing vacuum-assisted closure (VAC) with modern wound dressings. J Vasc Surg 2006 Nov;44(5):1029-38.

101. Sociedade Brasileira de Diabetes. Consenso Sobre Diabetes- 2007.

102. DCCT Research Group: The effect of intensive treatment of diabetes on the development and progression of long-term complications in insulin dependent diabetes mellitus. N Engl J Med 1993;329(14):977-86.

103. Armstrong D G, Nguyen HC, Lavery LA, et all. Off-loading the diabetic foot wound: A randomized clinical trial. Diabetes Care 2001Jun;24(6):1019-22. 
104. Young MJ, Cavanagh PR, Thomas G, Johnson MM, Murray $H$, Boulton AJM. The effect of callus removal on dynamic foot pressures in diabetic patients. Diabetes Medicine 1992;9:55-7.

105. Janisse D. The Therapeutic Shoe Bill: medicare coverage for prescription footwear for diabetic patients. Foot Ankle Int 2005;26(1):42-5.

106. Pinzur M, Slovenkai M, Trepman E, Shields N. Diabetes Committee of American Orthopaedic Foot and Ankle Society. Guidelines for diabetic foot care: recommendations endorsed by the Diabetes Committee of the American Orthopaedic Foot and Ankle Society. Foot Ankle Int 2005;26:113-9.

107. Chantelau E, Kushner T, Spraul M. How effective is cushioned therapeutic footwear in protecting diabetic feet? A clinical study. Diabetes Med 1990;7:355-9.

108. Chantelau E, Haage P. An audit of cushioned diabetic footwear: relation to patient compliance. Diabetes Méd 1994;11:114-6.

109. Uccioli L, Faglia E, Monticone G, Favales F, Durola L, Aldeghi A, Quarantiello A, Calia P, Menzinger G. Manufactured shoes in the prevention of diabetic. Diabetes Care 1995; 18(10):1376-8.

110. Katz I, Harlan A, Miranda-Polma B, Prieto-Sanchez L, Armstrong D, Bowker J, Mizel M, Boulton A. A randomized trial of two irremovable off-loading devices in management of plantar neuropathic diabetic foot ulcers. Diabetes Care 2005;28(3): 555-9.

111. Hartsell H, Brand R, Frantz R, Saltzman C. The effects of total contact casting materials on plantar pressures. Foot Ankle Int 2004;25(2):73-8.
112. Ha Van G, Siney H, Hartmann-Heurtier A, Jacqueminet S, Greau F, Grimaldi A. Nonremovable, windowed, fiberglass cast boot in the treatment of diabetic plantar ulcers: efficacy, safety and compliance. Diabetes Care 2003;26:2848-52.

113. Ulbrecht J, Cavanagh P, Caputo G. Foot problems in diabetes: an overview. Clin Infect Dis 2004;39(Suppl. 2):S73-82.

114. Birke JA, Pavich MA, Patout CA, Horswell R. Comparison of forefoot ulcer healing using alternative offloading methods in patients with diabetes mellitus. Adv Skin Wound Care 2002;15(5):210-5.

115. Helm P, Walker S, Pullium G. Total contact casting in diabetic patients with neuropathic foot ulcerations. Arch Phys Med Rehabil 1984;65(11):440-6.

116. Frykberg RG. Diabetic foot ulcers: current concepts.J Foot Ankle Surg 1998;37(5):528-31.

117. Blume PA, Walters J, Payne W, Ayala J, Lantis J. Comparison of Negative Pressure Wound Therapy Using Vacuum Assisted Closure With Advanced Moist Wound Therapy in the Treatment of Diabetic Foot Ulcers: A multicenter randomized controlled trial. Diabetes Care 2008;31(4):631-6.

118. Deresh GM, Cohen M. Reconstruction of the diabetic charcot foot incorporating bone grafts. J Foot Ankle Surg 1996;35(5):474-88.

119. Petrov O, Pfeifer M, Flood M, Chagares W, Daniele C. Recurrent plantar ulceration following pan metatarsal head resection. - J Foot Ankle Surg 1996 nov-dec;35(6):573-7.

120. Margolis DJ, Kantor J, Berlin JA. Healing of diabetic neuropathic foot ulcers receiving standard treatment. A meta-analysis. Diabetes Care 1999;22(5):692-5. 


\section{Apendice 1.}

1. Anote a presença de complicações do DM (olhos, rins, nervos, sistema vascular ).

2. Verifique e anote a presença de úlceras.

3. Examine os tornozelos e pés, inclusive entre os dedos. Inspecione pelos, pele, unhas, calos, lesões e úlceras. Anote as anormalidades na ficha de atendimento.

4. Verifique e anote a atrofia da almofada plantar ( gordura ).

5. Verifique os pulsos arteriais dos pés.

6. Examine a sensibilidade plantar (monofilamento de 10g).

7. Classifique o risco dos dois pés separadamente.

8. Examine cuidadosamente os sapatos usados pelo paciente.

9. Verifique e anote o grau de educação e conhecimento do paciente.

10. Trace o plano de educação, diagnóstico, tratamento e retornos do paciente.

Apendice 2

\begin{tabular}{|c|c|c|c|c|}
\hline \multicolumn{5}{|c|}{ PÉ DIABÉTICO } \\
\hline CATEGORIAS DE RISCO & SENSIBILIDADE & DEFORMIDADE/ HIPERCERATOSE & ÚLCERA & ENCAMINHAMENTO \\
\hline GRAU 0 & Presente & Ausente & Ausente & $\begin{array}{l}\text { Acompanhamento clínico, revisão do pé a cada } 6 \\
\text { meses ou anual* }\end{array}$ \\
\hline GRAU 1 & Ausente & Ausente & Ausente & $\begin{array}{l}\text { Acompanhamento clínico, revisão do pé a cada } 3 \text { ou } \\
6 \text { meses* }^{*}\end{array}$ \\
\hline GRAU 2 & Ausente & Presente & Ausente & $\begin{array}{l}\text { Acompanhamento clínico, revisão do pé a cada } 3 \\
\text { meses. Encaminhamento para Terapia Ocupacional* }\end{array}$ \\
\hline GRAU 3 & Ausente & Presente ou Ausente & Cicatrizada & $\begin{array}{l}\text { Acompanhamento clínico, revisão do pé a cada } 3 \\
\text { meses. Encaminhamento para Terapia Ocupacional* }\end{array}$ \\
\hline GRAU $3 A$ & \multicolumn{3}{|c|}{ Úlcera superficial com ou sem infecção superficial } & $\begin{array}{l}\text { Curativo na unidade, antibiótico se indicado. Se } \\
\text { houver evidência de isquemia, encaminhamento ao } \\
\text { Centro Secundário de Atenção ao Pé Diabético* }\end{array}$ \\
\hline GRAU 3B & \multicolumn{3}{|c|}{ Úlcera profunda, sem infecção e sem atingir osso } & $\begin{array}{l}\text { Encaminhamento ao Centro Secundário de Atenção } \\
\text { ao Pé Diabético. Marcação em no máximo } 48 \text { horas }\end{array}$ \\
\hline GRAU 3C & \multicolumn{3}{|c|}{ Infecção profunda (celulite, abscesso, tendinite, sinovite, osteomielite) } & Internação imediata \\
\hline GRAU 3D & \multicolumn{3}{|c|}{ Necrose ou grangrena localizada } & $\begin{array}{l}\text { Encaminhamento ao Centro Secundário de Atenção } \\
\text { ao Pé Diabético. Marcação em no máximo } 48 \text { horas. } \\
\text { No caso de gangrena, avaliar internação imediata }\end{array}$ \\
\hline GRAU 3E & \multicolumn{3}{|c|}{ Necrose ou gangrena extensa } & Internação imediata \\
\hline
\end{tabular}

* A presença de isquemia potencializa enormemente o risco. Todos os pacientes deverão ser submetidos à avaliação da árvore vascular arterial dos membros inferiores. Qualquer que seja a categoria de risco, a confirmação ou mesmo a suspeita de isquemia deve levar ao encaminhamento imediato ao Centro Secundário de Atenção ao Pé Diabético para avaliação por especialista. ** Caiafa JS et alii. Atenção Integral ao Paciente com Pé Diabético: um modelo descentralizado de atuação no Rio de Janeiro. J VASC BR 2003, vol 2, n 1, 75-78. ${ }^{5}$ 
Apendice 3

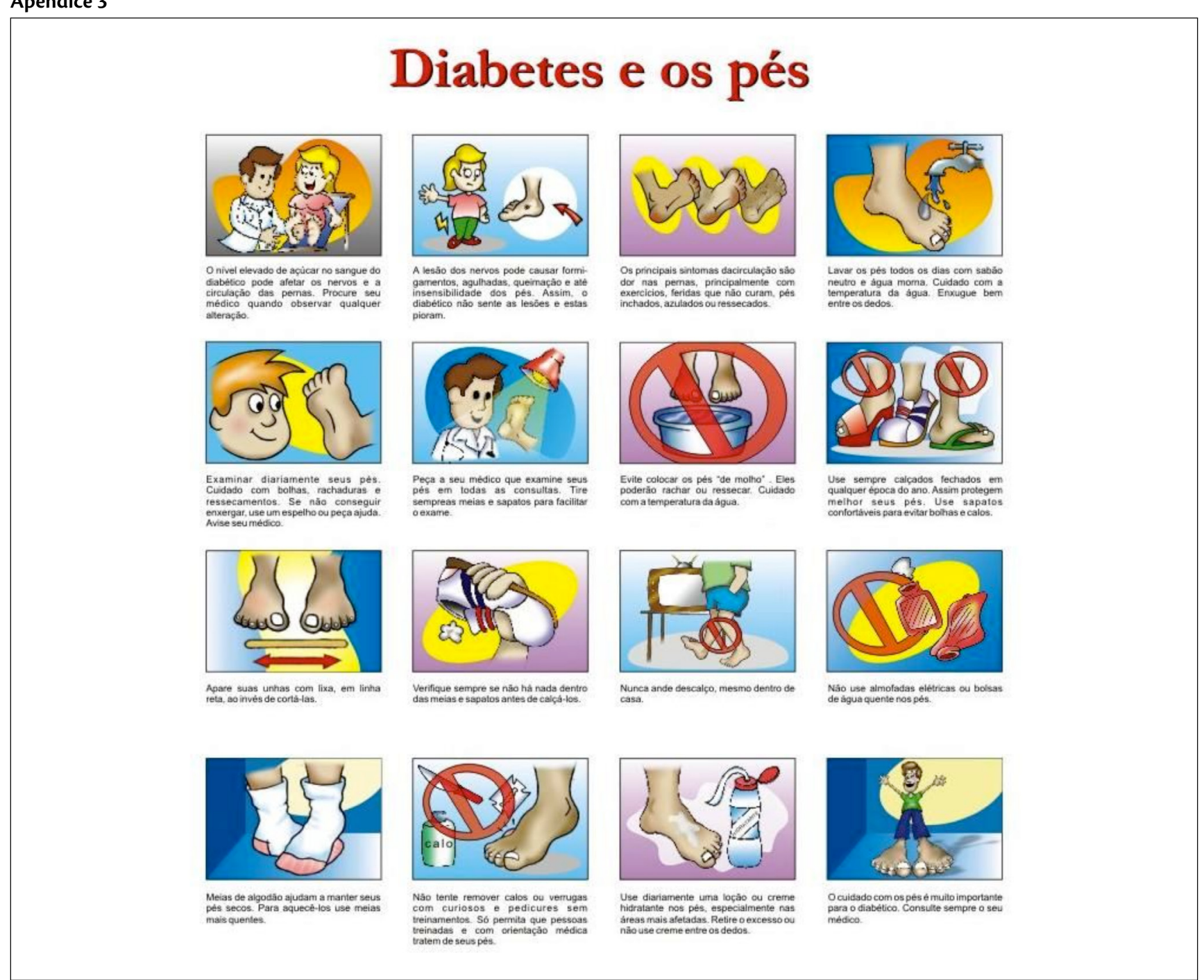

Imagens cedidas pela ACD - Associação Carioca dos Diabéticos e SBACV-RJ - Sociedade Brasileira de Angiologia e Cirurgia Vascular do Rio de Janeiro

\section{Perguntas:}

1- Que achados laboratoriais não são característicos do Charcot Agudo?
a. Aumento de segmentados
b. VHS aumentado
c. Leucocitose
d. a e c estão corretas

\section{2- Quais das características clínicas abaixo são encontradas no pé neuropático?}

a. Pés ressecados.

b. Hiperemia cutânea.

c. Diminuição da sensibilidade.

d. Todas as respostas acima.
3- Qual a principal característica clínica da úlcera neuropática de um paciente diabético não isquêmico?
a. Lesão profunda.
b. Lesão dolorosa.
c. Lesão indolor.
d. Presença de osteomielite.

4- No exame físico de um paciente diabético com oclusão infrapatelar e neuropatia, poderá (ão) estar presente(s) a(s) seguinte(s) manifestação(ões):
a. Ressecamento cutâneo.
b. Enchimento venoso normal.
c. Ausência de pulsos arteriais no pé.
d. Todas as opções acima 
5- Assinale a alternativa falsa:

a. A microangiopatia contra-indica a tentativa de revascularizaçâo em diabéticos.

b. Nos diabéticos a doença vascular costuma ser mais precoce e de evolução mais rápida do que em não diabéticos.

c. Nos diabéticos, os vasos arteriais da perna (infra-patelares) são mais atingidos que em não diabéticos.

d. As cirurgias de revascularização em diabéticos tem resultado estatisticamente semelhantes aos encontrados em não diabéticos.

6- Em relação ao pé diabético, assinale a afirmativa correta:

a. O uso da metformina não interfere na realização das arteriografias em diabéticos.

b. O índice tornozelo-braço pelo dopller nos diabéticos é menos confiável que nos não diabéticos.

c. Nas gangrenas diabéticas, ao exame clínico, pelo menos um dos pulsos distais está sempre ausente.

d. A polineuroropatia diabética compromete apenas a inervação sensitiva dos pés.

7- Paciente diabético há 20 anos, em tratamento com insulina, o índice de pressão sistólica tornozelo braço é 0,85 e o índice artelho-braço é 0,18. Suspeita-se que o paciente possa ter:

a. Esses índices nâo têm significado clínico.

b. Pressões digitais falsamente diminuídas.

c. Índice tornozelo - braço falsamente elevado.

d. Índice de tornozelo, normal para diminuído.

8- Sobre as infecções profundas nas úlceras do pé diabético com neuropatia sensitiva, é correto afirmar:

a. Geralmente é produzida por uma única bactéria.

b. As bactérias que habitam as regiões mais superficiais são geralmente as mesmas que habitam os planos profundos.

c. Sempre determinam sinais sistêmicos, tais como febre e queda do estado geral.

d. Todas estão erradas

9- É a principal situação responsável pelo aparecimento de úlceras no pé diabético:
a. Vasculopatia.
b. Neuropatia.
c. Infecção.
d. Microangiopatia.

10- Assinale a alternativa falsa:

a. O ITB no diabético, não é um indicador totalmente confiável do grau de isquemia.

b. A neuroartropatia de Charcôt pode ser uma das conseqüências da neuropatia diabética.

c. A cicatrização de uma úlcera em pé diabético, em cujo membro a sudorese está ausente, se fará mais rápida após simpatectomia lombar.

d. A neuropatia autonõmica do diabético é uma complicação que pode acometer diversos órgãos e sistemas.

11- Um paciente diabético com ulceração em planta do pé, na projeção da cabeça do $2^{\circ}$ metatarso, com 8 meses de evolução, submetido a debridamentos, sem melhora apesar dos curativos adequados e uso de antibióticos, podemos suspeitar de osteomielite. Qual o primeiro exame de imagem a ser solicitado?

a. Cintilografia óssea.

b. Rx do pé em AP, perfil e oblíqua.

c. Tomografia Computadorizada.

d. Ressonância Magnética.

12- Das manifestações clínicas da neuropatia diabética, qual a que representa maior risco para ulceração?

a. Ressecamento.

b. Fissuras e rachaduras.

c. Hiperemia cutânea.

d. Perda da sensibilidade protetora.

13- Paciente diabético com 15 anos de diagnóstico, sem controle adequado, entra no posto de saúde com história de "ferida no pé direito" há mais de 1 ano. Ao exame clínico apresenta pé direito edemaciado, com hiperemia ascendendo para médio pé, pulso pedioso presente, apresentando mal perfurante plantar em projeção da cabeça do $1^{\circ}$ metatarso, drenando secreção purulenta e com toque no osso à exploração com instrumento rombo. Qual o primeiro diagnóstico a ser considerado?

a. Síndrome isquêmica crônica descompensada'.

b. Oclusão arterial aguda

c. Osteomielite.

d. Úlcera de estase.

14- Em virtude da complexidade operacional, as ações educativas na prevenção das complicações do pé diabético devem ser direcionadas apenas aos pacientes.
( ) Certo
( )Errado

15- A existência de centros especializados no tratamento das complicações do pé diabético é suficiente para uma boa assistência de saúde a esses pacientes.
( ) Certo
( ) Errado 


\section{Respostas:}

\section{1- d. a e c estão corretas}

Durante a fase aguda da instalação do Pé de Charcot não há hemograma característico de infecção, apesar dos sinais clínicos sugestivos como o calor local e a hiperemia cutânea causadas pela intensa reação inflamatória.

\section{2- d. Todas as respostas acima}

A neuropatia autonômica leva à alteração do funcionamento das glândulas sudoríparas, com diminuição da hidratação da pele e à abertura de comunicações artério-venosas, provocando hiperemia e maior temperatura cutânea.

\section{3- c. Lesão indolor}

A Polineuropatia Diabética tem como manifestação mais significativa a perda da sensibilidade tátil e dolorosa nas extremidades o que possibilita o aparecimento de lesões causadas pela pressão e pioradas pela ausência da dor.

\section{4- d. Todas as opções acima}

A neuropatia autonômica pode levar ao ressecamento cutâneo por alterar o funcionamento das glândulas sudoríparas e ao incremento do retorno venoso pela abertura das comunicações artério-venosas. A existência de oclusão arterial troncular supra-patelar leva, na maioria dos casos, à ausência de pulsos distais.

\section{5- a. A microangiopatia contra-indica a tentativa de revascularizaçâo em diabéticos.}

A Microangiopatia não contra-indica as tentativas de revascularização em diabéticos. A doença vascular dos diabéticos é mais precoce e agressiva que nos pacientes não diabéticos em função dos distúrbios do metabolismo lipídico causados pela hiperglicemia, sendo as artérias da perna mais acometidas que as proximais.

\section{6-b. O índice tornozelo-braço pelo dopller nos diabéticos é menos confiável que nos não diabéticos}

A não suspensão do uso da metformina pode levar à acidose lática durante a realização de exames contrastados. A presença da Arterioesclerose de Monckeberg, com a calcificação da camada média das artérias, pode levar à ocorrência de índices falsamente elevados em diabéticos. As gangrenas diabéticas ocorrem, na maioria das vezes pela infecção em pés neuropáticos, com pulsos arteriais distais presentes. A polineuropatia diabética acomete a inervação sensitiva, motora e autonômica.

\section{7- c. Índice tornozelo - braço falsamente elevado}

A calcificação da camada média das artérias (Arterioesclerose de Monckeberg) pode levar a um índice falsamente elevado em diabéticos.

\section{8- $\mathbf{d}$. Todas estão erradas}

A infecção profunda no mal perfurante plantar é, geralmente, polimicrobiana e acompanhada de flora superficial variada. Muitas vezes, essas infecções evoluem por longo tempo sem manifestações sistêmicas até a descompensação.

\section{9- b. Neuropatia.}

A neuropatia, com perda da sensibilidade protetora é a maior causa do aparecimento do mal perfurante plantar, ulceração crônica mais comum no pé do diabético.

\section{0- c. A cicatrização de uma úlcera em pé diabético, em cujo membro a sudorese está ausente, se fará mais rápida após simpatectomia lombar.}

Em virtude da neuropatia autonômica do diabetes, que tem como uma de suas características a diminuição ou ausência da sudorese, a resposta vascular à simpatectomia pode estar ausente ou não ser adequada tendo em vista que esse paciente pode já ser "auto-simpatectomizado".

\section{1- b. Rx do pé em AP, perfil e oblíqua.}

Por ser um exame simples e disponível em qualquer nível do atendimento, e por sua boa sensibilidade e, principalmente por ter alta especificidade , a radiografia simples do pé afetado é o primeiro exame de imagem a ser solicitado na suspeita de osteomielite.

\section{2- d. Perda da sensibilidade protetora.}

Apesar do risco de infecção representado pela neuropatia autonômica, responsável pelp ressecamento cutâneo, com conseqüentes rachaduras e fissuras, o maior risco de ulcerações profundas, como o mal perfurante plantar, é originário da neuropatia sensitiva com a perda da sensibilidade protetora.

\section{3- c. Osteomielite.}

As lesões crônicas profundas, com evolução arrastada, sinais infecciosos aparentes e, principalmente, mas não obrigatoriamente, prova positiva de "toque no osso" devem, prioritariamente, incluir o possível diagnóstico de osteomielite.

\section{4- Errado}

Para um resultado satisfatório dos programas de prevenção, é fundamental a educação continuada das equipes de saúde e a permanente atenção ao apoio e orientação aos familiares e/ou pessoas próximas ao diabético.

\section{5- Errado}

Em virtude da enorme prevalecia das complicações nos pés dos diabéticos, a simples existência de centros de excelência não provê uma assistência de qualidade, sendo necessária a descentralização do conhecimento e do cuidado, aproximando a educação e os cuidados iniciais do paciente. 